University of Louisville

ThinkIR: The University of Louisville's Institutional Repository

$5-2011$

\title{
Reconciliation of IL-1ß loss with TRIF-biased TLR4 signaling by monophosphate lipid A.
}

Chelsea A. Embry

University of Louisville

Follow this and additional works at: https://ir.library.louisville.edu/etd

\section{Recommended Citation}

Embry, Chelsea A., "Reconciliation of IL-1ß loss with TRIF-biased TLR4 signaling by monophosphate lipid A." (2011). Electronic Theses and Dissertations. Paper 405.

https://doi.org/10.18297/etd/405

This Doctoral Dissertation is brought to you for free and open access by ThinkIR: The University of Louisville's Institutional Repository. It has been accepted for inclusion in Electronic Theses and Dissertations by an authorized administrator of ThinkIR: The University of Louisville's Institutional Repository. This title appears here courtesy of the author, who has retained all other copyrights. For more information, please contact thinkir@louisville.edu. 


\title{
RECONCILIATION OF IL-1 $\beta$ LOSS WITH TRIF-BIASED TLR4 SIGNALING BY MONOPHOSPHATE LIPID A
}

\author{
By \\ Chelsea A. Embry \\ B.S., Old Dominion University, 2007 \\ M.S., University of Louisville School of Medicine, 2008
}

A Dissertation Submitted to the Faculty of the Graduate School of the University of Louisville in Partial Fulfillment of the Requirement for the Degree of

\section{Doctor of Philosophy}

Department of Microbiology and Immunology

University of Louisville, School of Medicine

Louisville, Kentucky

May 2011 


\title{
RECONCILIATION OF IL-1 $\beta$ LOSS WITH TRIF-BIASED TLR4 SIGNALING BY MONOPHOSPHATE LIPID A
}

\author{
By \\ Chelsea A. Embry \\ B.S., Old Dominion University, 2007 \\ M.S., University of Louisville School of Medicine, 2008
}

A Dissertation Approved on

February $3^{\text {rd }} 2011$

by the following Dissertation Committee:

Thomas C Mitchell (Dissertation Director)

Dr. Robert Stout

Dr. Jill Suttles

Dr. Haribabu Bodduluri

Dr. George Hajishengallis 


\section{ACKNOWLEDGMENTS}

I thank my mentor Dr. Mitchell, lab members, committee members and the Department of Microbiology and Immunology at the University of Louisville.

To my family: I could not have completed this without your support. Thank you. 


\title{
RECONCILIATION OF IL-1 $\beta$ LOSS WITH TRIF-BIASED TLR4 SIGNALING BY MONOPHOSPHATE LIPID A
}

\author{
Chelsea A. Embry
}

February $3^{\text {rd }} 2011$

\begin{abstract}
Monophosphoryl Lipid A (MPLA), a derivative of LPS endotoxin, is a TLR4 agonist that displays as little as $0.1-1 \%$ as much toxicity as its parent molecule while retaining immunostimulatory properties. We discovered that MPLA activates a TRIF-biased pattern of TLR4 signaling, resulting in reduced production of MyD88-dependent pro-inflammatory factors, and credited TRIF-bias for MPLA's reduced toxicity. A contemporary study showed that MPLA fails to promote maturation of the potent inflammatory cytokine $\mathrm{IL}-1 \beta$. This dissertation seeks to reconcile MPLA's TRIF-biased signaling with IL-1 $\beta$ loss, and to determine the ultimate cause of MPLA's reduced toxicity compared to LPS. We find that TRIF-biased TLR4 activation results in weak MyD88-dependent induction of NLRP3, a critical inflammasome component required for IL-1 $\beta$ production. MPLA's loss of IL-1 $\beta$ results in decreased potentiation of MyD88-dependent inflammatory factors in vivo and reduced IL-1RI-dependent hepatotoxicity. Ultimately, TRIFbiased TLR4 signaling is the causative factor resulting in MPLA's immunogenicity with low toxicity; however more studies are needed to determine the initial events leading to the TRIFdependent signaling cascade. This dissertation describes the mechanisms responsible for MPLA's reduced induction of inflammatory responses and outlines how this signaling may be exploited for therapeutic use.
\end{abstract}




\section{TABLE OF CONTENTS}

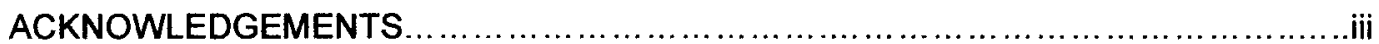

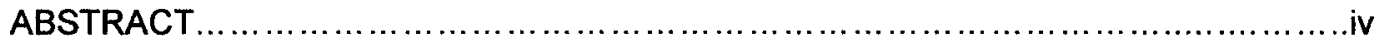

LIST OF FIGURES

\section{CHAPTER I: INTRODUCTION}

TLR4 recognizes pathogen and damage associate molecular patterns

MyD88-dependent TLR4 signaling.

TRIF-dependent TLR4 signaling

MPLA is an immune-stimulant with reduced toxicity ...........................10

MPLA represents a structural variant of LPS on commensal bacteria............ 12

Proposed mechanism of MPLA's reduced toxicity ............................ 12

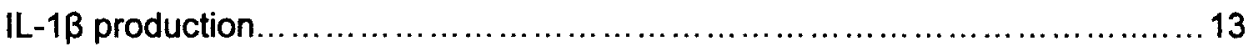

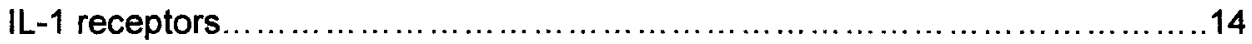

PAMP and DAMP activators of the NLRP3 inflammasome ....................15

MPLA pretreatment prevents ischemic reperfusion injury and protects against

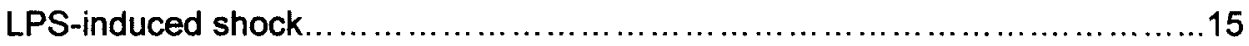

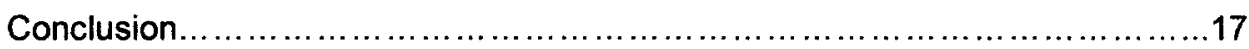

\section{CHAPTER II: MATERIALS AND METHODS}

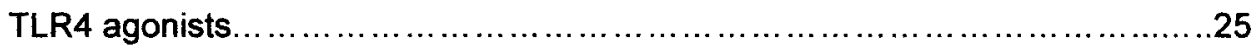

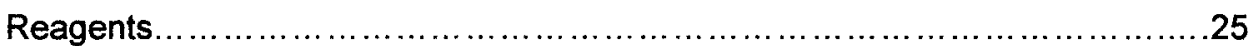

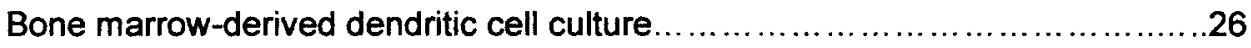

Bone marrow-derived macrophage cell culture .............................27

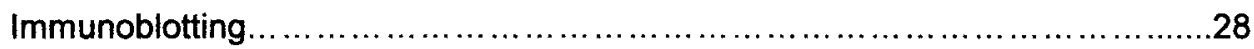

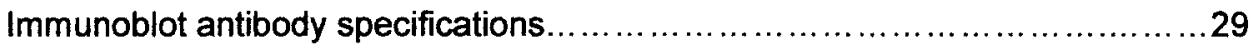

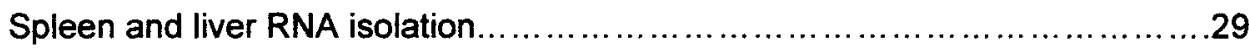




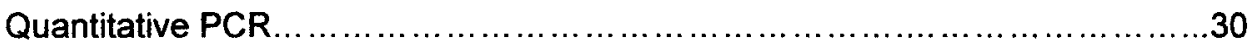

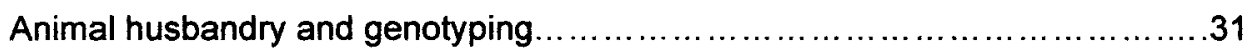

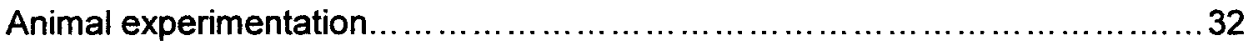

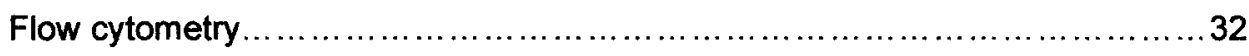

Culture supernatant cytokine detection........................................33

Plasma cytokine, C5a, SAA and ALT detection ............................. 33

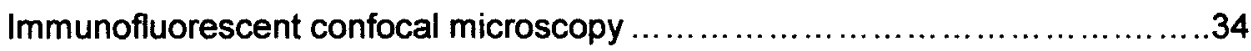

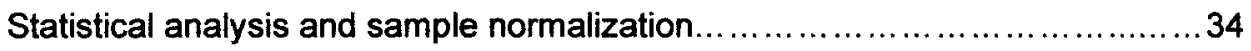

CHAPTER III: NLRP3 INFLAMMASOME ACTIVATION BY MLA AND LIPID A

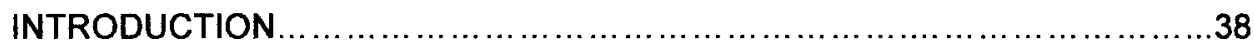

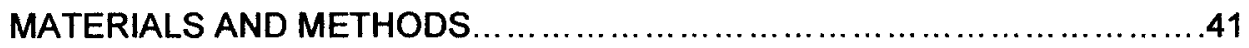

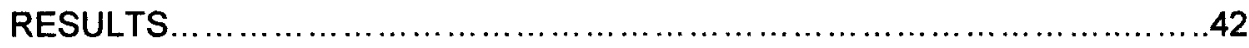

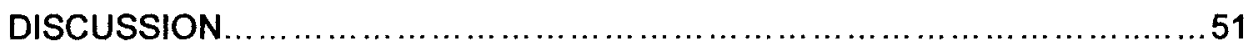

CHAPTER IV: IL-1 $\beta$ LOSS CONTRIBUTES TO REDUCED TOXICITY OF MPLA

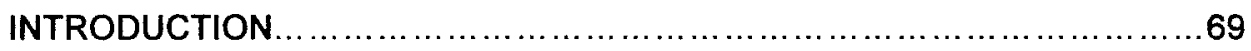

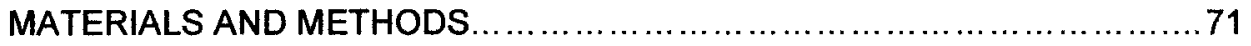

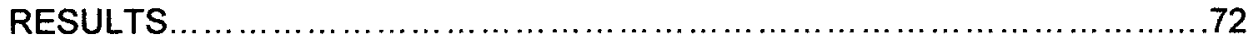

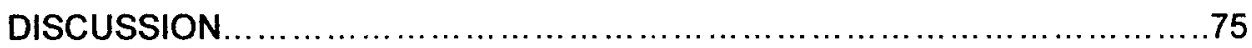

CHAPTER V: COMPLEMENT AND TLR4 CO-RECEPTOR ACTIVATION BY MLA AND LIPID A

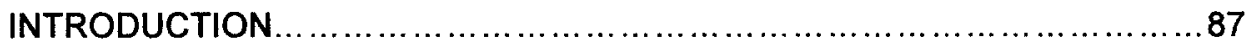

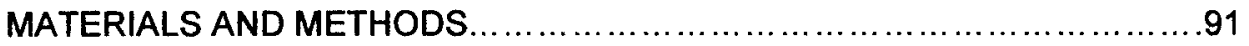

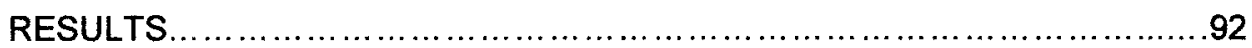

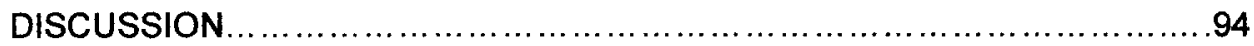

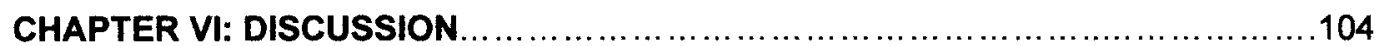


REFERENCES.

108

CURRICULUM VITAE.

130 


\section{LIST OF FIGURES}

PAGE

\section{CHAPTER I: INTRODUCTION}

1. LPS is a cell wall component of Gram negative bacteria....................... 18

2. The crystal structure of MD2-bound LPS interacting with TLR4 ................19

3. Lipid A structures from S. minnesota and E. coli...........................20

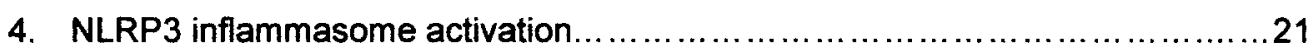

5. PAMP and DAMP activators of the NLRP3 inflammasome $\ldots \ldots \ldots \ldots \ldots \ldots \ldots .22$

\section{CHAPTER II: MATERIALS AND METHODS}

6. Phenotype of bone marrow derived dendritic cells.............................35

7. Phenotype of bone marrow derived macrophages............................ 36

\section{CHAPTER III: NLRP3 INFLAMMASOME ACTIVATION BY MLA AND LIPID A}

8. Mass spectroscopic analysis of synthetic Lipid A ............................54

9. Mass spectroscopic analysis of synthetic Monophosphate Lipid A.

10. TRIF-biased TLR4 signaling proceeds independently of IL-1RI.

11. IL-1 $\beta$ priming in WT, Trif ${ }^{p s 2}$ and Myd88 $8^{-t-}$ DCs activated with MLA and Lipid A

12. Generation of mature IL-1 $\beta$ by TLR4 agonists alone is co-dependent on MyD88 and TRIF 60

13. MyD88 is critically required for ATP-stimulated IL-1 $\beta$ production. 62

14. MLA-primed myeloid DCs display fewer ASC-specks and less active caspase-1 compared to Lipid A. 64

15. NLRP3 transcript and protein induction in WT, Trif ${ }^{1 p s 2}$ and MyD88 $8^{-}$myeloid DCs activated with MLA or Lipid A 


\section{CHAPTER IV: IL-1 $\beta$ LOSS CONTRIBUTES TO REDUCED TOXICITY OF MPLA}

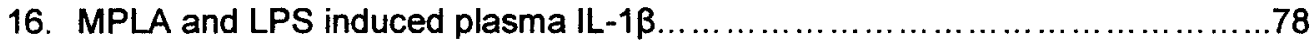

17. Plasma TNF and MCP-1 induced by LPS or MPLA ......................... 79

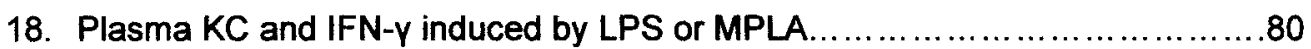

19. Plasma IL-6 induced by LPS or MPLA .................................... 81

20. Splenic Endothelin-1, Serpine-1, Cox-2 and NIrp3 transcript levels.................82

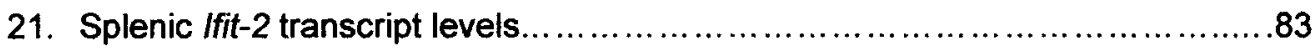

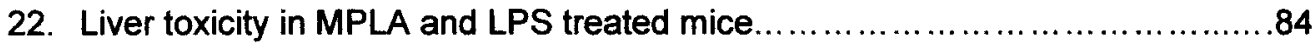

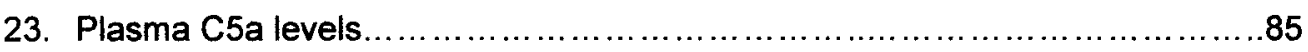

\section{CHAPTER V: COMPLEMENT AND TLR4 CORECEPTOR ACTIVATION BY MLA AND LIPID A}

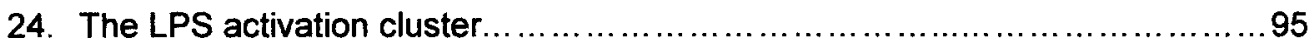

25. The alternative pathway of the complement cascade.........................96

26. C5a contributes to pathogenesis of sepsis .................................

27. CD11b expression on bone marrow-derived dendritic cells...................98

28. CD14 expression on bone marrow-derived dendritic cells....................99

29. CXCR4 expression on bone marrow-derived dendritic cells .................. 100

30. Inhibition of TLR4 co-receptors .........................................101 


\section{CHAPTER I}

\section{INTRODUCTION}

\section{TLR4 recognizes pathogen and damage associate molecular patterns}

Pattern recognition receptors (PRRs) such as Toll like receptor 4 (TLR4) recognize "pathogen associated molecular patterns" (PAMPs) expressed on various bacteria, viruses and fungi, performing a critical 'watch keeper' function for the immune system. However, in addition to being aware of non-self invaders, the body must recognize when its own tissue has been damaged even in the absence of infection. Therefore, PRRs also recognize "damage associated molecular patterns" (DAMPs). DAMPs are endogenously expressed proteins and molecules released during tissue damage or stress [1]. For example, cellular stress in the form of ion perturbation induces release of ATP [2], a potent DAMP that induces inflammation by activation of an inflammatory cytokine processing complex called the NLRP3 inflammasome [3]. Stressed or dying cells may directly release or cause the formation of many other DAMPs including, uric acid crystals, hyaluranon fragments, heat shock proteins, "high-mobility group box protein 1" (HMGB1), S100-A8 (calgranulin-A), and S100-A9 (calgranulin-B, also known as "migration inhibitory factor-related protein 14" or MRP-14) [1], all of which are recognized by TLR4 [4].

A major PAMP ligand of TLR4 is lipopolysaccharide (LPS), the principle Endotoxin (toxin produced during destruction of bacterial cell walls) of Gram negative bacterial sepsis [5]. LPS is made up of several structurally distinct parts: an outer O-antigen consisting of polysaccharide chains, a core oligosaccharide region containing keto-deoxyoctulosonate (KDO) directly linked to Lipid A. Lipid A is the immuno-stimulatory portion of LPS, and consists of a phosphorylated diglucosamine head group with four to seven acyl chains (Figure 1). The TLR4 structure consists of a curved extracellular ligand-binding "leucin-rich-repeat" (LRR) domain and an intracellular "Toll/Interleukin T 1 receptor" (TIR) signal transducing domain. Much of what is known regarding TLR4 activation has been elucidated using LPS. If found in circulation, LPS is sequestered by the liver-produced serum factor "lipopolysaccharide binding protein" (LBP) that shuttles LPS to membrane bound or soluble CD14 of various cells [6]. Cationic residues at the C-terminus of LBP 
bind the phosphorylated region on Lipid A [7], and then transfers LPS to MD2 (also known as lymphocyte antigen 96) [8]. MD2, a co-receptor required for Endotoxin recognition, is a glycoprotein consisting of two anti-parallel $\beta$-sheets that create a hydrophobic pocket in which five of Lipid A's acyl chains sit. The sixth acyl chain extends outside of the MD2 pocket and simultaneously interacts with the LRR of TLR4 and the external face of MD2 (Figure 2). MD2 alone is able to interact with TLR4; however, the dimerization of TLR4 required for signal transduction occurs only when MD2 is occupied by Lipid A. LPS binding induces a structural change in MD2 leading to a hydrophilic interaction between MD2 and TLR4 [9]. The phosphate groups of Lipid A protrude from the MD2 pocket, and also interact with charged residues of TLR4 [9]. The complex binding interactions between MD2, TLR4 and Lipid A emphasize how minor changes in Lipid A structure could modify its interaction with MD2/TLR4 and thereby alter downstream signaling events.

\section{MyD88-dependent TLR4 signaling}

TLR4 utilizes both "TIR-domain containing adapter protein inducing interferon- $\beta$ " (TRIF) and "myeloid differentiation factor $88^{\prime \prime}$ (MyD88) as adapters for signal transduction. MyD88

interacts with "TIR-domain containing adaptor protein" (TIRAP, also known as "MyD88 adapterlike protein" or MAL), which contains "phosphatidyl inositol bisphosphate" $\left(\mathrm{PIP}_{2}\right)$-binding domains, allowing it to associate with the plasma membrane where MyD88 resides [10]. MyD88 then interacts with the Serine/Threonine kinase "IL-1 receptor-associated kinase 4" (IRAK-4) bringing it in close proximity to IRAK-1 [11]. After phosphorylation by IRAK-4, IRAK-1 undergoes autophosphorylation, leading to dissociation from MyD88 and increased interaction with "TNFreceptor-associated factor 6" (TRAF-6) $[12,13]$. IRAK-1 remains at the plasma membrane and is degraded [14], while TRAF-6 moves to the cytosol and promotes phosphorylation of the effector kinase "TGF- $\beta$ activated kinase 1 " (TAK-1) [15]. TAK-1 signaling activates the "mitogenassociated protein kinase" (MAPK) pathway, which induces "activator protein 1" (AP-1) transcriptional activity [16]. This signaling pathway also activates IKB kinase (IKK) leading to IKB degradation and translocation of the transcription factor NF-KB to the nucleus (19). Activation of these transcription factors leads to the production of pro-inflammatory mediators, pyrogenic 
factors and cytokines like IL-1 $\beta$, tumor necrosis factor alpha (TNF- $\alpha$ ), cyclooxygenase 2 (COX-2), Serpine-1, Endothelin-1 and IL-6 [17].

\section{TRIF-dependent TLR4 signaling}

TRIF signaling is thought to take place from an endosomal location after the internalization of the MD2/TLR4 receptor complex. Endocytosed TRIF interacts with TRIF-related adaptor protein (TRAM), which activates TANK-binding kinase 1 (TBK-1) via "TNF receptorassociated factor $3^{\mathrm{n}}$ (TRAF-3), a protein of exclusive subcellular location [10]. TRIF/TRAM signaling activates transcriptional activity of "interferon regulatory factor 3" (IRF-3) (21) driving the transcription of "interferon- $y$-induced protein 10" (IP-10, also known as CXCL-10), "interferoninduced protein with tetratricopeptide repeats 1 and 2" (IFIT-1 and IFIT-2) and anti-viral Type-1 Interferon genes such as IFN- $\beta$ (22). In addition to activation of MAPK and NF-KB through TRAF6 (23), TRIF/TRAM signaling leads to increased antigen presentation in dendritic cells (20) and up-regulated expression of co-stimulatory molecules [18], two events important for $T$ cell activation.

\section{MPLA is an immune-stimulant with reduced toxicity}

LPS is a potent stimulator of immune responses, however its excessive induction of inflammation is inhibitory to any possible therapeutic uses. However, hydrolysis or alkaline phosphatase treatment of LPS yields a monophosphorylated form of Lipid A, known as "Monophosphoryl Lipid A" (MPLA), a TLR4 agonist that displays as little as $0.1-1 \%$ as much toxicity as its parent molecule while retaining immuno-stimulatory properties [19-24] (see Figure 3 for structural comparisons of Lipid A chemotypes). During the initial years following its discovery, MPLA was found to increase non-specific immune responses to bacterial infection, improving survival of mice subsequently infected with E. coli or S. epidermis [25]. MPLA has also been used

to stimulate antibacterial leukocyte function in previously refractory cells of patients receiving "continued ambulatory peritoneal dialysis" (CAPD) who are at risk of bacterial peritonitis from catheter contamination [26]. The adjuvanting properties of MPLA were immediately realized, and in less than a decade after its initial discovery, MPLA was being used to boost immune responses 
during vaccination $[27,28][29]$. MPLA co-administered with antigen leads to enhanced antigenspecific antibody titers and enhanced antigen-specific $T$ cell proliferation, survival and function [17, 30] [31]. A PubMed search for "MPLA adjuvant 2010" yielded an extensive list of effective MPLA-mediated adjuvanted vaccines against murine pulmonary tumor metastasis [32], murine visceral leishmaniasis [33], HBV-related cirrhosis in human liver transplants recipients [34], murine tuberculosis [35], and pollen allergens in children [36]. The uncoupling of immunestimulation from toxicity makes MPLA an excellent candidate for clinical use as a vaccine adjuvant. Indeed, GlaxoSmithKleine uses their proprietary MPLA formulation, MPL ${ }^{\circledR}$ adjuvant, approved for human use by the U.S. Food and Drug Administration in 2009, in its Hepatitis B virus vaccine Fendrix ${ }^{\circledast n}$ and Human Papilloma virus vaccine Cervarix ${ }^{\circledR}$ [37].

\section{MPLA represents a structural variant of LPS on commensal bacteria}

MPLA was first discovered as a hydrolytic derivative of LPS that could be generated in vitro, but recent work has shown that various commensal and opportunistic pathogenic bacteria species produce monophosphorylated LPS, including Bacteroides thetaiotamicron and fragilis, Porphormonys gingivalis, and Heliobacter pylori [38-41]. It is interesting to note that bacteria often evade detection by the immune system via modification of their LPS structures [42-45]. In fact, the actual position of that single phosphate group on the Lipid A head group affects the potency of host immune responses, with a 4' phosphate being less immune-stimulatory than a 1' monophosphate structure $[39,46]$. This increased potency of a 1' versus 4 ' phosphate may be due to the interaction of the 1' phosphate with TLR4, possibly inducing better receptor clustering.

\section{Proposed mechanism of MPLA's reduced toxicity}

Two models for MPLA's reduced toxicity have emerged in recent years. First, Okemoto et al. found that MPLA fails to stimulate secretion of the highly inflammatory cytokine IL-1 $\beta$ to the same levels as LPS and traced this failure to defective activation of caspase-1, which is needed for proteolytic maturation of IL-1 $\beta$ from its precursor prolL-1 3 [47]. Subsequently, Mata-Haro et al. reported that MPLA signals through TLR4 in a TRIF-biased manner characterized by impaired stimulation of MyD88-dependent signaling events, relative to Lipid A or LPS $[17,48]$. In this 
second model, weak MyD88 signaling is proposed to account for reductions in a broad range of inflammatory activities with little impairment of TRIF-dependent promotion of adaptive immune responses. Currently, it is unclear whether these two low-toxicity mechanisms operate independently of one another, or if one is induced by the other such that either i) impaired IL-1 $\beta$ maturation generates the appearance of TRIF-bias through a loss of autocrine/paracrine signaling through IL-1R, which requires MyD88 as a signaling adaptor, or ii) if TRIF-biased TLR4 signaling directly results in decreased IL-1 $\beta$ maturation via a novel mechanism.

\section{IL-1 $\beta$ production}

IL-1 $\beta$ production is organized into two regulated phases: an initial priming event involving de novo protein synthesis of $31 \mathrm{kD}$ prolL- $1 \beta$, followed by assembly and activation of a multiprotein complex termed the inflammasome which is responsible for proteolytic maturation of IL-1 $\beta$ to its $17 \mathrm{kD}$ active form. In response to TLR4 activation, priming includes up-regulation of both prolL-1 $\beta$ and the "NACHT, LRR and PYD domains containing protein 3" (NLRP3, also known as NALP3, PYPAF1 and cryopyrin), a regulatory component of the inflammasome $[49,50]$. Several events can then provide a secondary stimulus for NLRP3 activation: adenosine triphosphate (ATP) ligation of the purinergic receptor $\mathrm{P} 2 \mathrm{X}_{7}$, bacterial pore-forming toxins and particulate matter such as asbestos, uric acid crystals, aluminum sulfate salts and silica [51]. Experimental treatment of primed cells with exogenous ATP induces the cytosolic protein "apoptosis-inducing speck-like protein containing a caspase recruitment domain" (ASC) to form large aggregates roughly $2 \mu \mathrm{m}$ in diameter that act as nucleation sites for NLRP3 inflammasome assembly via PYD interactions $[52,53]$. Procaspase- 1 is recruited and cleaved to form functional heterodimeric complexes of $10 \mathrm{kDa}$ and $20 \mathrm{kDa}$ subunits capable of IL-1 $\beta$ maturation [54]. IL-1 $\beta$ is then released in a non-classical manner independent of the Golgi apparatus, which appears to involve the Rab GTPase Rab39a mediated traffic to the cell membrane for secretion by a little understood mechanism [55]. ATP can also induce the release of immature prolL-1 $1 \beta$ from the cell where it may be cleaved into the active $17 \mathrm{kDa}$ form by extracellular matrix metalloproteins [56]. This complex regulation of production is critical due to the potent inflammatory effects exerted by IL$1 \beta$. See Figure 4 for an overview of NLRP3 inflammasome-dependent IL-1 $1 \beta$ production. 


\section{IL-1 receptors}

$\mathrm{IL}-1 \beta$ binds to the IL-1 receptor (IL-1R), of which there are two types. Type 1 (IL-1RI) transmits an activating signaling, while non-signaling Type 2 IL-1R (IL-1RII) acts as a decoy receptor [57]. There also exists an IL-1R antagonist (IL-1RA) which competes with IL-1R for IL-1 $\beta$ binding, thereby inhibiting signal transduction [58]. IL-1RI is expressed by lymphoid and myeloid cells of the immune system, cardiovascular and gastrointestinal epithelia and hypothalamic tissue $(17,18) . \quad I L-1 \beta$ mediates its pyrogenic effects by activating IL-1RI in the hypothalamus $(17)$. The almost ubiquitous expression of these two receptors makes their agonists important inducers of damaging systemic effects. IL-1RI, in conjunction with the transmembrane IL-1R accessory protein (IL-1RAcP), transduces signals via MyD88, leading to MAPK, AP-1 and NF-KB activation (24). Both IL-1 $\alpha$ and IL-1 $\beta$ can activate IL-1RI (25), however only IL-1 $\beta$ requires inflammasomeinduced caspase-1 activation for processing (26). IL-1a also appears to play a role in intracellular signaling $(27,28)$, whereas IL-1 $\beta$ is a secreted protein with potent pro-inflammatory properties (29).

\section{PAMP and DAMP activators of the NLRP3 inflammasome}

LPS is capable of priming cells for IL-1 $\beta$ production, while many TLR4 DAMPs, such as ATP, crystals of monosodium urate and cholesterol, amyloid $\beta$ and hyualuranon, are able to act as a secondary stimulus for activation of the NLRP3 inflammasome (Figure 5) [59]. Several DAMPs are activators of both TLR4 signaling and NLRP3 inflammasome activation, and have been implicated in the pathogenesis of many diseases including: gout, pseudogout, silicosis, asbestosis, atherosclerosis and Alzheimer's disease (Table 1) [59].

MPLA pretreatment protects against LPS-induced shock and prevents ischemic reperfusion injury

MPLA has therapeutic potential beyond use as a vaccine adjuvant. Pretreatment with intravenous MPLA prior to administration of endotoxin protects patients against LPS-induced fever and tachycardia; MPLA-treated patients also displayed reduced serum levels of TNF, IL-6 
and IL-8 versus patients pretreated with vehicle control [60]. The inhibition of LPS-induced proinflammatory cytokines by MPLA has been confirmed using animal models of septic shock [61, 62]

MPLA also protects against ischemia reperfusion (1/R) injury, which is caused by reestablishment of blood flow to tissue after a prolonged period of ischemia. I/R injury can occur after a variety of cardiovascular events in which the flow of oxygenated blood is inhibited, including myocardial infarct (5) and stroke (6). Studies using pre-administration of MPLA before surgical manipulation of tissue result in increased oxygenation of tissue, decreased severity of $1 / R$ injury (7) and protection from potentially fatal post-ischemia arrhythmias (8). MPLA also inhibits post-translational TNF-a production in reperfused ischemic heart tissue, which protects cardiocytes from TNF- $a$ mediated necrosis $(9,10)$. Clinical trial patients receiving a pre-treatment of MLA before intravenous injection of LPS, as a simulation of endotoxemia, displayed a reduction in elicited serum TNF-a levels compared to patients pre-treated with vehicle control (11). IL-1 $\beta$, a pro-inflammatory cytokine that plays a significant role in contributing to cardiomyocyte death and myocardial inflammation after reperfusion of ischemic heart tissue (12) was also undetectable in MPLA vs. non-treated volunteers. IL-1 $\beta$ not only contributes to I/R injury, but can play a causal role in the pathogenesis of atherosclerotic disease (13-15). It is necessary to elucidate the mechanism responsible for MLA's post-translational IL-1 $1 \beta$ defect, to determine the possibility that MLA actively inhibits production of inflammatory cytokines that play pathogenic roles in cardiovascular and other diseases.

\section{Conclusion}

Even though MPLA is an effective immune adjuvant and can be utilized to prevent tissue death in several inflammatory conditions, the mechanism responsible for these effects and its overall reduced toxicity compared to LPS has not been determined. The body of work described in this dissertation was initiated to determine the relationship between MPLA's IL-1 $\beta$ loss and its activation of TRIF-biased TLR4 signaling, and to elucidate the signaling mechanisms responsible for IL-1 $\beta$ loss. The studies described here increase understanding needed for further exploitation of MPLA's immunogenic and protective effects. 


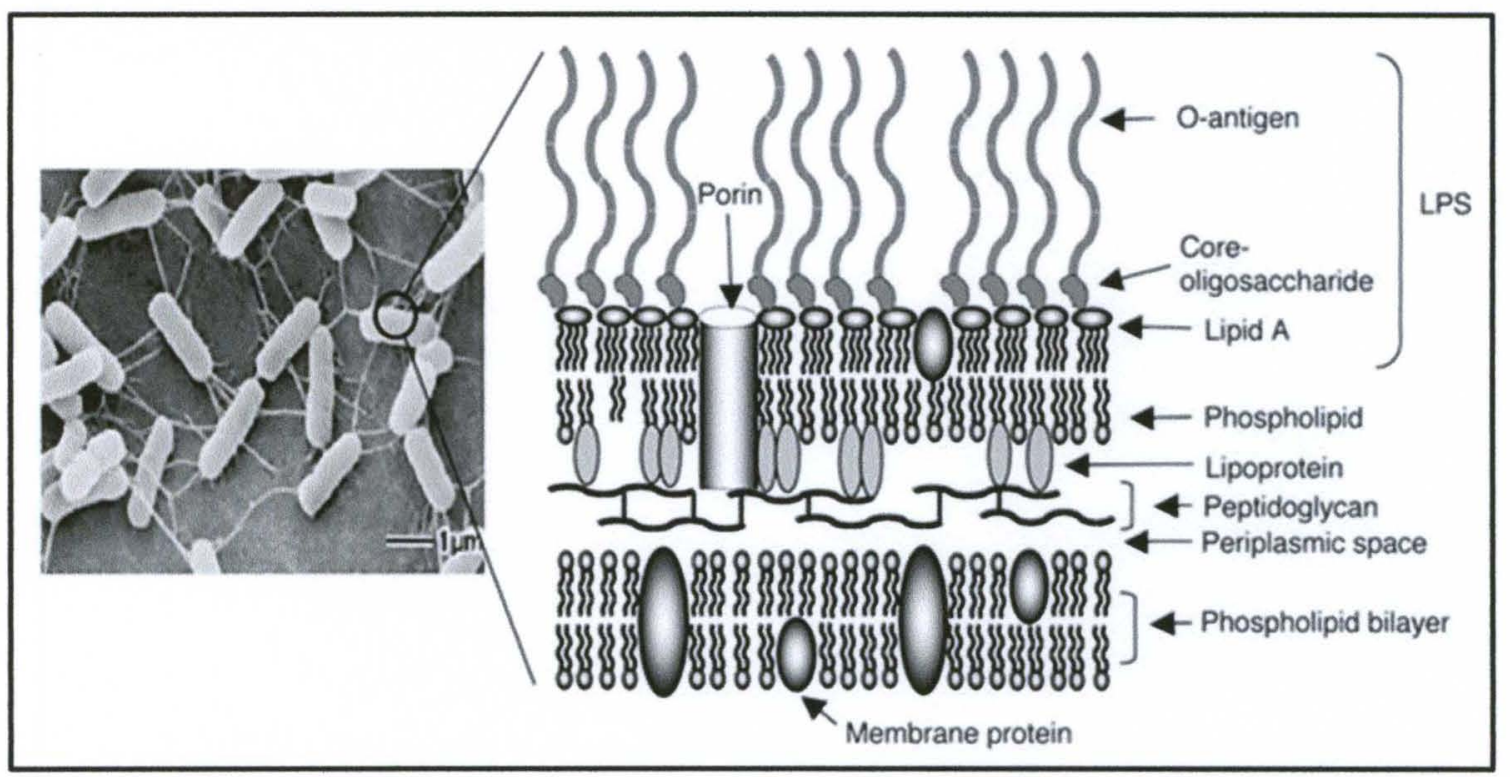

Figure 1. LPS is a cell wall component of Gram negative bacteria. Lipopolysaccharide (LPS) resides in the outer phospholipid bilayer of Gram negative bacteria. LPS is made up of three parts: the polysaccharide O-antigen, the core oligosaccharide also known as $\mathrm{KDO}$, and highly immuno-stimulatory Lipid $\mathrm{A}$. 


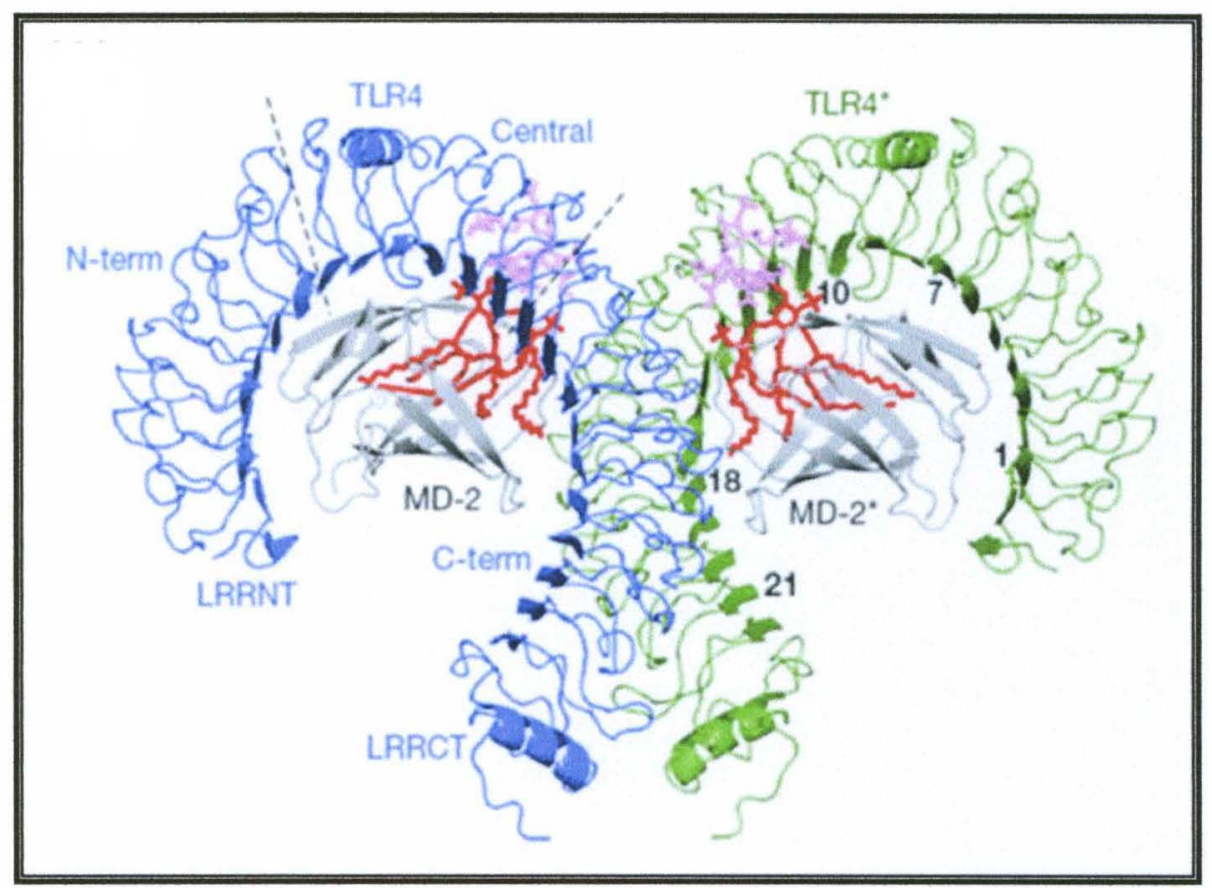

Figure 2. The crystal structure of MD2-bound LPS interacting with TLR4.

The acyl chains of Lipid A fit inside the MD2 pocket. The diglucosamine head group and attached phosphates that sit outside of the MD2 pocket then interact with the "leucine-rich repeats" (LRRs) of TLR4. MD2-bound LPS induces oligomerization or clustering of TLR4, which leads to a downstream intracellular signaling cascade. B.S. Park et al. The structural basis of lipopolysaccharide recognition by the TLR4-MD2 complex. Nature. 2009. 


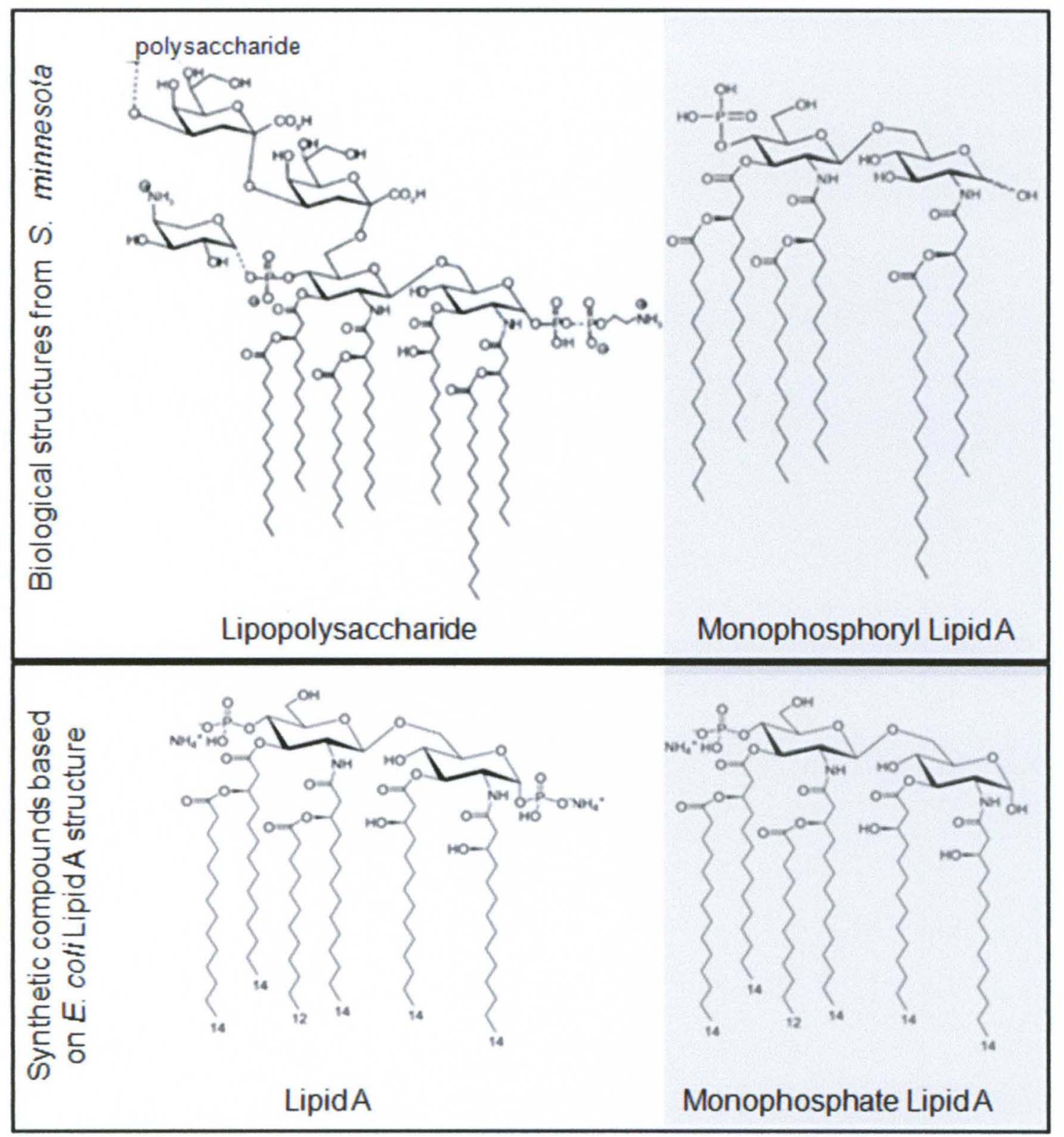

Figure 3. Lipid A structures from S. minnesota and E. coli. Salmonella minnesota lipopolysaccharide and Monophosphoryl Lipid A structures (Top panel) and synthetic Lipid A and Monophosphate Lipid A structures based on E. coli (Bottom panel). 


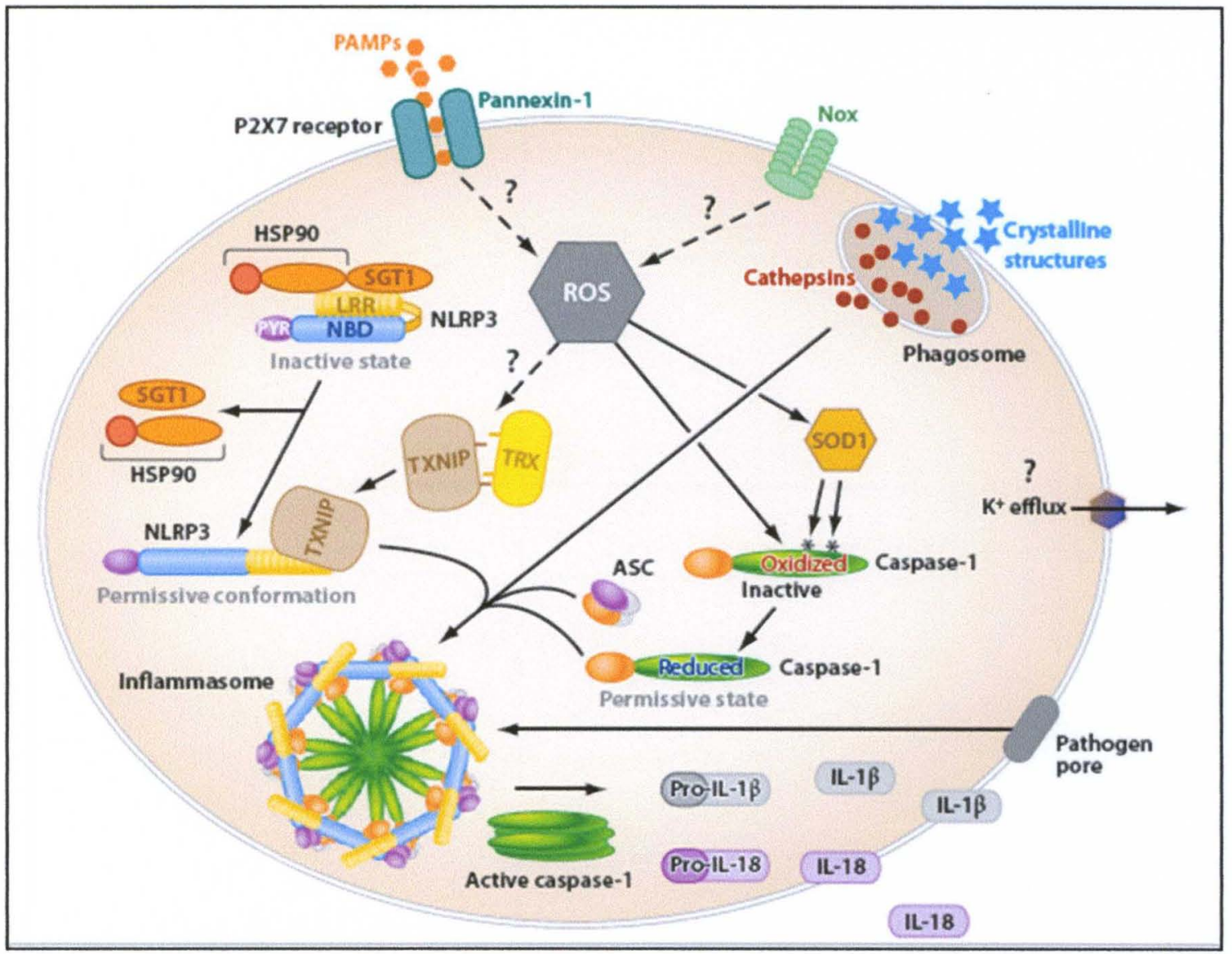

Figure 4. NLRP3 inflammasome activation. Three models have been put forth to explain mechanisms of inflammasome activation. Reactive oxygen species (ROS) are induced by many of the known activators of inflammasomes. It is postulated that the generation of ROS, possibly via the phagosomal NADH-oxidase, releases thioredoxin-interacting protein (TXNIP) from thioredoxin (TRX). TXNIP, which is free from TRX, can bind to NLRP3, possibly by competing with HSP90 and SGT1, which retain NLRP3 in an inactive state. Alternatively, the release of cathepsin B due to lysosomal destabilization activates the inflammasome during phagocytosis. The final model posits pore formation at the plasma membrane that allows for $\mathrm{K}+$ efflux. Pore formation can occur via the $\mathrm{P} 2 \mathrm{X} 7$ receptor/pannexin-1 oligo-structure via pathogen toxins or ion channels. A modification to the last model suggests that small PAMPs can gain cytosolic access via the P2X7 receptor/pannexin-1 hemichannel and activate the inflammasome. B.K. Davis, H. Wen and J.P. Ting. The inflammasome NLRs in immunity, inflammation and associated diseases. Annul. Rev. Immunol. 2011 


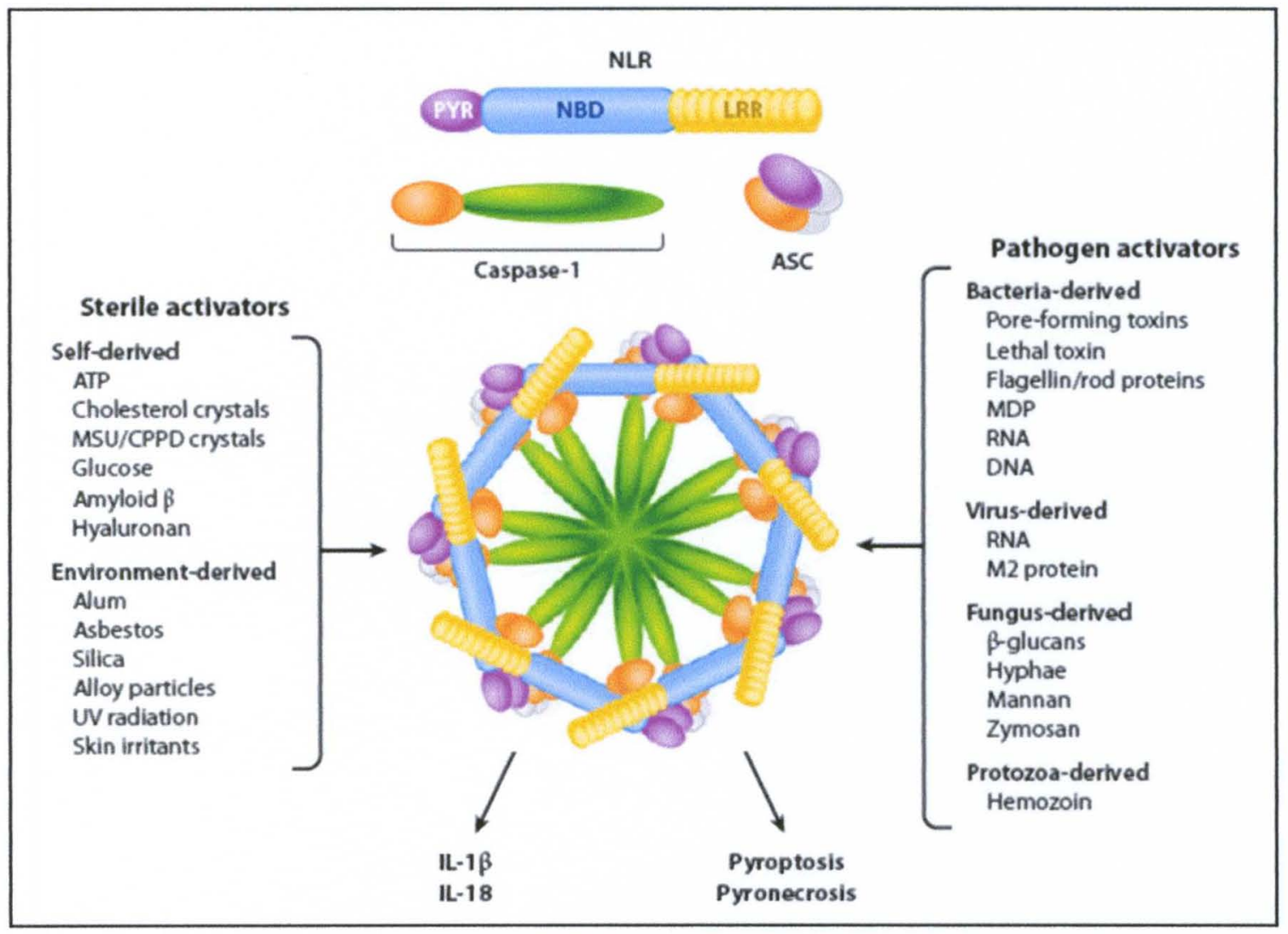

Figure 5. PAMP and DAMP activators of the NLRP3 inflammasome. Activators of the inflammasome are divided into two categories: Sterile activators include host- and environmentderived molecules, and pathogen-associated activators include PAMPs derived from bacteria, virus, fungus, and protozoa. Assembly of the NLRs, ASC, and caspase-1 leads to the formation of a penta- or heptamer structure: the inflammasome. Activation of the inflammasome leads to maturation and secretion of IL-1ßand IL-18 as well as inflammatory cell death, by either pyroptosis or pyronecrosis. (Abbreviations: ASC, apoptosis-associated speck-like protein containing a caspase recruitment domain; CPPD, calcium pyrophosphate dihydrate; MDP, muramyl dipeptide; MSU, monosodium urate; NLR, nucleotide-binding domain, leucine-rich repeat containing; PAMP, pathogen associated molecule patterns.) B.K. Davis, H. Wen and J.P. Ting. The inflammasome NLRs in immunity, inflammation and associated diseases. Annul. Rev. Immunol. 2011. 
Table 1. Sterile activators of the NLRP3 inflammasome

\begin{tabular}{|c|c|c|c|c|c|}
\hline $\begin{array}{l}\text { Sterile } \\
\text { stimulus }\end{array}$ & Diseases & Organs & $\begin{array}{l}\text { Symptoms or } \\
\text { consequences }\end{array}$ & IL-1 dependency & $\begin{array}{c}\text { Inflammasome } \\
\text { dependency }\end{array}$ \\
\hline Cell death & $\begin{array}{l}\text { Many (ischemia, } \\
\text { toxic damage, } \\
\text { etc.) }\end{array}$ & Many & Increased damage, fibrosis & Yes (in vivo and|vitro) & Yes (in vivo and vitro) \\
\hline $\begin{array}{r}\text { Monosodium } \\
\text { urate crystal }\end{array}$ & Gout & Joint & $\begin{array}{l}\text { Inflammation, chronic } \\
\text { arthritis }\end{array}$ & Yes (in vivo and vitro) & Yes (in vivo and vitro) \\
\hline $\begin{array}{l}\text { Calcium } \\
\text { pyrophosphate }\end{array}$ & Pseudogout & Joint & $\begin{array}{l}\text { Inflammation, chronic } \\
\text { arthritis }\end{array}$ & Yes (in vivo and vitro) & Yes (in vivo and vitro) \\
\hline Silica & Silicosis & Lung & Inflammation, fibrosis & Yes (in vivo and vitro) & Yes (in vivo and vitro) \\
\hline Iron oxide & Siderosis & Lung & Inflammation, fibrosis & $\mathrm{ND}^{4}$ & $\mathrm{ND}^{\mathrm{s}}$ \\
\hline $\begin{array}{l}\text { Metal wear } \\
\text { particulates } \\
\end{array}$ & Joint loosening & $\begin{array}{l}\text { Joint } \\
\text { (implanted) }\end{array}$ & $\begin{array}{l}\text { Periprosthetic osteolysis, } \\
\text { revision surgery }\end{array}$ & Yes (in vivo and vitro) & Yes (in vitro) \\
\hline Asbestos & Asbestosis & Lung & $\begin{array}{l}\text { Inflammation, fibrosis, } \\
\text { mesothelioma, lung } \\
\text { cancer }\end{array}$ & Yes (in vivo and vitro) & Yes (in vivo and vitro) \\
\hline $\begin{array}{l}\text { Cholesterol } \\
\text { crystal }\end{array}$ & Atherosclerosis & Arteries & $\begin{array}{l}\text { Inflammation, occlusion } \\
\text { of arteries to ischemia }\end{array}$ & Yes (in vivo and vitro) & Yes (in vivo and vitro) \\
\hline$\overline{\text { Amyloid }-\beta}$ & $\begin{array}{l}\text { Alzheimer's } \\
\text { disease }\end{array}$ & Brain & Neuronal degeneration & Yes (in vivo and vitro) & Yes (in vivo and vitro) \\
\hline Aluminum salts & & $\begin{array}{l}\text { Skin, } \\
\text { peritoneal } \\
\text { cavity }\end{array}$ & $\begin{array}{l}\text { Inflammation, adjuvant } \\
\text { activity }\end{array}$ & Yes (in vivo and vitro) & Yes (in vivo and vitro) \\
\hline Talcum powder & & Pleural cavity & Inflammation, pleurodesis & $\mathrm{ND}^{4}$ & $\mathrm{ND}^{2}$ \\
\hline
\end{tabular}

Ann. Rev. Immunol. 2010.28:321-342 


\section{CHAPTER II}

\section{MATERIALS AND METHODS}

\section{TLR4 agonists}

Synthetic Lipid A (Peptides International) and synthetic Monophosphate Lipid A (Invivogen) corresponding to the $E$. coli structures of LPS were reconstituted in DMSO, aliquoted and at stored at $-80^{\circ} \mathrm{C}$. Paired lots of Lipid $A$ and MLA were used for all experiments, such that each aliquot went through only one freeze/thaw. TLRgrade ${ }^{T M}$ Ready-to-Use Monophosphoryl Lipid A and LPS from Salmonella minnesota R595 (Re) were purchased from Alexis Biologicals (now Enzo Life Sciences). In order to facilitate optimum solubility, MPLA and LPS were transferred to sterile, depyrogenated glass vials (Research Laboratory Supply) and sonicated at $60^{\circ} \mathrm{C}$ at a frequency of $40 \mathrm{kHz}$ for $1 \mathrm{~h}$ in a Branson Ultrasonic Cleaner (model 1510). Sonicated MPLA and LPS were stored at $4^{\circ} \mathrm{C}$ until use.

\section{Reagents}

Adenosine-5'-triphosphate (Roche) and the caspase inhibitor peptide Z-YVAD-FMK (R\&D Systems) were used at concentrations of $5 \mathrm{mM}$ and $50 \mu \mathrm{M}$ respectively. Recombinant murine $\mathrm{C} 5 \mathrm{a}$

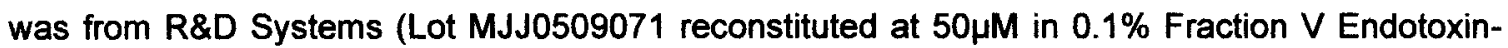
Free BSA from Calbiochem). The CXCR4 antagonist AMD3100 (from Sigma, re-constituted in $\mathrm{diH}_{2} \mathrm{O}$ and stored in single use aliquots at $-80^{\circ} \mathrm{C}$ ) was added as a pre-treatment to cells $30 \mathrm{~min}$ prior to TLR4 agonist. No cellular toxicity (assessed by Trypan-blue uptake compared to no treatment) was observed with AMD3100 at highest dose, $10 \mu \mathrm{g} / \mathrm{mL}$, tested. Functional grade rat anti-mouse CD11b (Clone M1/70 Lot E017819 from eBiosciences), purified rat anti-mouse CD14 (Lot 84234 BD Pharmingen) and functional grade rat $\operatorname{lgG}_{2 b}$ isotype control (Clone eB149/10H5 from eBioscience) were added as a pre-treatment (functional blocking) to cells $\mathbf{3 0}$ min prior to activation with TLR4 agonist. Fluorescein isothiocyanate (FITC) conjugated anti-mouse CD11b 
(Clone M1/70 from eBiosciences), allophycocyanin (APC) conjugated anti-mouse CD14 (Clone Sa2-8 from eBiosciences) and a 1:100 dilution of monoclonal anti-mouse CXCR4 (Clone 247506 R\&D Systems) with 1:800 dilution of phycoerythrin (PE) conjugated Rat IgG (Clone $_{2 b}$ (149/10H5 from eBiosciences) were used for cell staining.

\section{Bone marrow-derived dendritic cell culture}

Femurs and tibiae of mice were flushed to obtain bone marrow plugs using a $221 \frac{1}{2}$ gauge needle and sterile HBSS. After centrifugation, bone marrow cells were re-suspended at $2 \times 10^{6}$ cells/mL in complete R10F media (Gibco RPMI 1640 supplemented with $1 \mathrm{mM}$ sodium pyruvate, $50 \mathrm{U} / \mathrm{mL}$ penicillin, $50 \mu \mathrm{g} / \mathrm{mL}$ streptomycin, $2 \mathrm{mM}$ L-glutamine) supplemented with $5 \mathrm{ng} / \mathrm{mL}$

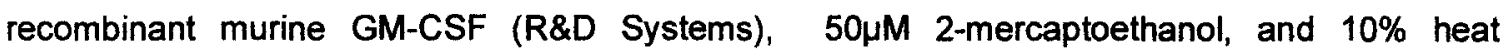
inactivated fetal bovine serum (Valley Biomedical)). Cells were cultured in 100mm-bacteriological Petri dishes and given fresh media on days 3,6 and 8 with the culture lasting 10 days. Nonadherent cells were harvested and washed in R10F, re-suspended and analyzed by flow cytometry for cell surface markers. This culture system yields a myeloid dendritic cell phenotype being $>97 \%$ positive for CD11b (83\% of which also express CD11c) and $<5 \%$ positive for CD4, CD8, CD19, B220 or GR1. R10F alone was used for activation of cells.

\section{Bone marrow-derived macrophage cell culture}

As described above, femurs and tibiae of mice were flushed to collect bone marrow plugs using a 221/2-gauge needle and sterile HBSS. After centrifugation, bone marrow cells were resuspended in $10 \mathrm{~mL}$ complete R5F media (Gibco RPMI 1640 with $1 \mathrm{mM}$ sodium pyruvate, $50 \mathrm{U} / \mathrm{mL}$ penicillin, $50 \mu \mathrm{g} / \mathrm{mL}$ streptomycin and $2 \mathrm{mM} \mathrm{L-glutamine)} \mathrm{was} \mathrm{supplemented} \mathrm{with} 10 \mathrm{ng} / \mathrm{mL}$ recombinant murine M-CSF (R\&D Systems), and $5 \%$ heat inactivated fetal bovine serum (Valley Biomedical)) with $30 \%$ L929 supernatant [17] in a $100 \mathrm{~mm}$-tissue culture dish and incubated overnight at $37^{\circ} \mathrm{C}, 5 \% \mathrm{CO}_{2}$. The next day, non-adherent cells were collected $(\sim 10 \mathrm{~mL})$, combined with $14 \mathrm{~mL}$ of $30 \%$ L929 in complete R5F with $10 \mathrm{ng} / \mathrm{mL}$ M-CSF, and plated $4 \mathrm{~mL}$ per well into a 6 well Ultra-Low Attachment Surface Costar plates. Four days later, cells were fed by addition of $1.5 \mathrm{~mL}$ R5F containing M-CSF and $30 \%$ L929 supernatant. Two days after that, cells were fed 
with $1 \mathrm{~mL}$ per well only complete R5F. The following day, non-adherent cells were harvested and washed in R5F, re-suspended and analyzed by flow cytometry for cell surface markers before use. R5F supplemented with only L-glutamine was used for activation of cells. This culture system yields macrophages that are positive for CD11b and $<5 \%$ positive for CD4, CD8, CD19, B220 or GR1.

\section{Immunoblotting}

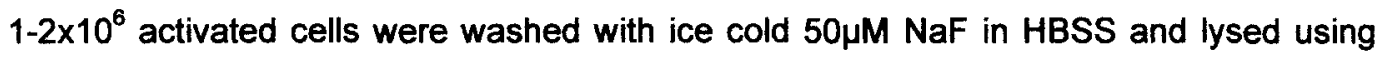
radio immuno-precipitation buffer (RIPA: $50 \mathrm{mM}$ Tris $\mathrm{pH} 7.4,150 \mathrm{mM} \mathrm{NaCl}, 1 \mathrm{mM}$ EDTA, $1 \%$ Triton $X-100,1 \%$ NaDeoxycholate, $0.1 \%$ SDS in distilled and Millipore filtered $\mathrm{H}_{2} \mathrm{O}$ ) supplemented with complete mini protease inhibitor cocktail tablets (Roche). Lysates were clarified by centrifugation and subsequent removal of supernatant from cell debris pellet. Equal protein amounts as determined by bicinchoninic acid kits (Pierce Biotechnology) from clarified lysates were separated on 8 or $12 \%$ polyacrylamide gels under reducing conditions. Resolved proteins were transferred to nitrocellulose membranes (GE Healthcare) that were then blocked in $5 \%$ non-fat dry milk or BSA depending on the antibody being used for immunoblotting. Membranes were incubated overnight at $4^{\circ} \mathrm{C}$ with primary antibody, and then incubated for $1 \mathrm{~h}$ with horse radish peroxidase (HRP) conjugated secondary antibody. ECL (Amersham) was used for band visualization via film or a FujiFilm LAS-4000(mini) Luminescent Image Analyzer. Densitometries of bands were measured using Quantity One 4.6.6 software (Bio-Rad).

\section{Immunoblot antibody specifications}

Information regarding primary antibody use for immunoblotting is shown in Table 2. For each of the immunoblots, polyclonal goat anti-mouse $\beta$-actin ( $1-19$ SantaCruz) was also used at a concentration of 1:1000 after membrane was blocked using 5\% NFDM. Primary antibodies were detected using HRP-conjugated anti-rabbit, anti-mouse and anti-goat antibodies from Jackson Immuno Research. 
Table 2. Antibody specifications for immunoblotting

\begin{tabular}{|c|c|c|c|c|}
\hline & ASC & P10 caspase -1 & IL-1及 & NLRP3 \\
\hline Company & SantaCruz & SantaCruz & Abcam & Adipogen \\
\hline Clone & $N-15-R$ & $\mathrm{M} 20$ & & Cryo-2 \\
\hline Cat. No. & sc-22514-R & sc-514 & $a b 9722-100$ & AG-20B-0014-C100 \\
\hline Lot No. & 11009 & K1109 & 761298 & $A 3028812$ \\
\hline Host & Rabbit & Rabbit & Rabbit & Mouse \\
\hline Specificity & Polyclonal & Polyclonal & Polyclonal & Hybridoma \\
\hline SDS-PAGE & $12 \%$ gel & $12 \%$ gel & $12 \% \mathrm{gel}$ & $8 \%$ gel \\
\hline Transfer & $15 \mathrm{~V} 25 \mathrm{~min}$ & $15 \mathrm{~V} 30 \mathrm{~min}$ & $15 \mathrm{~V} 30 \mathrm{~min}$ & $15 \mathrm{~V} 45 \mathrm{~min}$ \\
\hline Block & $5 \%$ NFDM & $5 \%$ BSA & $5 \%$ NFDM & $5 \%$ NFDM \\
\hline Dilution & $1: 1000$ & $1: 1000$ & 1850 & $1: 1000$ \\
\hline Band size & $22 \mathrm{kDa}$ & $10 \mathrm{kDa}$ & $17 \& 31 \mathrm{kDa}$ & $120 \mathrm{kDa}$ \\
\hline
\end{tabular}

Abbreviations: NFDM- non-fat dry milk (Carnation), BSA- bovine serum albumin

\section{Spleen and liver RNA isolation}

Whole spleen and liver sections in RNAlater Stabilization Reagent were stored at $4^{\circ} \mathrm{C}$ no more than 4 days before tissues were cut into small pieces with scissors and placed in 700 $\mathrm{L}$ RLT buffer (Qiagen) supplemented with 1\% 2-mercaptoethanol in plastic Eppendorf tubes (not polystyrene flow tubes). Tissues were then sonicated on ice for $30 \mathrm{sec}$ using a Fisher Scientific 550 Sonic Dismembrator. $700 \mu \mathrm{L}$ of $70 \%$ molecular grade ethanol were added to tissue samples, and RNA isolation was performed using RNeasy Mini Kits (Qiagen) according to the manufacturer's protocol by loading column with $700 \mu \mathrm{L}$ twice in a row.

\section{Quantitative PCR}

Gene expression was measured by measuring RNA transcript levels. First, cellular RNA was isolated from whole cell lysates using Qiagen RNeasy Mini Kits according to the manufacturer's protocol. Briefly, cells were washed with ice cold HBSS, lysed using RLT buffer supplemented with $1 \% 2$-mercaptoethanol, and frozen at $-80^{\circ} \mathrm{C}$ until RNA isolation. RLT samples were thawed at room temperature, mixed with equal volumes of $70 \%$ molecular grade ethanol and transferred to microfuge RNA isolation columns for isolation. Isolated RNA was synthesized 
into cDNA using Quanta qScript cDNA Synthesis Kits according to manufacturer's protocol. RNA quality was checked using NanoDrop $2000^{\mathrm{TM}}$ (Thermo Scientific) with a $260 \mathrm{~nm} / 280 \mathrm{~nm}$ absorbance ratio of $1.8-2.0$ being considered pure RNA. CDNA was used with $0.5 \mu \mathrm{M}$ target (/fit2, Asc, Serpine-1, I1b, Cox-2, Endothelin-1, Tnf- $\alpha$ ) or control (Actin or Gapdh) QuantiTect Primer Assays from Qiagen. Primers for target NIrp3 (Forward- ATG GTA TGC CAG GAC AG, ReverseATG CTC CTT GAC CAG TTG GA) were synthesized by Sigma. Quantitative real-time PCR was performed on a CFX96 Real-Time System C1000 Thermal Cycler (BioRad) (10min at $94^{\circ} \mathrm{C}$, followed by 40 cycles of $15 \mathrm{sec}$ at $94^{\circ} \mathrm{C}$ and $30 \mathrm{sec}$ at $55^{\circ} \mathrm{C}$ ) using Power SYBR Green Master Mix (Applied Biosystems). Specificity of amplification was determined by melt curve analysis immediately following each RTqPCR. Relative mRNA expression was calculated using the comparative cycle method $(\Delta \Delta \mathrm{Ct})$.

\section{Animal husbandry and genotyping}

C57 BL/6 (WT), Trif ${ }^{\text {fps2 }}$ and IL1RI ${ }^{\text {tmlRoml }}$ (referred to as IL-1RI ${ }^{\text {mu }}$ ) mice were purchased from Jackson Laboratories. Myd88-1 mice were a gift from S. Akira (via Ross Kedl, University of Colorado Health Science Center). Myd88 breeders were paired as heterozygous and homozygous female and male respectively to confer maternally-derived passive immunity to pups. Each litter was typed for homozygosity of $M y d 88^{-1-}$ via PCR amplification of WT and KO gene segments from ear punches. (WT forward 5'-TGG CAT GCC TCC ATC ATA GTT AAC C; reverse 5'-GTC AGA AAC AAC CAC CAC CAT GC and KO forward 5'-TGG CAT GCC TCC ATC ATA GTT AAC A reverse 5'-ATC GCC TTC TAT CGC CTT CTT GAC G). Amplified gene segments were run on agarose gels for determination of Myd88 genotype, with expected PCR products of $550 \mathrm{bp}$ for $\mathrm{WT}$ and $650 \mathrm{bp}$ for KO. All mice were kept in a specific pathogen-free animal facility at the University of Louisville, under the supervision of its IACUC.

\section{Animal experimentation}

Individual mice were moved sequentially to a clean cage and placed under a heat lamp

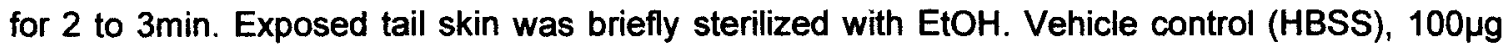
MPLA or $100 \mu g$ LPS in $100 \mu \mathrm{L}$ total volume was injected via tail vein. At $1 \mathrm{~h}$ post injection, mice 
were heated again and bled via tail vein for plasma cytokine analysis. At $6 \mathrm{~h}$ post injection, animals were euthanized via $\mathrm{CO}_{2}$ and blood was collected via cardiac puncture for plasma cytokine analysis. Whole spleen and liver sections were collected and placed in RNAlater Stabilization Reagent (Qiagen) for subsequent transcript analysis.

\section{Flow cytometry}

$1 \times 10^{6}$ cells in polystyrene flow cytometry tubes were washed in ice cold Stain Buffer (Gibco HBSS with $2 \%$ heat inactivated FBS (Valley Biomedical) and $0.1 \%$ sodium azide). Nonspecific binding sites were blocked for $10 \mathrm{~min}$ at room temperature using $\sim 100 \mu \mathrm{L}$ of $20 \% 2.4 \mathrm{G} 2$ anti-FcR hybridoma supernatant in Stain Buffer. Cells were incubated with previously determined dilutions of fluorochrome labeled antibodies for $30 \mathrm{~min}$ at $4^{\circ} \mathrm{C}$ in the dark. Cells were washed once more in Stain Buffer, and re-suspended in Stain Buffer for analysis on a BD FACSCalibur ${ }^{\mathrm{TM}}$ flow cytometer. Data were analyzed using FlowJo Flow Cytometry Analysis Software v.7.6.1 for Mac.

\section{Culture supernatant cytokine detection}

Culture supernatants from $2 \times 10^{5}$ cells were collected and stored at $-80^{\circ} \mathrm{C}$ until ELISA. Culture supernatants were analyzed using BD OptEIA ${ }^{\text {TM }}$ mouse IL-6 ELISA sets (BD Biosciences), mouse IL-1 $\beta$ and TNF-a Ready-Set-Go! ${ }^{\oplus}$ ELISA sets (eBioscience) according to each manufacturer's protocol. OD values were obtained at a wavelength of $450 \mathrm{~nm}$ using a Molecular Devices $E_{\max }$ precision microplate reader and SoftMax ${ }^{\oplus}$ Pro software ( 5.2 rev C).

\section{Plasma cytokine, C5a, serum amyloid $A$ and alanine aminotransferase detection}

Blood from tail vein or cardiac puncture was collected in BD Microtainer Plasma Separator Tubes with Lithium Heparin according to the manufacturer's protocol. Plasma samples were immediately analyzed for IL-1 $\beta$, TNF, IL-12p70, MCP-1, IL-6, IL-10 and KC using Cytometric Bead Array (CBA) according to the manufacturer's protocol (CBA Flex Sets, Flex Standards and Mouse/Rat Soluble Protein Master Buffer Kit from BD Pharmingen). Samples were run on a BD FACSCalibur ${ }^{\mathrm{TM}}$ flow cytometer, and data were analyzed using BD CBA FCAP Array software v1.0.1. Plasma samples were then stored at $-80 \mathrm{C}$ until ELISA for C5a, IL-6, serum 
amyloid $A(S A A)$ and alanine aminotransferase (ALT). Plasma C5a levels were detected using purified rat anti-mouse C5a and biotin rat anti-mouse C5a (BD Pharmingen), and IL-6 was detected using BD OptEIA TM mouse IL-6 ELISA sets (BD Biosciences). SAA levels in plasma were analyzed using SAA Mouse ELISA Kits from Invitrogen according to the manufacturer's protocol. Plasma levels of ALT were determined using Mouse ALT ELISA Kits from Uscn Life Sciences according to manufacturer's protocol.

\section{Immunofluorescent confocal microscopy}

$5 \times 10^{4}$ cells were activated in each well of microscopy chamber slides (Nalge Nunc International) for $5 \mathrm{~h}$ with TLR4 agonists. Cells were then pulsed with $5 \mathrm{mM}$ ATP (Roche) for $5 \mathrm{~min}$. Chamber slides were placed on ice and incubated with Alexa Flour-594 conjugated cholera toxin subunit-B (CTB at 1:500) (Invitrogen) for an additional $5 \mathrm{~min}$ before being fixed and permeabilized using ice cold 1:1 methanol:acetone solution. Non-specific binding sites were blocked using 4-5

drops of Image-iT ${ }^{\otimes}$ FX Signal Enhancer (Invitrogen) for $1 \mathrm{~h}$ prior to overnight incubation at $4^{\circ} \mathrm{C}$ with polycional anti-ASC, (Clone N-15-R, Santa Cruz, at 1:200). Slides were then incubated with Alexa Fluor-488 conjugated goat anti-rabbit $\lg G$ at $1: 400$ (Invitrogen) for $1 \mathrm{~h}$ before preparation using VectaSheild Hard-Mount Medium with DAPI (Vector Laboratories). Images were captured by a Leica TCS SP5 II confocal microscope using LAS AF 2.2.0 software. Cells and ASC specks (which appear as bright spots $\sim 2 \mu \mathrm{m}$ in size inside the cell) were enumerated using ImageJ 1.43 analysis software.

\section{Statistical analysis and sample normalization}

Each experiment used separate cell cultures derived from individual mice. The difference between groups in time course experiments was statistically analyzed using balanced one-way ANOVA. Individual data points were analyzed by paired two-sample for means $t$-test using a hypothesized mean difference of zero and a confidence level of 0.05 . A P-value of $<0.05$ was considered statistically significant. Data points in ELISA and RTqPCR were averaged from triplicate wells +/- SEM. All RTqPCR data were normalized to Actin or Gapdh. Signals from vehicle-only treated cells were used as reference points for calculation of fold increase. 


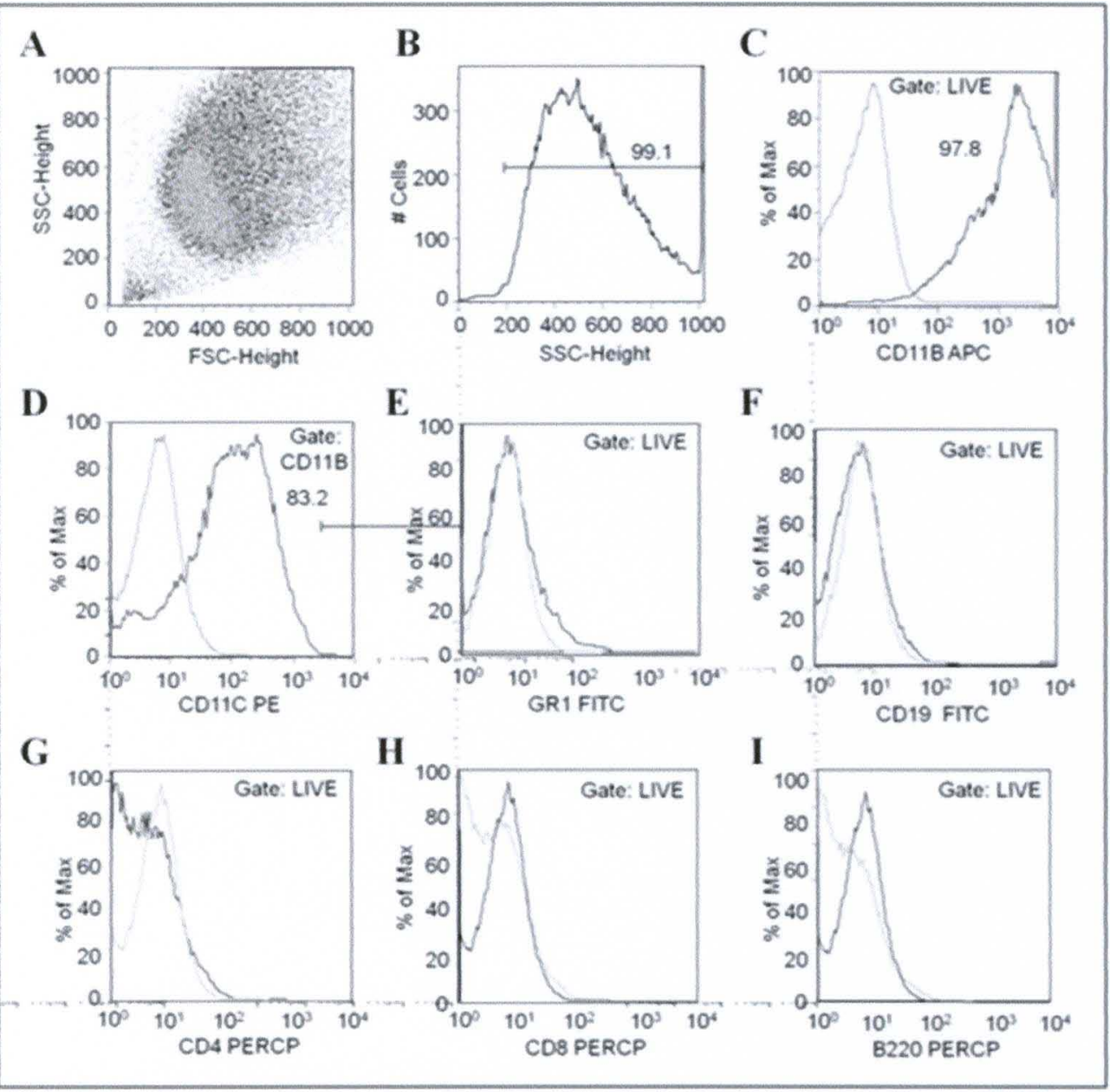

Figure 6. Phenotype of bone marrow derived dendritic cells. $1 \times 10^{6}$ bone marrow derived dendritic cells were stained with anti CD11b, CD11c, GR1, CD19, CD4, CD8 and B220 fluorochrome-labeled antibodies after 10 day culture as described on page 26 . 


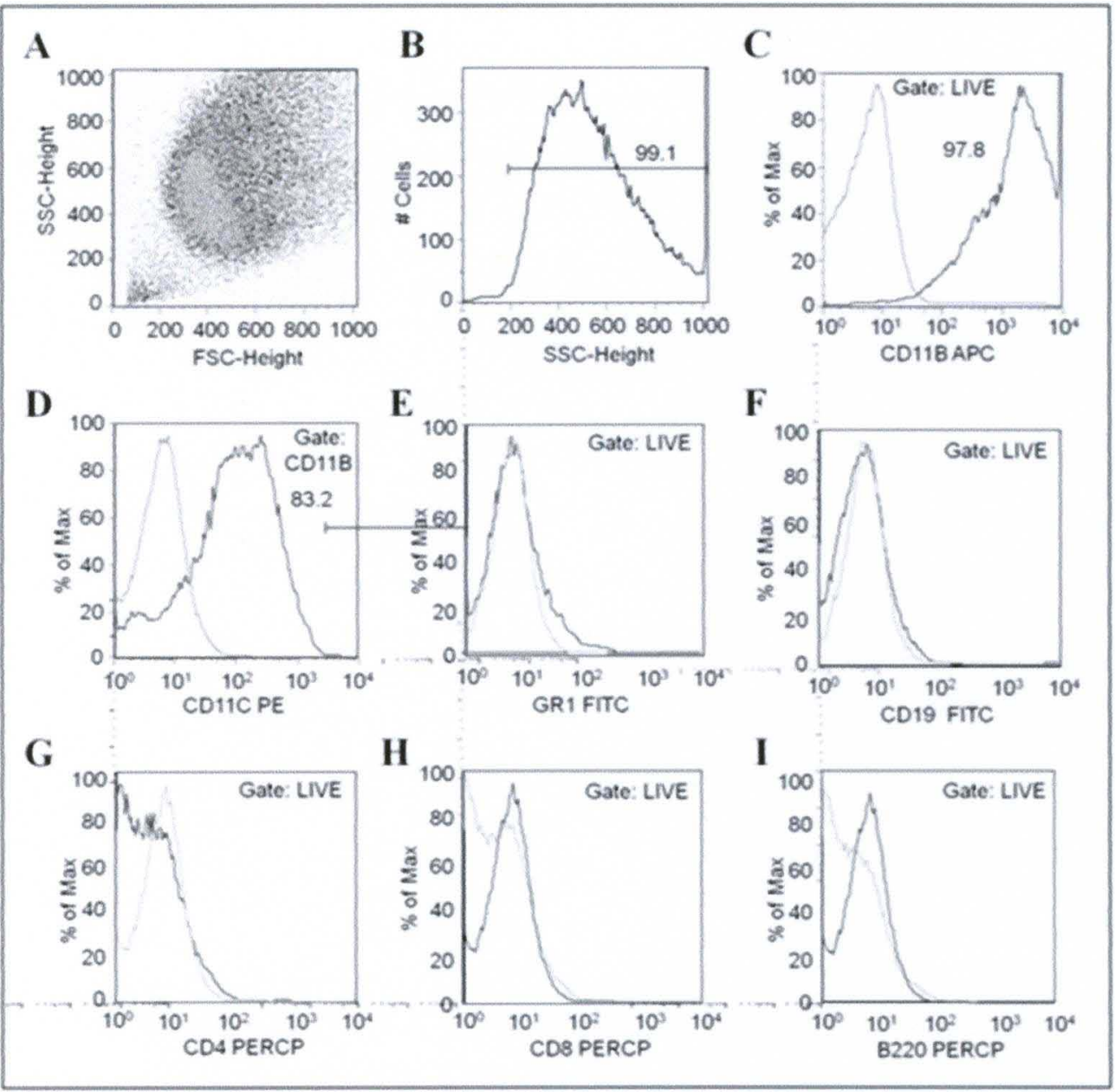

Figure 7. Phenotype of bone marrow derived macrophages. $1 \times 10^{6}$ bone marrow derived macrophages were stained with anti CD11b, CD11c, GR1, CD19, CD4, CD8, F4/80, CD14 and B220 fluorochrome-labeled antibodies after 7 day culture as described on page 27. 


\section{CHAPTER III}

\section{NLRP3 INFLAMMASOME ACTIVATION BY MLA AND LIPID A}

\section{INTRODUCTION}

TLR4 recognizes a wide range of PAMPs and endogenously released DAMPs that alert the immune system to invading pathogenic organisms or cellular damage, respectively. LPS of gram negative bacteria is TLR4's canonical PAMP ligand, inducing a pro-inflammatory cytokine response as well as up-regulation of factors involved in antigen presentation and $T$ cell activation by monocytic cells. TLR4's two signaling pathways, named for the adaptor proteins MyD88 and TRIF mediate these outcomes respectively [63]. The immune-stimulatory properties of TLR4 ligands make them potentially useful as vaccine adjuvants [64], but therapeutic exploitation requires careful consideration of the potentially toxic inflammatory side effects of TLR4 signaling. One derivative of LPS, MPLA, is potently immuno-stimulatory while exhibiting $0.1-1 \%$ as much toxicity as its parent molecule [65] which has led to its approval for use as a vaccine adjuvant in its clinical grade form, MPL adjuvant@ [66]. Clinical use of MPL adjuvant $($ for prophylactic immunization demonstrates that low toxicity stimulation of TLR4 for therapeutic purposes is feasible, however the intracellular signaling activities that control whether or not a given TLR4 ligand is likely to trigger inflammatory side effects are not fully defined.

Two main hypotheses have been proposed for explaining MLA's reduced toxicity: i) that weak induction of IL-1 $\beta$ leads to decreased inflammation [47] and ii) that TRIF-biased activation of TLR4 results in weak induction of MyD88-dependent pro-inflammatory factors [17]. IL-1B is potent inflammatory cytokine that can potentiate MyD88 signaling through IL-1RI. After a priming event for prolL-1 $\beta$ induction, a secondary stimulus promotes the formation of the NLRP3 inflammasome which activates procaspase- $1[49,50]$. Mature caspase-1 can then cleave prolL$1 \beta$ into mature IL-1 $\beta$ [54]. It is unknown if TRIF-biased signaling by MLA is related to its weak promotion of IL-1 $\beta$ maturation. 
TLR4 signaling alone is sufficient for production of significant levels of the inflammatory cytokine IL-1 $\beta[47]$, and although the levels of IL-1 $\beta$ produced by this mechanism are lower than with activation by experimental addition of ATP, they may be relevant in situations of chronic inflammation. For example, DAMPs recognized by TLR4 have been implicated in the pathogenesis of several inflammatory conditions including diabetes, arthritis, systemic lupus erythematosus, septic shock, stroke and myocardial infarct as well as Alzheimer and Crohn's disease, each of which has been linked to aberrant production of IL-1 $\beta$ and/or NLRP3 activation [67-73]. Additionally, MPLA has been shown to prevent ischemic reperfusion injury if given prior to organ transplant or cardiac tissue manipulation in several animal models [74-79], suggesting a possible mechanism whereby MPLA exerts a protective effect in tissues via interference with TLR4/DAMP-induced inflammasome assembly. A more precise understanding of the means by which TLR4 signaling results in IL-1 $\beta$ maturation is needed for the development of targeted signaling therapies, as well as to generate next-generation vaccine adjuvants that remain immuno-stimulatory with as little risk of adverse inflammatory effects as is possible.

Despite obvious clinical significance, the contributions of MyD88 and TRIF to TLR4dependent inflammasome priming and activation remain surprisingly undefined. A previous study attempted to define the roles of TLR4 signaling adapters in terms of caspase activation; however, this study utilized low purity LPS preparation likely to contain microbial contaminants such as peptidoglycan (PGN) and muramyl dipeptide (MDP) which are capable of priming cells and inducing IL-1 $\beta$ production by themselves via TLR2 and nucleotide-binding oligomerization domain (NOD) receptors [80-84]. Moreover, this study concluded that caspase-1 activation is independent of either MyD88 or TRIF [84], while it has been definitively shown elsewhere that purified LPS does not induce IL-1 $\beta$ production from cells doubly deficient in MyD88 and TRIF [49, $50,85-87]$. Use of highly pure, synthetic TLR4 agonists allowed us to more accurately define the relative contributions of the MyD88 and TRIF signaling pathways to various phases of IL-1 $\beta$ production, without confounding activation of other TLRs or NOD receptors. Our results demonstrate that MPLA's TRIF-biased TLR4 signaling activity is the cause and not a consequence of impaired IL-1 $\beta$ production because TLR4-induced priming at the level of NLRP3 induction is a MyD88-dependent event. 


\section{METHODS}

Before any treatment or activation, cells were rested for $2 \mathrm{~h}$ at $37^{\circ} \mathrm{C}, 5 \% \mathrm{CO}_{2}$ in a humidified incubator.

\section{Reagents}

Synthetic MLA and Lipid A based on the E. coli structures MPLA and Lipid A were used for in vitro experimentation. Predicted structures of synthetic Lipid A compounds were determined using mass spectroscopic analysis by Dr. Bogdan Bogdonov and Dr. Rick Higashi at the University of Louisville's Mass Spectroscopy Core Facility. Experimental mass-charge ratios for both Lipid A and MLA matched reported values (Figure 8 and 9).

\section{Transcript analysis}

$1 \times 10^{6}$ myeloid DCs per treatment were activated for $1 \mathrm{~h}$ (unless otherwise indicated) in polystyrene tubes before taking cell lysates for RNA isolation, CDNA synthesis and RTqPCR.

\section{Cytokine detection by ELISA}

$2 \times 10^{5}$ myeloid DCs per treatment were activated for $6 \mathrm{~h}$ in 96 -well polystyrene plates with TLR4 agonist before culture supernatant was harvested and stored at $-80^{\circ} \mathrm{C}$ until ELISA. Where indicated, cells were pulsed for $20 \mathrm{~min}$ with $5 \mathrm{mM}$ ATP before supernatant was harvested.

\section{Immunoblot analysis}

$2 \times 10^{6}$ myeloid DCs per treatment were activated for $5 \mathrm{~h}$ in polystyrene tubes before lysates were taken. Anti-mouse ASC, procaspase-1, p10 caspase-1, IL-1 $\beta$, NLRP3 and Actin were used as described in MATERIALS and METHODS (page 28). 
Immunofluorescent confocal microscopy

$5 \times 10^{4}$ myeloid DCs per treatment were activated for $5 \mathrm{~h}$, and then pulsed for $10 \mathrm{~min}$ with $5 \mathrm{mM}$ ATP before being fixed for staining. For stain and antibody information refer to MATERIALS and METHODS (page 34).

\section{RESULTS}

Lipid A, but not MLA, induces significant IL-1 $\beta$ production from myeloid DCs in a caspase1 dependent manner in the absence of exogenous ATP

To confirm previously published findings that MLA fails to stimulate IL-1 $\beta$ production in our cell culture system, and to establish that the absence of one phosphate from the Lipid A diglucosamine head group is sufficient for this effect, we treated myeloid DCs with structurally defined, synthetic TLR4 agonists in the absence of exogenously added ATP and analyzed culture supernatants by ELISA. Myeloid DCs activated with Lipid A secreted significantly more IL-1 $\beta$ compared to those activated with MLA (Figure $10 \mathrm{~A}$ ). This secretion of IL-1 $\beta$ was dependent on caspase activity, because pretreatment of DCs with the caspase inhibitor peptide Z-YVAD-FMK reduced IL-1 $\beta$ levels to undetectable levels. Production of IL-6, a caspase- 1 independent cytokine [88], was not affected by addition of Z-YVAD-FMK (Figure $10 \mathrm{~B}$ ). These data show that synthetic Lipid $A$ induces $\mathrm{IL}-1 \beta$ production in a caspase-dependent manner, that MLA fails to promote significant IL-1 $\beta$ production from myeloid DCs, and that removal of one phosphate from the Lipid A's head-group is sufficient for this effect.

\section{TRIF-biased TLR4 signaling proceeds independently of IL-1RI}

The receptor for IL-1ß, IL-1RI, requires MyD88 as a signaling adaptor and it is therefore formally possible that the greater amounts of IL-1 1 released by Lipid A-stimulated cells generated the higher levels of MyD88-associated outcomes, relative to TRIF-biased MLA, that we previously observed when comparing Lipid A and MLA $[17,48]$. In the current study, IL-1 $\beta$ was not detectable in culture supernatants within $1 \mathrm{~h}$ of treatment with Lipid A or MLA, which is the time frame when TRIF-biased signaling by MLA was evident in the previous studies [17, 48]. 
Nevertheless, low levels of early IL-1 $\beta$ production could potentiate MyD88 signaling through autocrine/paracrine activation of its receptor, IL-1RI, so we tested whether or not the presence of a functional IL-1RI was required for Lipid A to induce higher levels of a MyD88-dependent gene product. First, tests of the ability of Lipid A to increase transcript levels of Cox-2 and Ifit-2 in WT, TRIF mutant (Trif ${ }^{\text {ps2 }}$ ) or MyD88 ${ }^{-\alpha}$ myeloid DCs confirmed these transcripts to be MyD88- or TRIFdependent, respectively (Figure $10 \mathrm{C}, \mathrm{E}$ ). As reported previously [48], MLA induced significantly less up-regulation of MyD88-dependent Cox-2 over time as compared to Lipid A, while upregulation of TRIF-dependent Ifit-2 were similar between the two agonists (Figure $10 \mathrm{D}, \mathrm{F}$ ). We reasoned that if differential up-regulation of MyD88-dependent transcripts between MLA and Lipid A was dependent on IL-1 $\beta$ production and subsequent IL-1RI autocrine signaling, Lipid A-induced levels of Cox-2 would decrease to those of MLA when tested in cells that lack IL-1RI signaling. Instead, differential up-regulation of MyD88-dependent Cox-2 was retained in Lipid A-treated IL1RI ${ }^{\mathrm{mu}}$ cells (Figure $10 \mathrm{D}, \mathrm{F}$ ), indicating that TRIF-biased TLR4 signaling by MLA proceeds independently of IL-RI signaling.

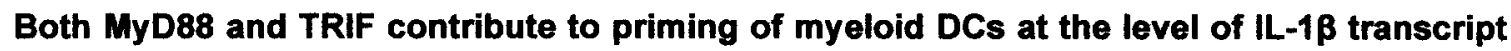
and prolL-1 $\beta$

We next investigated several of the steps involved in IL-1 $\beta$ maturation in order to determine whether MLA's signaling could directly lead to impaired IL-1 $1 \beta$ production. Okemoto et al., and subsequently our group (Mata-Haro et al.), have shown that biological preparations of MLA induce $/ 11 b$ transcript up-regulation to the same extent as LPS $[17,47]$. Using synthetic agonists, we first confirmed that MLA and Lipid A-treated DCs have similar levels of IL-1 $\beta$ transcript, with induction peaking $1 \mathrm{~h}$ after activation (Figure11 A). We next measured levels of prolL-1 $1 \beta$ protein in activated DCs, and found slight differences in protein induction after MLA vs. Lipid A stimulation (Figure $11 \mathrm{~B}$ ). To test further for any differences in prolL-1 $\beta$ priming, experiments were performed in the presence of caspase inhibitor Z-YVAD-FMK, which normalizes translation of prolL-1 $\beta$ by preventing its loss due to proteolytic cleavage and also by preventing any potentiation of prolL-1 $\beta$ induction by mature IL-1 $\beta$ via IL-1RI-MyD88 signaling. As shown in Figures $11 \mathrm{C}$ and D, pretreatment with Z-YVAD-FMK led to induction of prolL-1 $\beta$ that 
was indistinguishable between MLA and Lipid A, indicating that the agonists induced prolL-1 $\beta$ transcription and translation with the same potencies. Caspase activity was indeed inhibited, as the $17 \mathrm{kDa}$ band of mature IL-1 $\beta$ in Lipid A stimulated DCs was absent after pre-treatment with peptide.

Upon analyzing the contributions of MyD88 vs. TRIF to up-regulation of IL-1 $1 \beta$ transcript in Lipid A-treated DCs, we discovered that full transcript induction required both MyD88 and TRIF signaling adapters (Figure $11 \mathrm{E}$ ). Although induction of transcript was previously viewed to be strictly MyD88-dependent, that conclusion was based on a study performed before the full extent of the complexity of inflammasome priming, assembly and activation was understood (and before new and more sensitive techniques for transcript detection were developed) [89]. In the absence of Z-YVAD-FMK treatment, MyD88 was found to contribute significantly to prolL-1 $\beta$ up-regulation, with TRIF being less critical for induction (Figure $11 \mathrm{~F}$ ), which may reflect in part the requirement for MyD88 in IL-1R1 signaling that could potentiate prolL-1 $1 \beta$ expression.

\section{Secretion of IL-1 $\beta$ induced by TLR4 agonists in the absence of exogenous ATP is co- dependent on MyD88 and TRIF}

Previous studies have reported weak IL-1 $\beta$ production by MLA [17, 47]. We confirmed this finding in myeloid DCs using synthetic MLA to stimulate the cells in the absence of exogenous ATP, which showed weak production of IL-1 $\beta$ at all doses when compared to Lipid A. When we assessed dependence of IL-1 $1 \beta$ production on MyD88 vs. TRIF, we found levels of both secreted and cell-associated mature IL-1 $\beta$ to be reduced in the absence of either signaling adapter. Additionally, MLA remained less potent than Lipid $A$ at inducing IL-1 $\beta$ production in Trif ${ }^{\text {pss }}$ or MyD88 ${ }^{-1}$ DCs. We were unable to directly detect caspase-1 maturation in cells treated with TLR4 agonist alone; however the caspase inhibitor experiments described above showed that the $17 \mathrm{kDa}$ product corresponding to mature IL-1 $\beta$ was dependent on caspase activity. These data demonstrate that the low levels of mature IL-1 $\beta$ produced in response to TLR4 activation alone, in the absence of exogenous ATP, are dependent on both TRIF and MyD88 signaling. Moreover, the different levels of mature IL-1 $\beta$ secretion induced by MLA vs. Lipid A did not 
appear to result from differences in ASC or procaspase-1 levels, as both proteins are constitutively expressed (Figure $12 \mathrm{~A}-\mathrm{C}$ ), as previously reported [54].

\section{MyD88 is critically required for ATP stimulated IL-1ß production}

Although production of mature IL-1 $\beta$ following TLR4 activation in the absence of added ATP was found to be co-dependent on MyD88 and TRIF, we speculated that addition of ATP could compensate for activities induced downstream of either adapter. This was tested by stimulating WT, Triffss or MyD88 ${ }^{-\alpha}$ cells with TLR4 agonists followed by an ATP pulse to stimulate inflammasome assembly and activation. We found that Lipid A-primed Trif ${ }^{\text {ps2 }}$ DCs showed only slight decreases in IL-1 $1 \beta$ production relative to $W T$ cells in the presence of ATP, while MyD88 appeared critical for any significant ATP-induced IL-1 $\beta$ production, a dependence that was correlated with the amount of secreted active caspase-1 (Figure $13 \mathrm{D}$ ). It was previously reported that ATP induces secretion of both pro and mature IL-1 3 [90]. In order to determine the relative contributions of pro and mature forms of $\mathrm{IL}-1 \beta$ to the total amounts detected in the ELISA experiment shown in Figure 13 A-C, we analyzed culture supernatants of MLA or Lipid A-primed, ATP-pulsed DCs by immunoblot (Figure $13 \mathrm{D}$ ). Although ATP addition markedly increased the amount of total IL-1 1 secreted by MLA-primed DCs, relative to the unassisted levels detected in Figure $4 A$, we found that approximately $99 \%$ of the IL-1 $\beta$ released by ATP to be unprocessed prolL-1 $\beta$ (Figure $13 \mathrm{E}$ ). This result confirms MLA's inability to activate caspase-1 even in the presence ATP [47]. Collectively, these data show a stringent requirement for MyD88, and to a much lesser degree for TRIF, in ATP-triggered IL-1 $\beta$ production by TLR4/Lipid A-primed cells. Additionally, MLA-primed DCs were unable to secrete the mature form of IL-1 $\beta$ even when given a strong secondary stimulus for inflammasome activation.

\section{MLA-primed myeloid DCs display reduced ASC-speck formation and caspase-1 activation}

The almost complete failure of MLA to support IL-1 $\beta$ maturation in the presence of ATP described above suggested that formation of higher order inflammasome structures might be impaired. Such structures are commonly detected by imaging a constitutively expressed inflammasome component, ASC, after exogenous ATP is provided to cells which had been 
primed with TLR4 agonists. ASC visualization under these conditions shows initially diffuse and then highly focused aggregation into ASC 'specks', reflecting assembly and activation of the inflammasome [53]. To test for the competence of MLA-primed cells to support formation of these structures, MLA and Lipid A-primed DCs were pulsed briefly with ATP before ASC-specks were visualized by confocal microscopy. Lipid A-primed DCs displayed significantly more ASC-specks than those primed with MLA (Figure 14 A), with MLA-primed DCs forming fewer ASC-specks at all doses tested (Figure $14 \mathrm{~B}$ ). The potency shift revealed by the dose response experiment suggested that MLA's potency was approximately $1 \%$ that of Lipid A. Further, ASC-speck formation was correlated with the amount of the $p 10$ subunit of mature caspase- 1 generated, with MLA-primed DCs generating markedly less p10 than those primed with Lipid A, upon ATP addition (Figure $14 \mathrm{C}$ ). These data show that MLA's activation of TLR4 results in impaired inflammasome assembly and caspase-1 activation even in the presence of an exogenous secondary stimulus for inflammasome activation.

Pre-treatment with low dose MLA prevents Lipid A-induced inflammasome activation in the presence of ATP

Since MLA was shown to have protective effects on IL-1 $\beta$ mediated pathology as in ischemic reperfusion injury and endotoxic shock [74-79], we wanted to see if stimulating myeloid DCs with low doses of MLA could inhibit subsequent Lipid A-induced inflammasome in the presence of ATP. As shown in Figure $14 \mathrm{D}$, while myeloid DCs treated with Lipid A for $5 \mathrm{~h}$ after overnight stimulation with vehicle control robustly generated active caspase-1, while cells pretreated with low dose MLA did not. Thus, MLA pretreatment can block Lipid A's ability to a required step in inflammasome activation, indicating that MLA could be used for protection from IL-1 $\beta$ mediated pathology.

\section{MLA weakly induces NLRP3 transcript and protein in myeloid DCs}

Because MLA-primed DCs failed to activate capase-1 and form ASC-specks upon addition of ATP, we considered whether other components of the inflammasome might explain MLA's deficient IL-1 $\beta$ production. It was recently reported that induction of NLRP3 is a required 


\section{DISCUSSION}

There is a need for safe vaccine adjuvants that stimulate the immune system without inducing inflammatory side effects. We previously demonstrated that MLA, used clinically in vaccine preparations as MPL adjuvant 8 , is a TRIF-biased agonist of TLR4 [17, 48], and argued that this TRIF-bias likely explains its low toxicity profile. Others have concluded that MLA's failure to induce IL-1 $\beta$ is responsible for decreased toxicity [47]. We now show that MLA's altered TLR4 signaling is upstream and is in fact responsible for IL-1 $\beta$ loss. Activation of TLR4 by MLA results in efficient priming at the level of prolL-1 $\beta$, but weak induction of NLRP3, an event requiring intact MyD88 signaling. The only other adjuvant approved for use in humans is alum, which is a potent activator of the NLRP3 inflammasome and induces both Th1 and Th2 type antibody responses [93-95]. However, a requirement of NLRP3 activation and IL-1 $\beta$ production for initiating protective immune responses is disputed [96]. In fact, alum's induction of specific Th-1 type immune responses, which are most effective at protecting against intracellular viral and bacterial

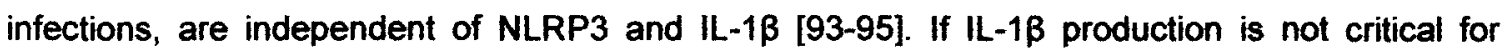
adjuvant-established protective immunity, then MLA, which fails to support production of this inflammatory cytokine, is preferable to alum or an admixture of both. Collateral inflammasome activation during vaccination could merely increase the likelihood of adverse side effects. Additional evidence for the dispensability of IL- $1 \beta$ in generating protective immunity is that NLRP3 activation and IL-1ß production are actively suppressed in antigen presenting cells by effector and memory $T$ cells during recall responses [97].

In addition to reconciling the causality of IL-1 $1 \beta$ loss with TRIF-biased signaling, we have clarified the contributions of TRIF and MyD88 to inflammasome priming and activation downstream of TLR4 signaling alone, or in the presence of exogenous ATP. In the absence of an exogenous stimulus for inflammasome activation, MyD88 signaling induces up-regulation of prolL-1 $\beta$ and NLRP 3 while TRIF signaling promotes some prolL-1 $\beta$ induction and low levels of IL$1 \beta$ maturation through a yet undefined mechanism. TRIF's contribution to inflammasome activation was previously demonstrated in mice deficient for autophagy genes, [98], but more studies are required to fully define TRIF's role in TLR4-dependent IL-1 $\beta$ production. The

elucidation of TRIF and MyD88 signaling pathways responsible for NLRP3 inflammasome priming 
and activation described here provide a knowledge base for the development of novel signaling therapies for IL-1 $\beta$-mediated pathologies; a current aim of many investigators and clinicians [51, $68,99-103]$. Additionally, the low levels of IL-1 $\beta$ produced in response to TLR4 stimulation alone may be clinically relevant to inflammatory conditions mediated by endogenous activators of TLR4 such as DAMPs [67-73].

Even in the presence of exogenous ATP, MLA-primed cells were unable to accomplish inflammasome assembly, caspase-1 activation and production of mature IL-1ß presumably, a critical deficiency at the level of NLRP3. Additionally, pretreatment with MLA inhibited Lipid Ainduced inflammasome activation at the level of p10 caspase-1 generation in the presence of ATP. This is intriguing considering that MLA can be used to prevent ischemic reperfusion injury [74-79], whose pathology is mediated in part by IL-1 $\beta$ [70]. MLA's effectiveness at inducing a tolerant state whereby cells are temporarily unresponsive to further stimulation through TLR4 has been demonstrated in both humans and several animal models $[60-62,104]$. Tolerance of this kind is achievable using endotoxin itself (LPS or Lipid A), however these TLR4 agonists induce a toxic inflammatory response prior to acquisition of tolerance $[105,106]$. Clinically, intravenous administration of MLA is well tolerated [60], and is an attractive alternative to endotoxin for conferring tolerance because initial induction of pro-inflammatory cytokines is greatly decreased. Preconditioning with MLA may result in a type of 'inflammasome tolerance', which could be critically valuable for conditions in which IL-1ß -mediated pathology occurs after reperfusion of ischemic tissue as in organ transplantation, myocardial infarct and stroke and subsequent release of inflammasome activating ATP from stressed or damaged cells.

Collectively, this work is the first thorough study of the adapter requirements involved in TLR4-dependent NLRP3 inflammasome priming for IL-1 $\beta$ production, and describes a possible mechanism for the protective effects seen with MLA in therapeutic settings such as prevention of ischemic reperfusion injury. Further studies will be required to reveal the extent to which tolerance is induced by MLA, and if TRIF-biased TLR4 signaling can be utilized effectively as a pre-conditioning regimen to prevent or mitigate $\mathrm{IL}-1 \beta$ mediated pathology. 


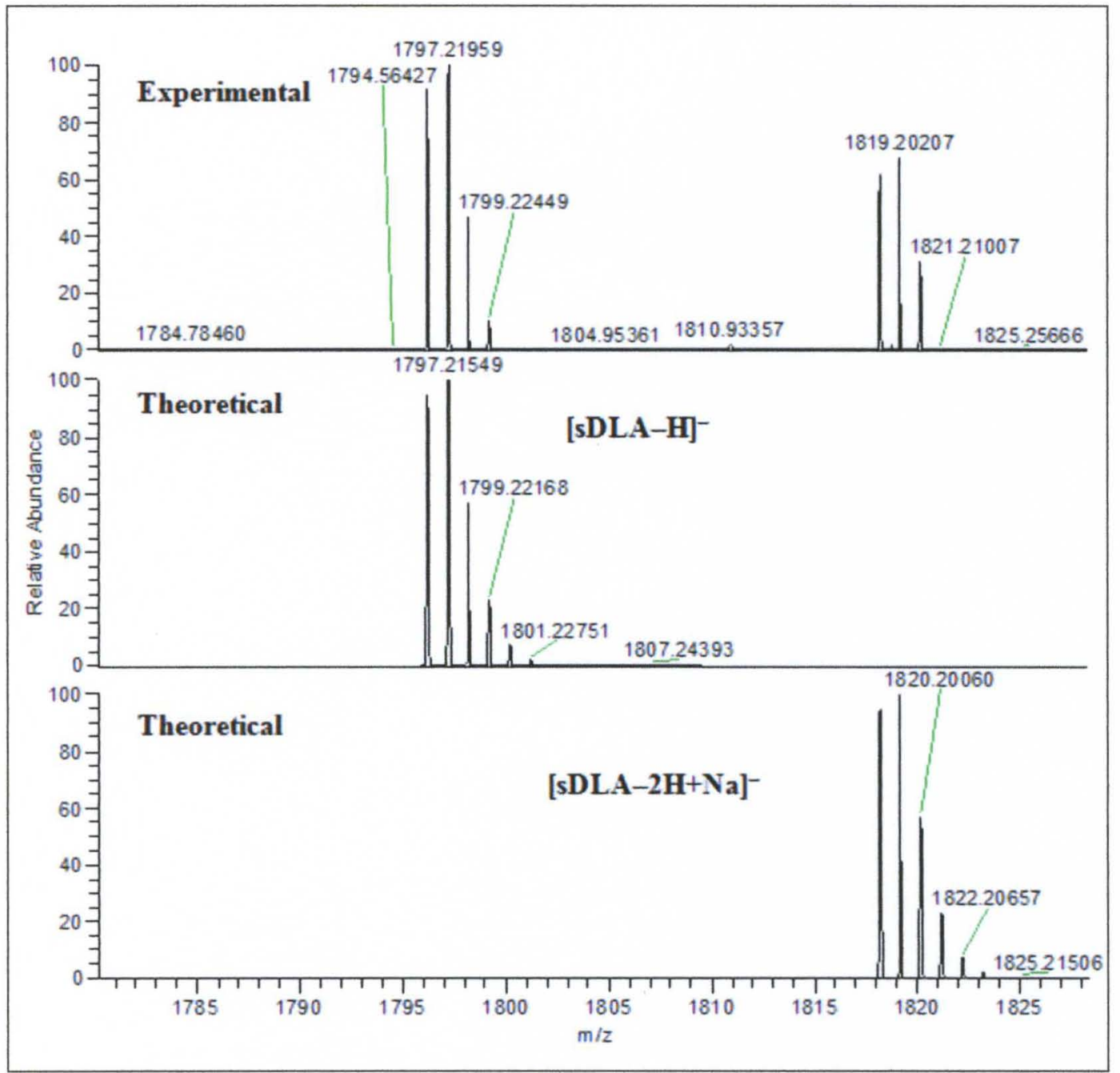

Figure 8. Mass spectroscopic analysis of synthetic Lipid A. Mass spectroscopy was performed under the supervision of Dr. Bogdan Bogdonov from the lab of Dr. Rick Higashi at the University of Louisville. 


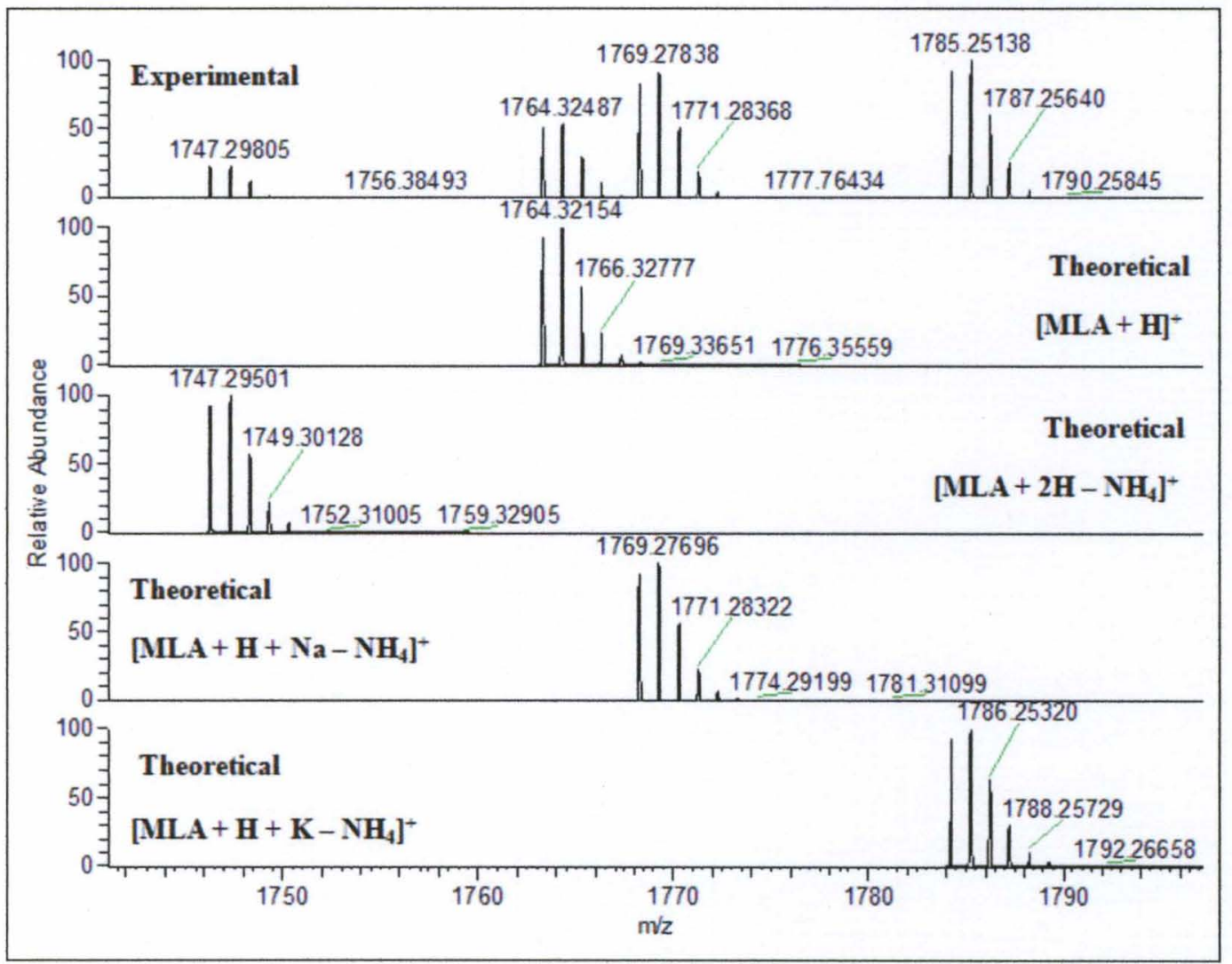

Figure 9. Mass spectroscopic analysis of synthetic Lipid A. Mass spectroscopy was performed under the supervision of Dr. Bogdan Bogdonov from the lab of Dr. Rick Higashi at the University of Louisville. 
A

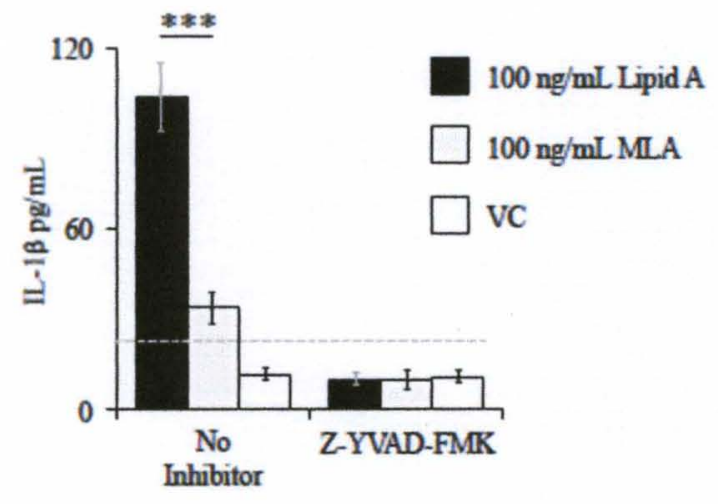

B

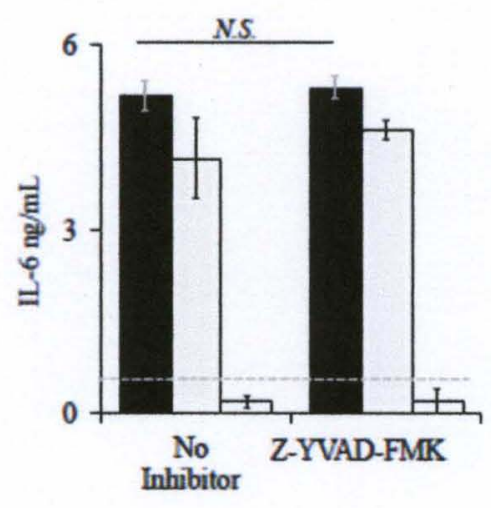

C

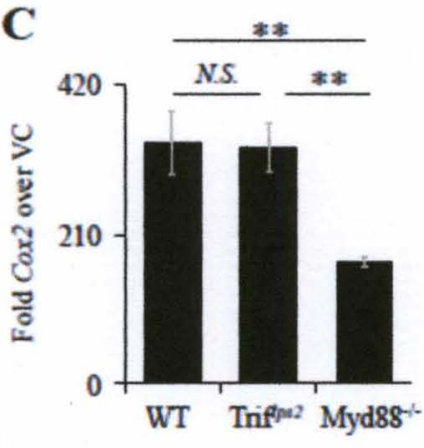

D

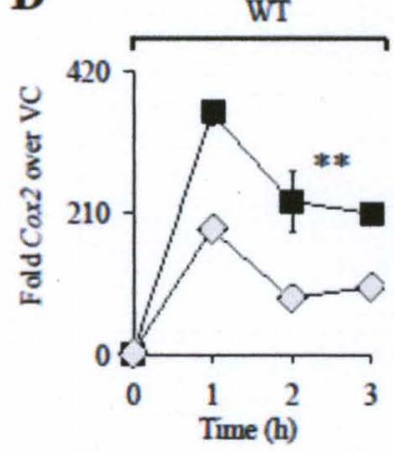

E
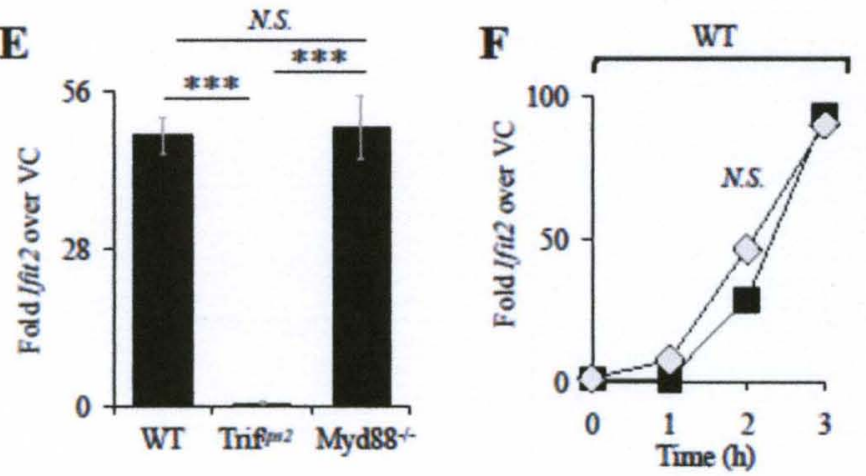
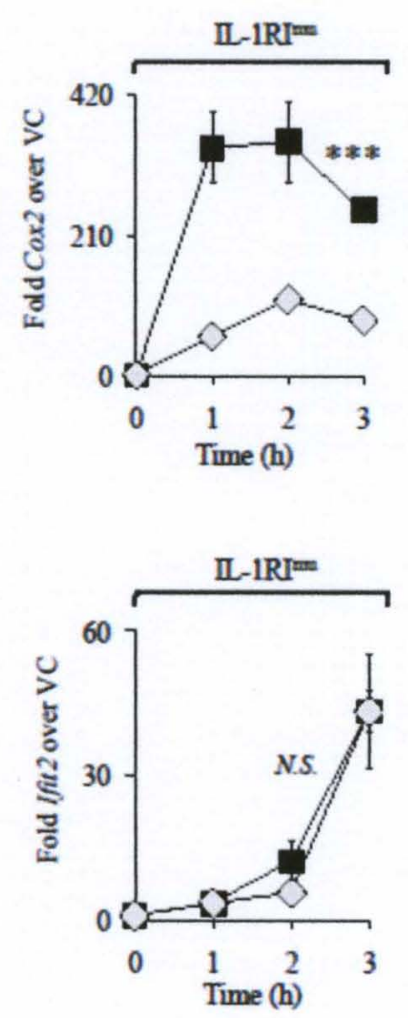
Figure 10. TRIF-biased TLR4 signaling proceeds independently of IL-1RI. (A, B) ELISA analysis of IL-1B (A) and IL-6 (B) in culture supernatant from $2 \times 10^{5} \mathrm{WT}$ myeloid DCs activated for $6 \mathrm{~h}$ with $100 \mathrm{ng} / \mathrm{mL}$ MLA or Lipid A after a $30 \mathrm{~min}$ treatment with Z-YVAD-FMK where indicated. (C, E) RTqPCR analysis of Cox2 (above) and lfit2 (below) from $1 \times 10^{6} \mathrm{WT}$, Trif pos 2 or Myd88 DCs activated for $1 \mathrm{~h}$ with $100 \mathrm{ng} / \mathrm{mL}$ MLA or Lipid A . (D, F) RTqPCR analysis of Cox2 (above) and Ifit2 (below) from $1 \times 10^{\circ} \mathrm{WT}$ or IL-1RI $\mathrm{I}^{\mathrm{mu}}$ myeloid DCs activated with $100 \mathrm{ng} / \mathrm{mL}$ MLA or Lipid A. Vehicle control (VC) is represented as the Oh time point. Results are the average of triplicate wells +/- SEM from four (A, B) or three (C-F) independent experiments. NS: not significant, * denotes $P$ value $<0.01$ and ${ }^{\star * \star}$ denotes $P$ value $<0.001$. 
A

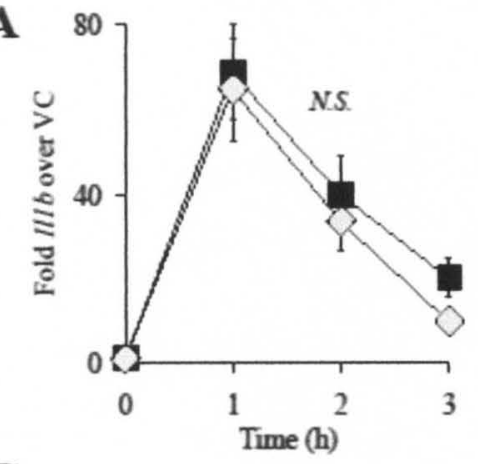

C

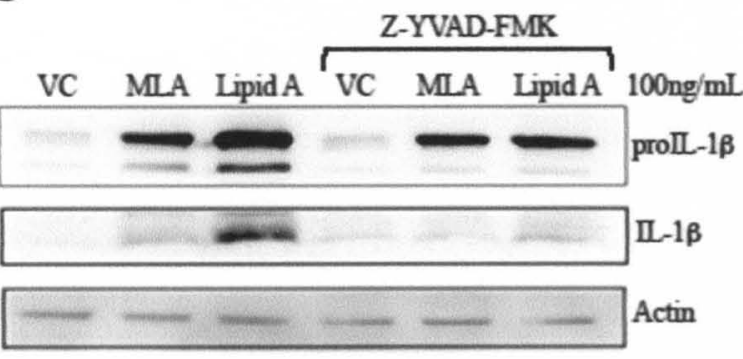

E

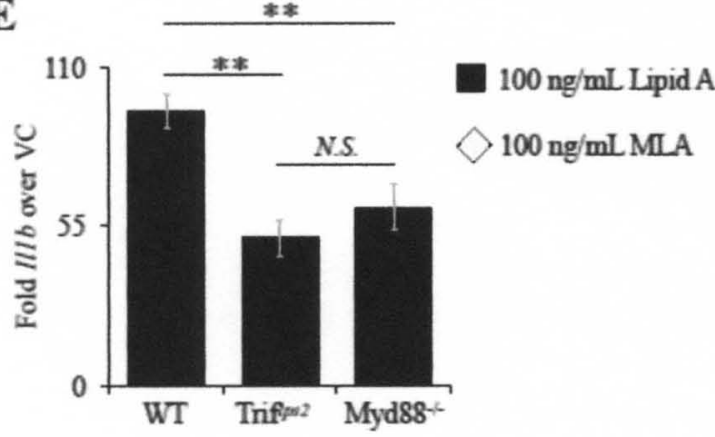

B

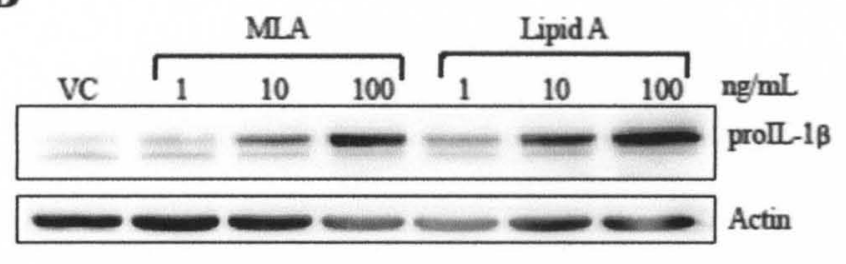

D

proIL-1;

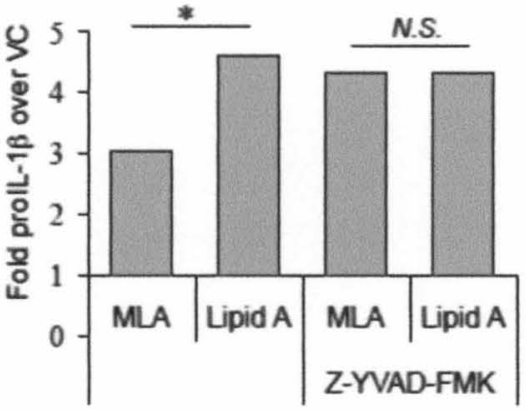

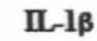

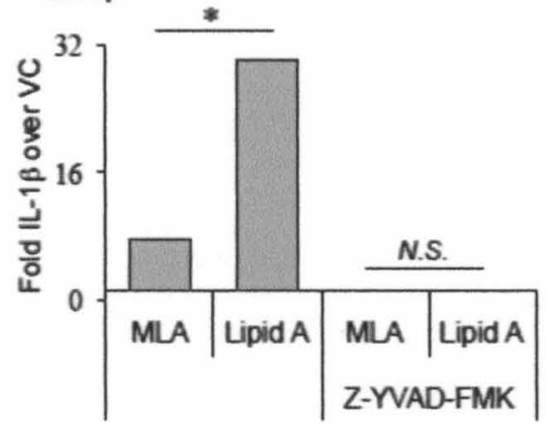

F Trifos 2 Myd88-

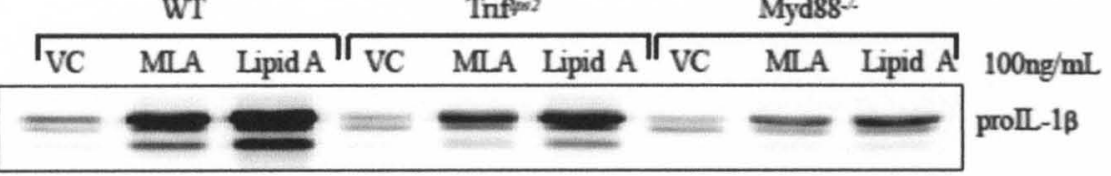

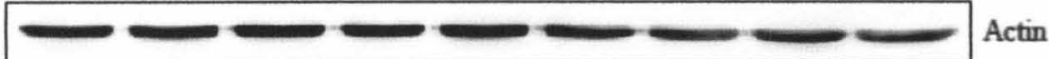




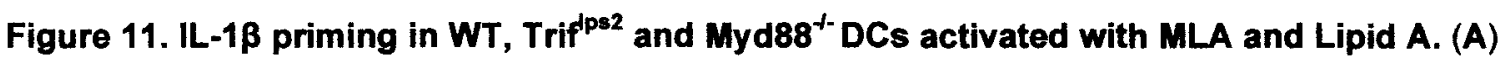
RTqPCR analysis of $/ 11 \mathrm{~b}$ from $1 \times 10^{6} \mathrm{WT}$ myeloid DCs activated for $1 \mathrm{~h}$ with $100 \mathrm{ng} / \mathrm{mL}$ MLA or Lipid A. Vehicle control (VC) is represented as the on time point. (B) Immunoblot analysis of prolL-1 $\beta$ from $2 \times 10^{6}$ WT myeloid DCs activated for $5 \mathrm{~h}$ with $100 \mathrm{ng} / \mathrm{mL}$ MLA or Lipid A. (C, D) Immunoblot analysis and quantitation of pro and mature IL-1ß. $2 \times 10^{6} \mathrm{WT}$ myeloid DCs were pretreated with $50 \mu \mathrm{M}$ Z-YVAD-FMK for $30 \mathrm{~min}$ before $5 \mathrm{~h}$ activation with $100 \mathrm{ng} / \mathrm{mL}$ MLA or Lipid A. (E) RTqPCR analysis of $\| 1 b$ from $1 \times 10^{6} \mathrm{WT}$, Trif ${ }^{\text {ps2 }}$ or Myd88 $8^{-1}$ myeloid DCs activated with $100 \mathrm{ng} / \mathrm{mL}$ MLA or Lipid A. (F) Immunoblot analysis of prolL-1 $\beta$ from $2 \times 10^{6} \mathrm{WT}$, Triflps 2 or Myd88/ myeloid DCs activated for $5 \mathrm{~h}$ with $100 \mathrm{ng} / \mathrm{mL}$ MLA or Lipid A. Results are the average of triplicate wells $+/$ - SEM from four independent experiments $(A, E)$ or are representative of four (B, F) or five (C, D) independent experiment. NS: not significant, * denotes $P$ value $<0.05$, ** denotes $P$ value $<0.01$ 

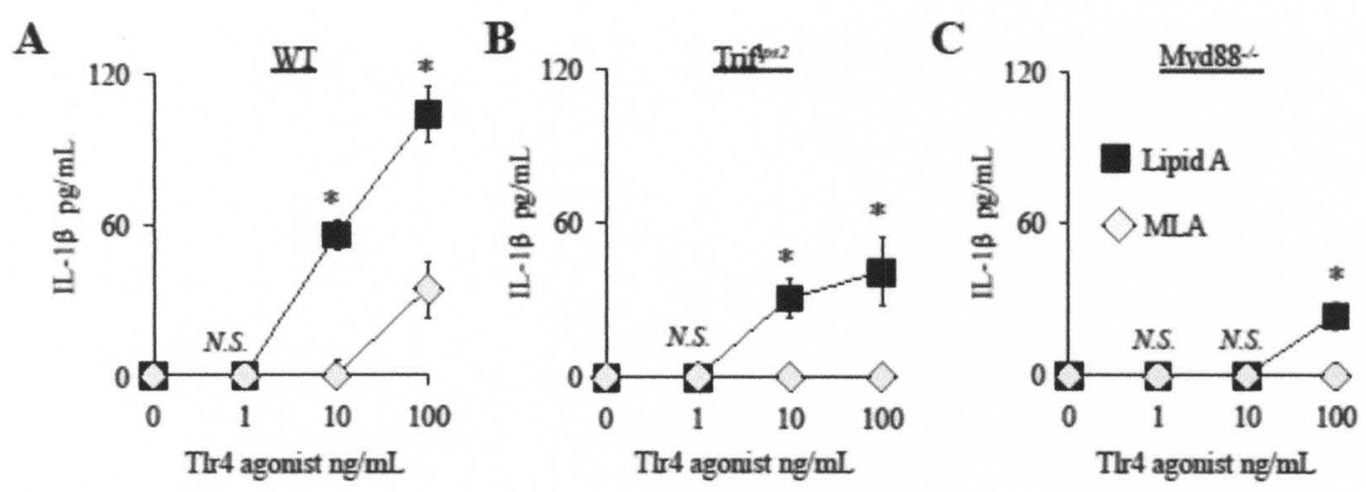

D
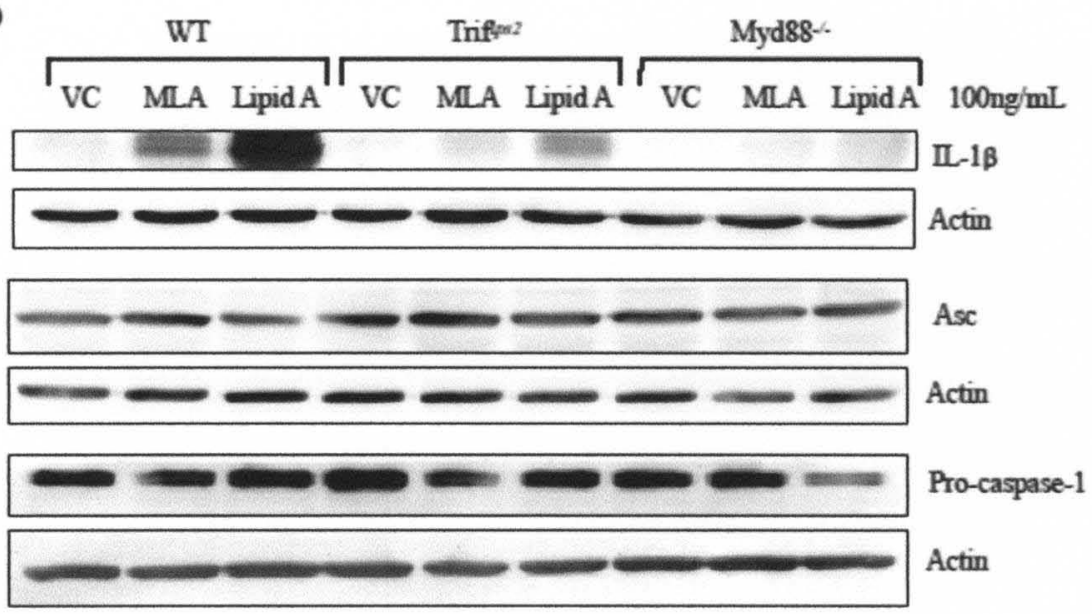

E

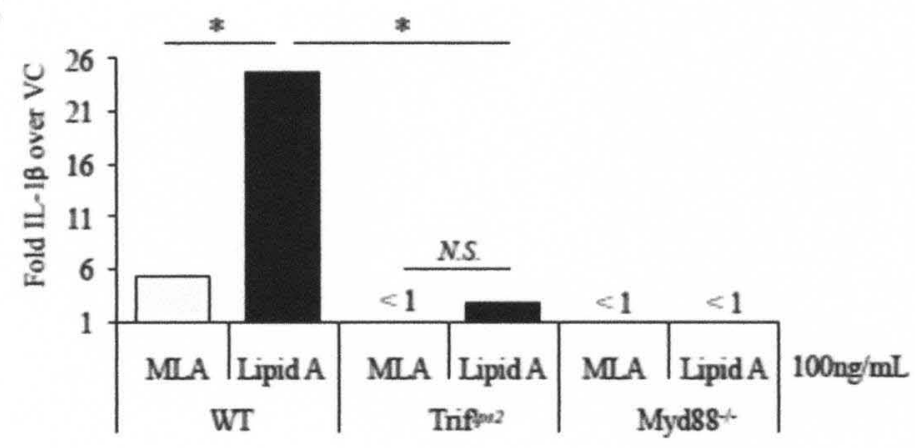


Figure 12. Generation of mature IL-1 $\beta$ by TLR4 agonists alone is co-dependent on MyD88 and TRIF. (A-C) ELISA analysis of IL-1 $\beta$ in culture supernatant from $2 \times 10^{5} \mathrm{WT}$, Trif ${ }^{\text {ps2 }}$ or Myd88 ${ }^{-1-}$ myeloid DCs activated for $6 \mathrm{~h}$ with $100 \mathrm{ng} / \mathrm{mL}$ MLA or Lipid A. (D, E) Immunoblot analysis and quantification of prolL-1 $\beta$ or Asc and procaspase-1 from $2 \times 10^{6} \mathrm{WT}$, Trif ${ }^{\text {fos } 2}$ or Myd8 $88^{\text {- }}$ myeloid DCs activated for $5 \mathrm{~h}$ with $100 \mathrm{ng} / \mathrm{mL}$ MLA or Lipid A. Results are the average of triplicate wells $+/$ SEM from three independent experiments $(A-C)$ or are representative of four (D, top and $E$ ), or three (D, middle and bottom) independent experiment. NS: not significant, * denotes $P$ value < 0.05 . 

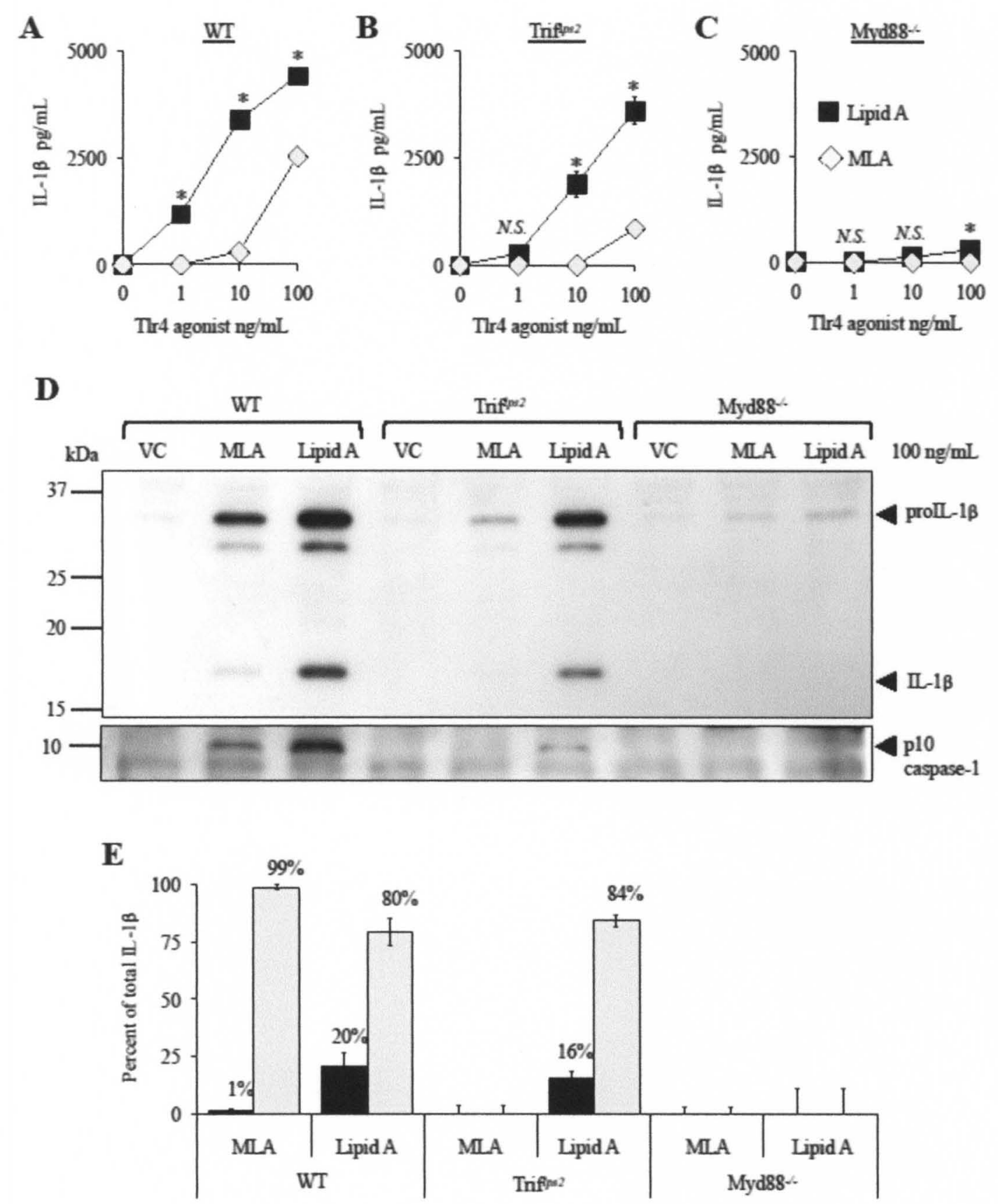
Figure 13. MyD88 is critically required for ATP-stimulated IL-1ß production. (A-C) ELISA analysis of IL- $1 \beta$ in culture supernatant from $2 \times 10^{5} \mathrm{WT}$, Trif ${ }^{\text {ps } 2}$ or Myd88 for $6 \mathrm{~h}$ with $100 \mathrm{ng} / \mathrm{mL}$ MLA or Lipid A then pulsed for 20 min with $5 \mathrm{mM}$ ATP. (D) Immunoblot analysis of IL-1 and p10 caspase-1 performed using equal volumes of supernatant from samples in A-C (100 ng/mL). (E) Using densitometry ratios of pro to mature IL-1 $\beta$ from (D) the percent of pro and mature IL-1 $\beta$ of total were calculated. Results are the average of triplicate wells +/- SEM from three independent experiments (A-C), are representative of three independent experiments (D) or are the average of three independent experiments $+/$ - SEM (E). NS: not significant, ${ }^{*}$ denotes $P$ value $<0.05$. 


\section{A}
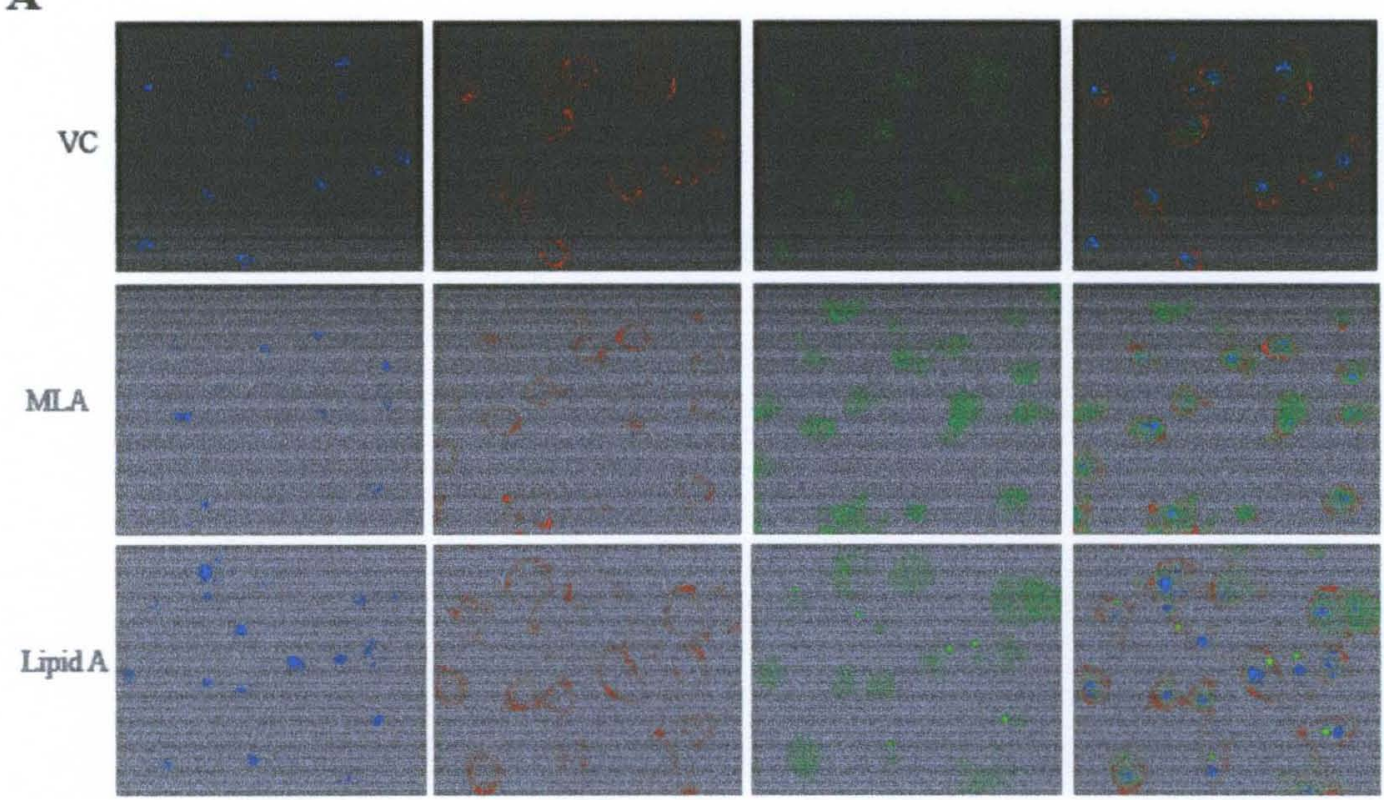

DAPI

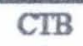

(membrane)

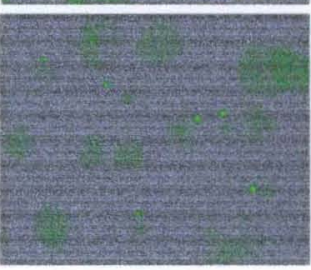

Asc

(inflammasome)

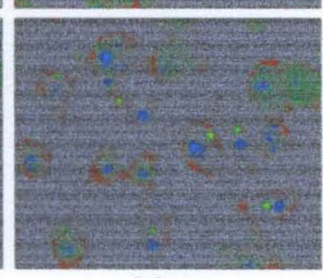

Merge

B

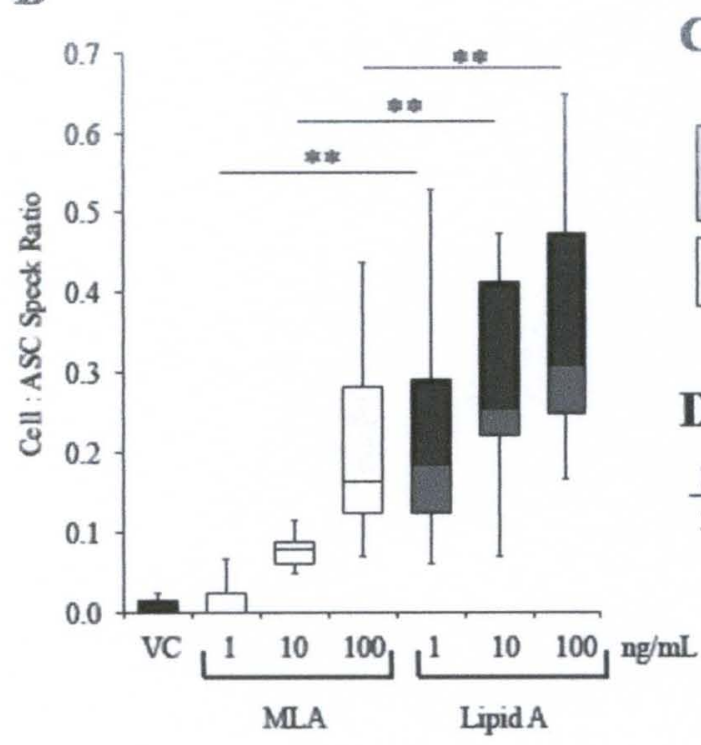

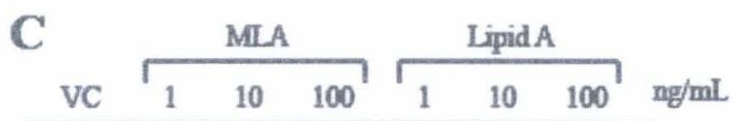

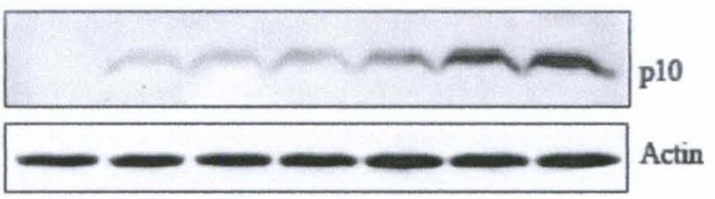

D

\begin{tabular}{lllll}
$18 \mathrm{~h}$ MLA $10 \mathrm{ng} / \mathrm{mL}$ & - & + & - & + \\
\hline $5 \mathrm{~h} \mathrm{Lipid} \mathrm{A} 1 \mu \mathrm{g} / \mathrm{mL}$ & - & - & + & +
\end{tabular}

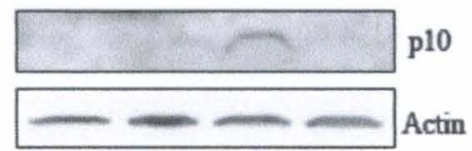


Figure 14. MLA-primed myeloid DCs display fewer ASC-specks and less active caspase-1 compared to Lipid A. (A, B) $5 \times 10^{4}$ WT myeloid DCs were activated for $5 \mathrm{~h}$ with MLA and Lipid A then pulsed for $5 \mathrm{~min}$ with $5 \mathrm{mM}$ ATP. (A) Representative images from confocal microscopy showing nuclei (DAPI, blue), plasma membrane (CTB, red) and inflammasomes (ASC, green). Images are representative of at least two independent experiments. (B) Box and whisker plot of enumerated cells and ASC-specks of images from at least two independent experiments containing $\sim 550$ cells per treatment. (C). Immunoblot analysis of the p10 subunit of caspase-1 from $1 \times 10^{6} \mathrm{WT}$ myeloid DCs activated for $5 \mathrm{~h}$ with MLA or Lipid A representing three independent experiments. (D) Immunoblot of the p10 subunit of caspase- 1 from $1 \times 10^{6} \mathrm{WT}$ myeloid DCs were pretreated with $10 \mathrm{ng} / \mathrm{mL}$ MLA or VC for $18 \mathrm{~h}$ before activation for $5 \mathrm{~h}$ with $1 \mu \mathrm{g} / \mathrm{mL}$ Lipid A before a $5 \mathrm{~min}$ pulse with $5 \mathrm{mM}$ ATP. Image representative of two independent experiments; ${ }^{* *}$ denotes $P$ value $<0.01$ 
A

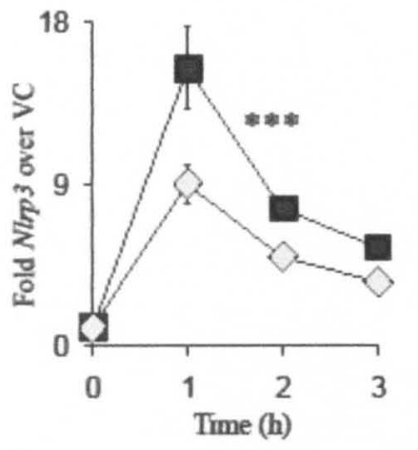

C

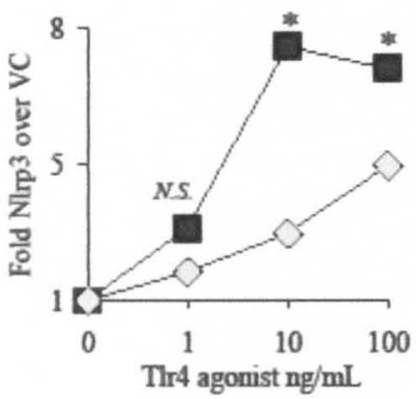

B
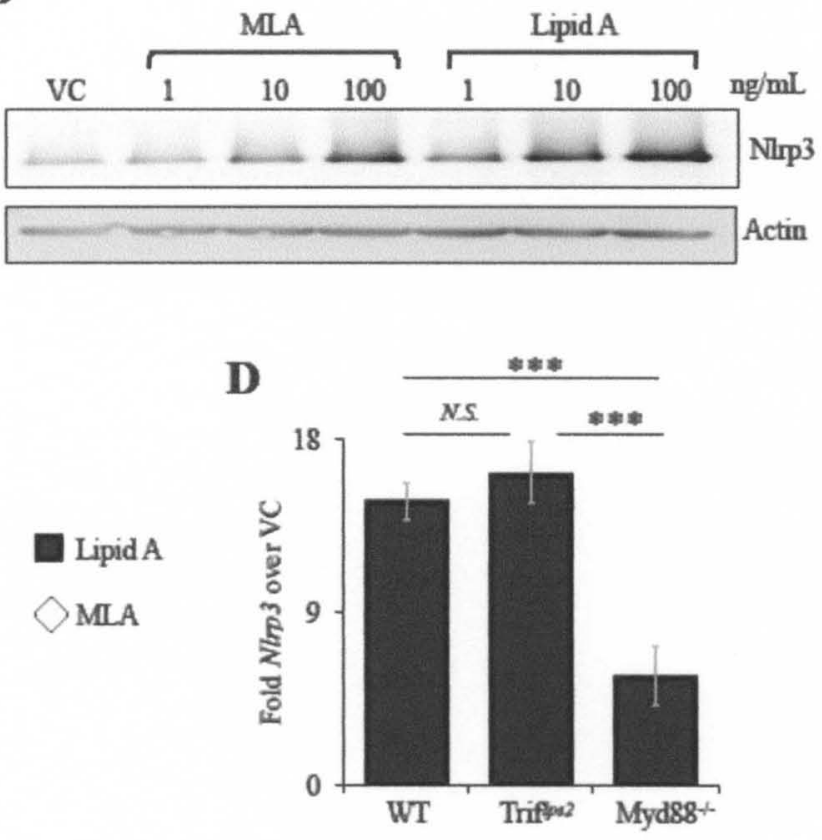

Lipid A

$\triangle$ MLA

E
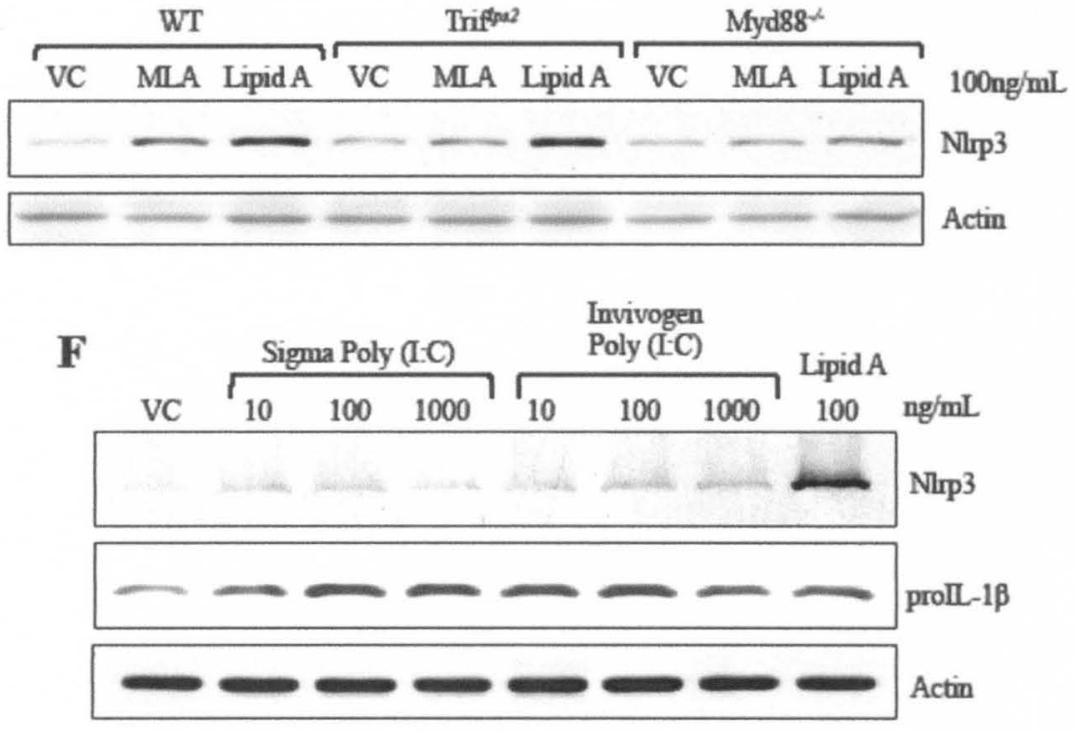


\section{CHAPTER IV}

\section{IL-1ß LOSS CONTRIBUTES TO REDUCED TOXICITY OF MPLA}

\section{INTRODUCTION}

We previously determined that TRIF-biased signaling downstream of TLR4 activation by Monophosphate Lipid A is responsible for its loss of IL-1 $1 \beta$ maturation activity in Chapter III of this dissertation (C.A. Eaves et al. Science Signaling; accepted for publication). This effect is due to the strict MyD88-dependence of NLRP3 induction, a required inflammasome priming event for IL-

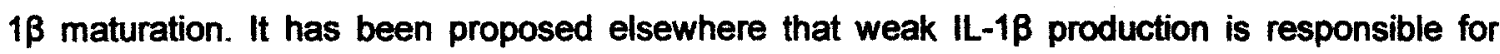
MPLA's reduced in vivo toxicity compared to LPS [47]. While we have shown that IL-1B loss is downstream of TRIF-biased TLR4 signaling, the role of IL-1 $\beta$ in mediating differential inflammatory processes in vivo between the two TLR4 agonists has yet to be clarified.

$\mathrm{IL}-1 \beta$ production is tightly regulated, presumably due to the cytokine's inflammatory potency and pervasive effects on nearly all tissues of the body. Downstream of TLR4, both TRIF and MyD88 signaling pathways contribute to priming at the level of prolL-1 $\beta$ induction, while NLRP3 induction strictly requires MyD88 (C.A. Eaves et al Science Signaling; accepted for publication). A fully primed cell responds to a secondary stimulus for inflammasome activation by assembling the NLRP3 inflammasome and converting constitutively expressed procaspase-1 into

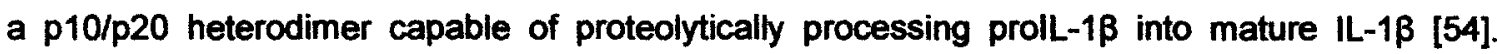
Mature $17 \mathrm{kDa}$ IL-1 $1 \beta$ is active at low concentrations, as serum levels of $50 \mathrm{pg} / \mathrm{mL}$ are well above the maximum pM range for the $\mathrm{Kd}$ of IL-1RI [107]. Hence the expression of IL-1RI in almost all tissues makes control of IL-1 $\beta$ production even more relevant in induction of systemic inflammation. In fact, very low concentrations of $\mathrm{IL}-1 \beta$ are physiologically significant because circulating levels rarely exceed $50-100 \mathrm{pg} / \mathrm{mL}$ under patho-inflammatory conditions caused by dysregulation of the NLRP3 gene in humans [108], such as in Muckle-Wells auto-inflammatory 
syndrome, familial cold urticaria, chronic infantile neurological cutaneous and articular (CINCA) syndrome and neonatal-onset multisystem inflammatory disease (NOMID) [109-111] .

Excessive levels of endotoxin (LPS) result in systemic inflammatory shock, mimicking many symptoms of disseminated bacteremia [112], which is characterized by refractory hypotension and subsequent tissue hypoxia, rapid respiratory rate, leukoctyosis or leucopenia, fever, cytokine production, rapid heart rate with decreased cardiac function, disseminated intravascular coagulation, multiple organ failure and death [113]. Shock in response to LPS results in part from an inflammatory cytokine storm mediated primarily by monocytes and

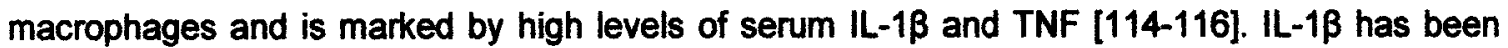
directly implicated in the pathogenesis of endotoxemia, and inhibitors of its production or signaling via IL-1RI (such as Fluorofenidone [70] and Kineret [117] protect mice from lethality of endotoxic shock. In contrast to LPS, MPLA fails to induce production of IL-1B in vitro or in vivo $[17,47]$ (C.A. Eaves et al. Science Signaling. 2011. Accepted for publication), and is $0.1-1 \%$ as toxic as LPS [19-24].

Although MPLA induces TRIF-dependent events like induction of Ifit-1 and 2, IP-10 (CXCL-10) and up-regulation of co-stimulatory molecules CD80/CD86 to similar levels as LPS [118], induction of inflammatory MyD88-dependent products such as Serpine-1, Endothelin-1, COX-2, IL-6, and NLRP3 are significantly decreased [48] (C.A. Eaves et al. Science Signaling. 2010 in press). We therefore hypothesized that LPS-induced IL-1ß contributes to in vivo toxicity by potentiating MyD88-driven inflammatory outcomes in a multi-step process. For MPLA, failure to maintain this positive feedback loop through IL-1RIMyD88 signaling then is likely to magnify its initial TRIF-biased TLR4 activation. Initial TRIF-biased TLR4 activation by MPLA results in loss of IL-1 $\beta$ production, which results in weaker IL-1RI-dependent MyD88 activation in vivo, making MPLA's TRIF-bias even more evident. To test this hypothesis, mice expressing a mutant, nonsignaling form of IL-1RI, were given high dose LPS or MPLA and monitored for inflammatory cytokine and transcript production. 
METHODS

\section{Reagents}

TLRgrade $^{\mathrm{TM}}$ Ready-to-Use Monophosphoryl Lipid A and LPS from Salmonella minnesota R595 (Re) were purchased from Alexis Biologicals (now Enzo Life Sciences). Paired lots of sonicated MPLA and LPS were used for experimentation.

Mice

Female, age-matched C57/BL6 and IL-1RI mutant mice $\left(B 6 ; 129 S 1-I 1 \mathrm{r}^{\text {tm1Romlys}}\right)$ were purchased from Jackson Laboratories, and were rested for at least seven days after arrival prior to use in experimentation.

\section{RESULTS}

\section{LPS, but not MPLA, induces high levels of plasma IL-1B}

We first examined the early production of IL-1 $1 \beta$ in mice treated with MPLA or LPS. LPStreated mice produced high levels of plasma IL-1 $\beta$ at $1 \mathrm{hr}$, while MPLA-treated mice failed to show any increase in IL-1 $\beta$ over that of vehicle control (Figure 16). This result confirms previous reports that MPLA fails to induce IL-1 $\beta$ in vivo and in vitro $[17,47]$ (C.A. Eaves et al. Science Signaling, accepted for publication). Considering the very early appearance of IL-1B in LPS-treated mice, we hypothesized that IL-1ß could potentiate all LPS-induced MyD88-associated inflammation in vivo.

\section{Early cytokine dependence on IL-1RI signaling}

We next analyzed the leveis of various pro-inflammatory cytokines at $1 \mathrm{~h}$ and $6 \mathrm{~h}$ post injection of TLR4 agonists. Both MPLA and LPS induced similar amounts of TNF, KC, IL-6, MCP1 and IFN-Y at 1 h (Figures 17-19). Most cytokines were completely unaffected by loss of IL-1RI signaling at $1 \mathrm{~h}$, however there was a significant decrease in MPLA-induced MCP-1 in the IL$1 R I^{\text {mu }}$ compared to WT (Figure 17). Because of the very early time point and the fact that MPLA 


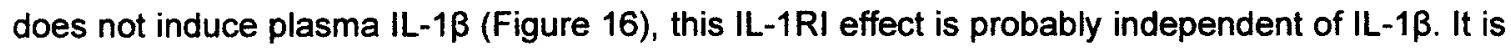
possible that an IL-1 $\beta$ independent IL-1RI signaling event contributes to MPLA's MCP-1 induction.

MPLA and LPS promote similar early cytokine profiles, but MPLA-induced cytokine levels are not sustained

By $6 \mathrm{~h}$ levels of all cytokines had decreased significantly in MPLA-treated mice, while inflammatory cytokine induced by LPS was sustained (with the exception of TNF). These data show that MPLA induces a transient increase in pro-inflammatory cytokines, while LPS induces robust, sustained cytokine production. While there was a trend for LPS-induced cytokines to decrease in the absence of IL-1RI signaling, only plasma levels of IL-6 at six hours post LPS treatment were significantly decreased in the IL-1RI ${ }^{\text {mu }}$ (Figures 17-19).

\section{IL-1RI signaling contributes to differential pro-inflammatory transcript levels between LPS and MPLA}

We next wanted to look at pro-inflammatory gene expression in organs targeted during intravenous administration of TLR4 agonist. We analyzed expression of various MyD88- or TRIFdependent transcripts in the spleen at $6 \mathrm{~h}$ after TLR4 agonist administration. In WT mice, LPStreatment led to high levels of Serpine-1, Endothelin-1, Ifit-2, Cox-2 and NIrp3 (Figure 20). In contrast, spleens from MPLA-treated mice had high levels of TRIF-dependent Ifit-2 (Figure 21), but relatively low expression of the pro-inflammatory MyD88-dependent transcripts tested. These results confirm the TRIF-biased results seen previously in spleen transcripts at lower doses of

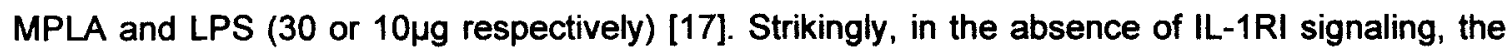
significant differential induction of MyD88-dependent genes between MPLA and LPS was lost (Figure 20, shaded panels). Ifit-2 expression remained similar to $\mathrm{WT}$ in the IL-1RI ${ }^{\mathrm{mu}}$ mice (Figure 21, shaded panels), presumably reflecting the strict TRIF-dependence of this transcript and the MyD88-dependence of IL-1RI contribution to its expression. These data indicate that IL-1RI plays a significant role in potentiating LPS-induced MyD88-dependent inflammatory transcripts [119], 
and that loss of IL-1RI signaling, through impaired IL-1 $\beta$ production, likely reinforces MPLA's TRIF-bias.

\section{IL-1RI and hepatotoxicity}

While pro-inflammatory cytokines may predict toxicity, we wanted to assess direct toxicity in the form of hepatocyte damage, and to determine any dependence on IL-1RI signaling. Plasma alanine aminotransferase (ALT) is an indicator of acute hepatotoxicity because it is released from the liver by cellular stress and death [120]. When we analyzed plasma levels of ALT at $6 \mathrm{~h}$ post injection with TLR4 agonists, we saw variability in the amount of ALT generated, however the average level of LPS-induced ALT was higher than MPLA (Figure 22). Plasma from LPS-treated IL-1RI ${ }^{\mathrm{mu}}$ mice did not have any detectable ALT, suggesting LPS-induced liver toxicity is mediated by IL-1RI signaling.

\section{In vivo complement activation}

Differential activation of IL-1RI appears to play some role in MPLA vs LPS inflammation in vivo, however IL-1 $\beta$ does not explain all differences in pro-inflammatory outcomes (Figures 17 and 18). Because direct interaction of LPS can trigger complement activation via the alternative pathway, we wanted to test whether complement could also be contributing to LPS toxicity in our experiments. Both MLA and Lipid A were found to synergize with C5a for cytokine production (see Chapter III), but it had not been determined whether MPLA or LPS induced differential complement activation in vivo. When we analyzed C5a levels in plasma, we found no increase over control with MPLA or LPS $6 \mathrm{~h}$ post-treatment; however LPS-induced IL-6 production significantly more than MPLA (Figure 23), indicating that C5a generation probably does not play a major role in toxicity associated with LPS in this model.

\section{DISCUSSION}

IL-1RI signaling contributes to specific differential inflammatory outcomes when comparing MPLA and LPS. While all MyD88-associated transcripts at $6 \mathrm{~h}$ showed some dependence on IL-1RI regardless of treatment with MPLA or LPS, only LPS-induced IL-6 cytokine 
responses showed a dependence on IL-1RI signaling. Production of KC, MCP-1, TNF and IFN-Y in response to LPS was not affected by the absence of IL-1RI.

It is important to note that MPLA and LPS induced similar levels of early KC, TNF and MCP-1 $1 \mathrm{hr}$ after treatment, demonstrating that MPLA is not devoid of activity and is capable of stimulating cytokine production equivalent to LPS. Induction of MCP-1 was shown elsewhere to be important for mediating the adjuvant effects of aluminum hydroxide and MF59 [121]. With these adjuvants, MCP-1 acted as a monocyte chemo-attractant, and enhanced differentiation of the recruited monocytes toward antigen presenting dendritic cells [121].MPLA's rapid induction of this important immunomodulatory molecule may therefore help explain MPLA's adjuvanticity.

LPS induced significantly more IFN-Y production than MPLA, but its production did not appear dependent on IL-1RI signaling. IFN-ץ has been shown elsewhere to potentiate LPSinduced pro-inflammatory cytokines including IL-1, TNF- $a$ and IL-6 [119]. Additionally, IFN-y was just recently described as the key mediator of endotoxic shock in a model using mice LPS-treated mice primed with heat killed $P$. acnes [122]. Production of IFN-y in response to LPS is dependent on MyD88 signaling [17], and may explain why TRIF-biased MPLA does not induce symptoms of shock.

Even though most LPS-induced cytokines and chemokines were found to be IL-1RIindependent, every MyD88-associated transcript tested was found to be significantly reduced in the splenic tissue of IL-1RI ${ }^{\mathrm{mu}}$ mice, at the same time that levels of the TRIF-dependent transcript Ifit-2 remained as high as those in WT mice. Interestingly, the absence of IL-1RI signaling lowered LPS-induced levels of MyD88-dependent transcripts to the same low levels as MPLA induction; indicating that IL-1 $\beta$ signaling is needed to prolong the TLR4/TRIF vs. MyD88 'balanced' signaling attributes of LPS, demonstrating the importance of IL-1 $1 \beta$ production in the toxicity of LPS.

We also observed greater plasma levels of ALT in LPS-treated vs. MPLA-treated mice, with a critical dependence of LPS-induced ALT levels on IL-1RI-signaling. IL-1 $\beta$ along with the pro-inflammatory cytokines TNF- $a$ and IL-6 have been implicated in the pathogenesis of liver cell death in various acute and chronic models of hepatotoxicity $[123,124]$. High dose acetaminophen (N-acetyl-p-aminopheno or APAP) causes acute liver injury and ultimately organ failure [125, 
126]. During APAP-induced liver toxicity, plasma levels of IL-1 $\beta$ are greatly increased [127], and the IL-1RI/MyD88 signaling pathway has been shown to contribute to APAP-induced heptatoxicity [128]. Separately, another group found a clear link between NLRP3-dependent caspase-1 activation, IL-1ß production and APAP-induced liver cell death [129], supporting our conclusion that IL-1RI signaling contributes to LPS-induced ALT levels.

Endotoxin has been show to be capable of activating the critical C3 complement component [130], however structural differences in LPS can greatly alter it complement activating activity [131-133]. The failure of the ability of LPS to activate complement was shown elsewhere to be caused by structural changes to regions other the polysaccharide O-antigen [134], and serum factors also contribute to complement activating competency [135]. We cannot currently say why our LPS did not generate C5a; however we suspect this to be an issue of endotoxin dose, or variability in acyl chain structure of the S. minnesota Re595 chemotype we used, or possibly host environment.

The results described here suggest that strong IL-1 $1 \beta$ production induced by LPS can account for most of the differential activation of MyD88-dependent inflammatory factors compared to MPLA at later time points in vivo. Additionally, our TLR4 agonist did not induce detectable levels of active complement in the form of plasma C5a. While reduced IL-1 $1 \beta$ production by MPLA may explain a portion of its reduced toxicity compared to LPS, we previously showed this phenomenon to be downstream of TRIF-biased TLR4 activation. Therefore, we suspect the differences in inflammation or toxicity induced by MPLA and LPA to ultimately be a result of this their respective modes of activation of TRIF vs. MyD88-dependent TLR4 signaling. Ultimately, it seems likely most of the toxic effects of LPS are attributable to various inflammatory cytokines downstream of MyD88 signaling, including IL-1 $\beta$ and IFN-Y production. MPLA's TRIF-biased TLR4 activation results in loss of these factors that potentiate inflammation and toxicity. 


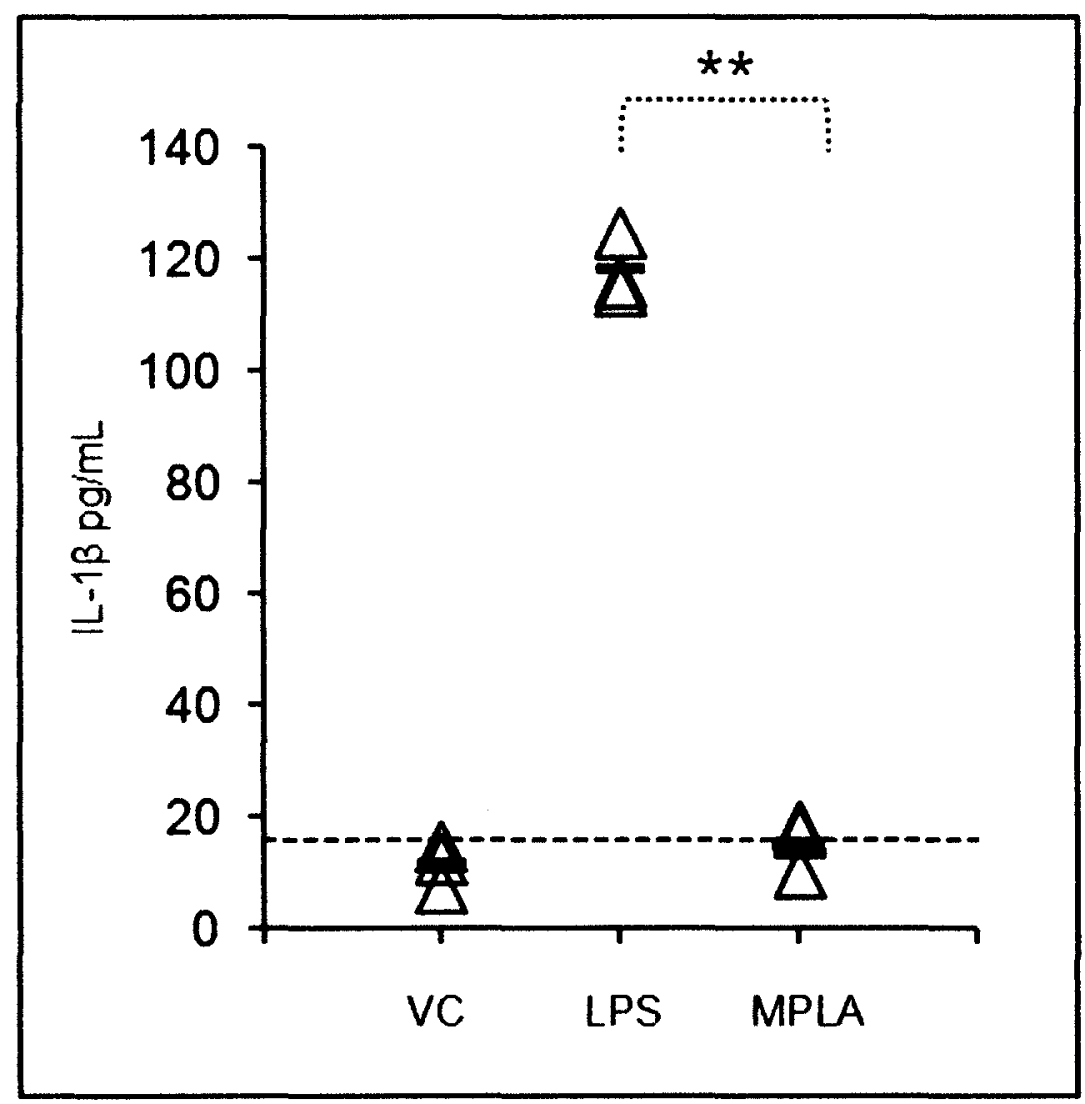

Figure 16. Plasma IL-1 induced by LPS or MPLA. S. minnesota LPS or MPLA were administered I.V. to C57/BL6 mice, $100 \mu g$ per recipient, blood was collected $1 \mathrm{~h}$ later. Plasma levels of IL-1 $\beta$ were analyzed by ELISA; statistical significance determined using a two-tailed, paired t-test; ** means $p<0.01$ 

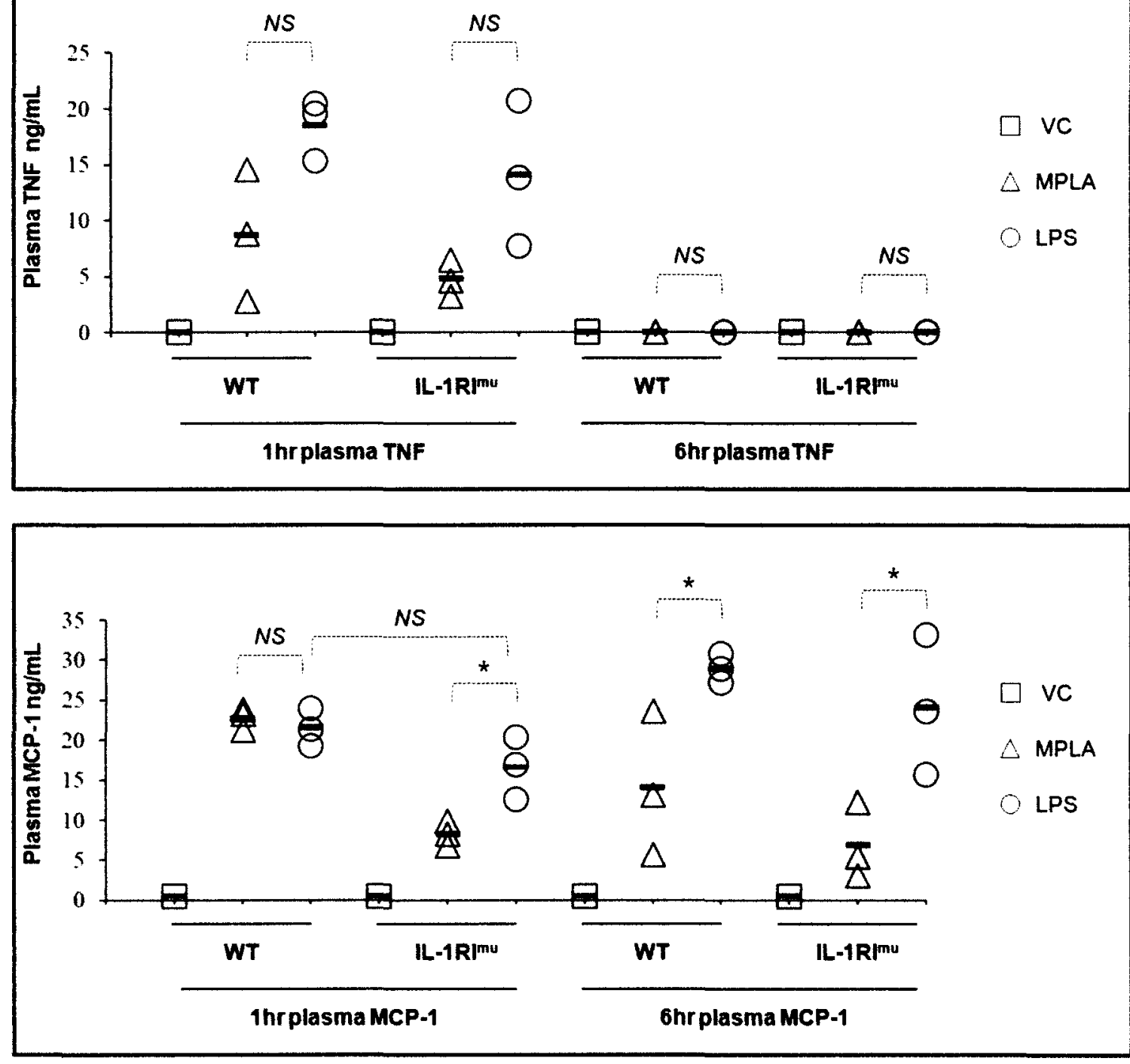

Figure 17. Plasma TNF and MCP-1 induced by LPS or MPLA. S. minnesota LPS or MPLA were administered I.V. to WT or IL-1RI ${ }^{\text {mu }}$ mice, $100 \mu g$ per recipient, blood was collected $1 \mathrm{~h}$ and 6h latert. Plasma levels of TNF and MCP-1 were analyzed by Cytometric Bead Array analysis. Statistical significance determined using a two-tailed, paired t-test, * indicates $p<0.05$; ** indicates $p<0.01$, Data is representative of two experiments. 

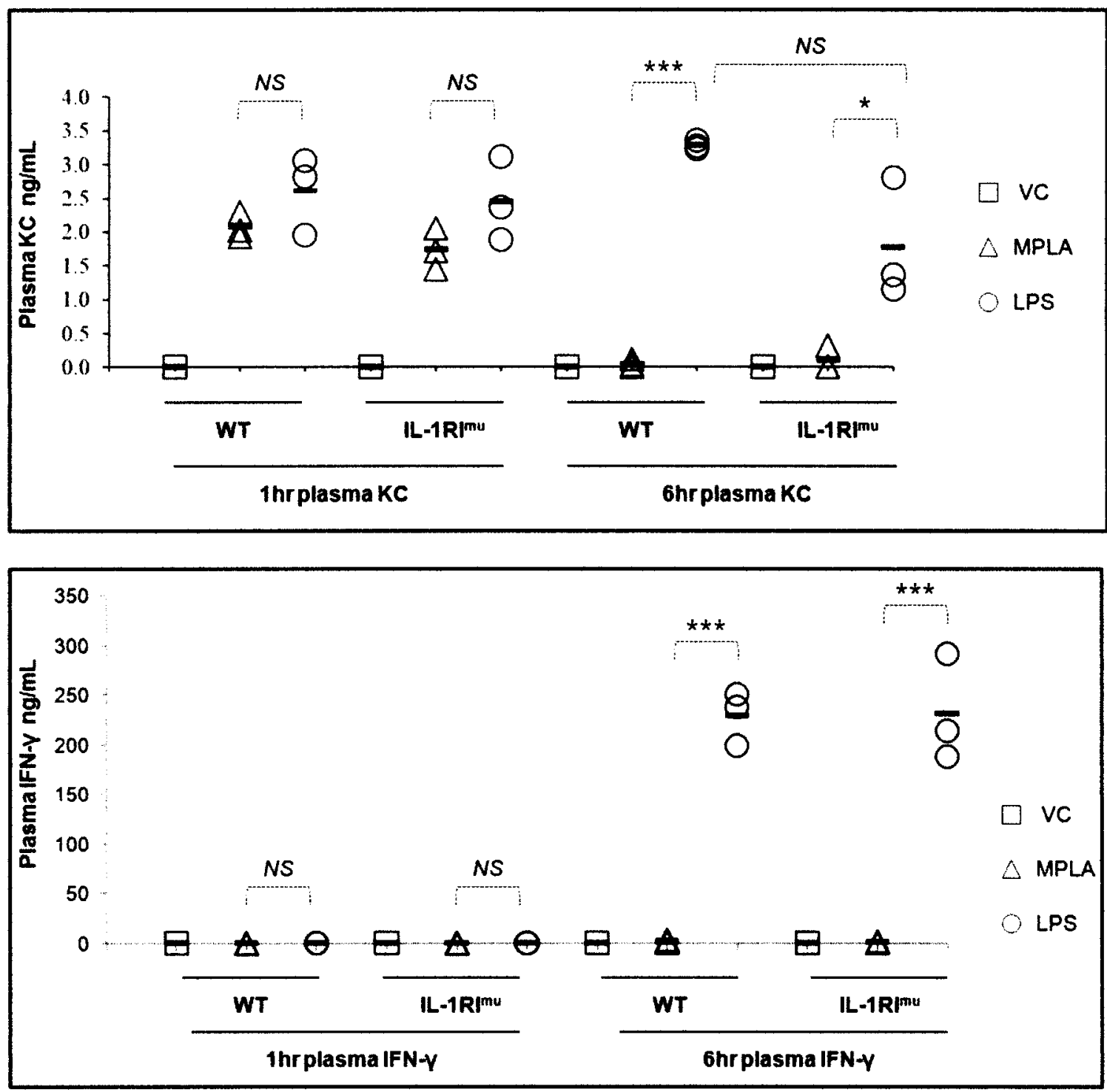

Figure 18. Plasma KC and IFN-Y induced by LPS or MPLA. S. minnesota LPS or MPLA were administered I.V. to WT or IL-1RI ${ }^{\mathrm{mu}}$ mice, $100 \mu \mathrm{g}$ per recipient, blood was collected $1 \mathrm{~h}$ and $6 \mathrm{~h}$ latert. Plasma levels of KC and IFN-y were analyzed by Cytometric Bead Array analysis. Statistical significance determined using a two-tailed, paired t-test, ${ }^{* \star \star}$ indicates $p<0.001$. Data is representative of two experiments. 


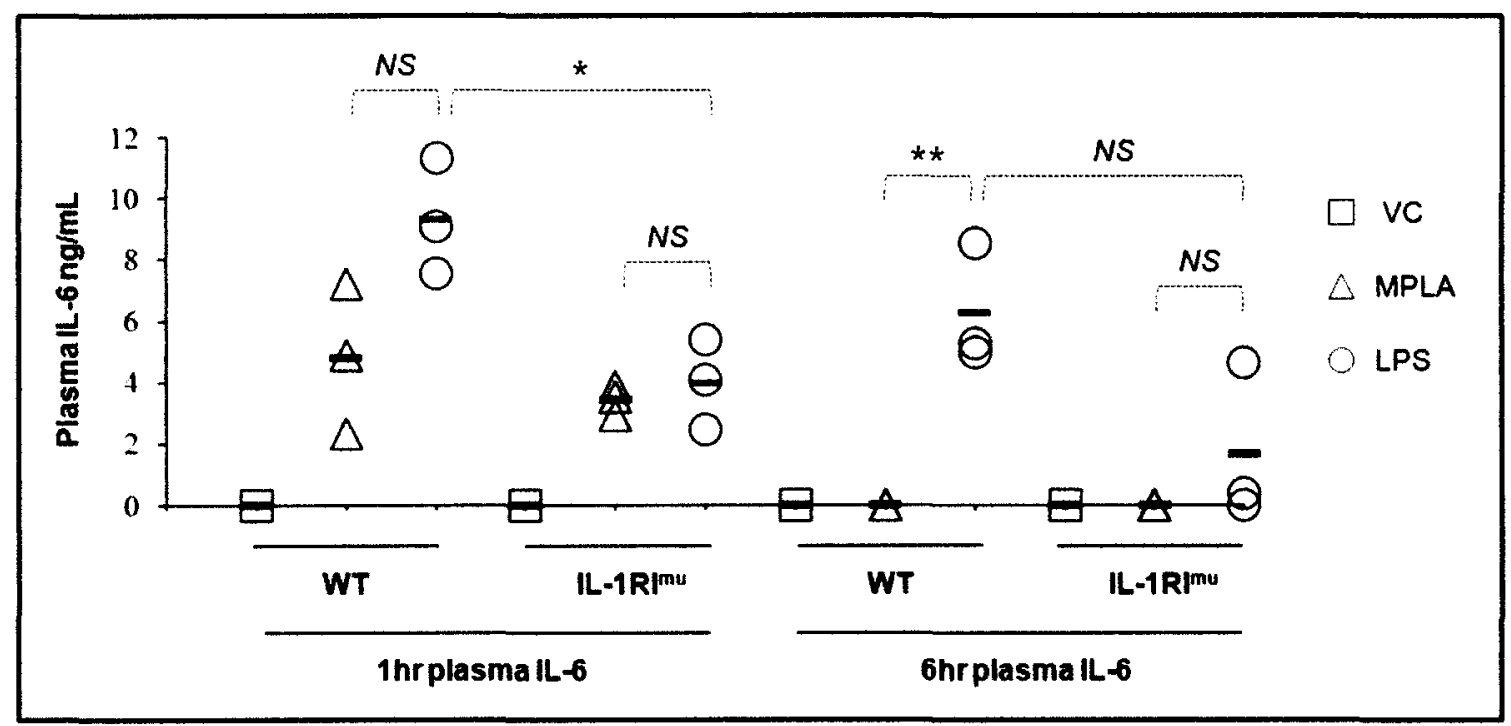

Figure 19. Plasma IL-6 induced by LPS or MPLA. S. minnesota LPS or MPLA were administered I.V. to WT or IL-1RI ${ }^{\mathrm{mu}}$ mice, $100 \mu \mathrm{g}$ per recipient, blood was collected $1 \mathrm{~h}$ and $6 \mathrm{~h}$ latert. Plasma levels of IL-6 were analyzed by Cytometric Bead Array analysis. Statistical significance determined using a two-tailed, paired t-test, ${ }^{*}$ indicates $p<0.05$; ${ }^{* *}$ indicates $p<0.01$, Data is representative of two experiments. 

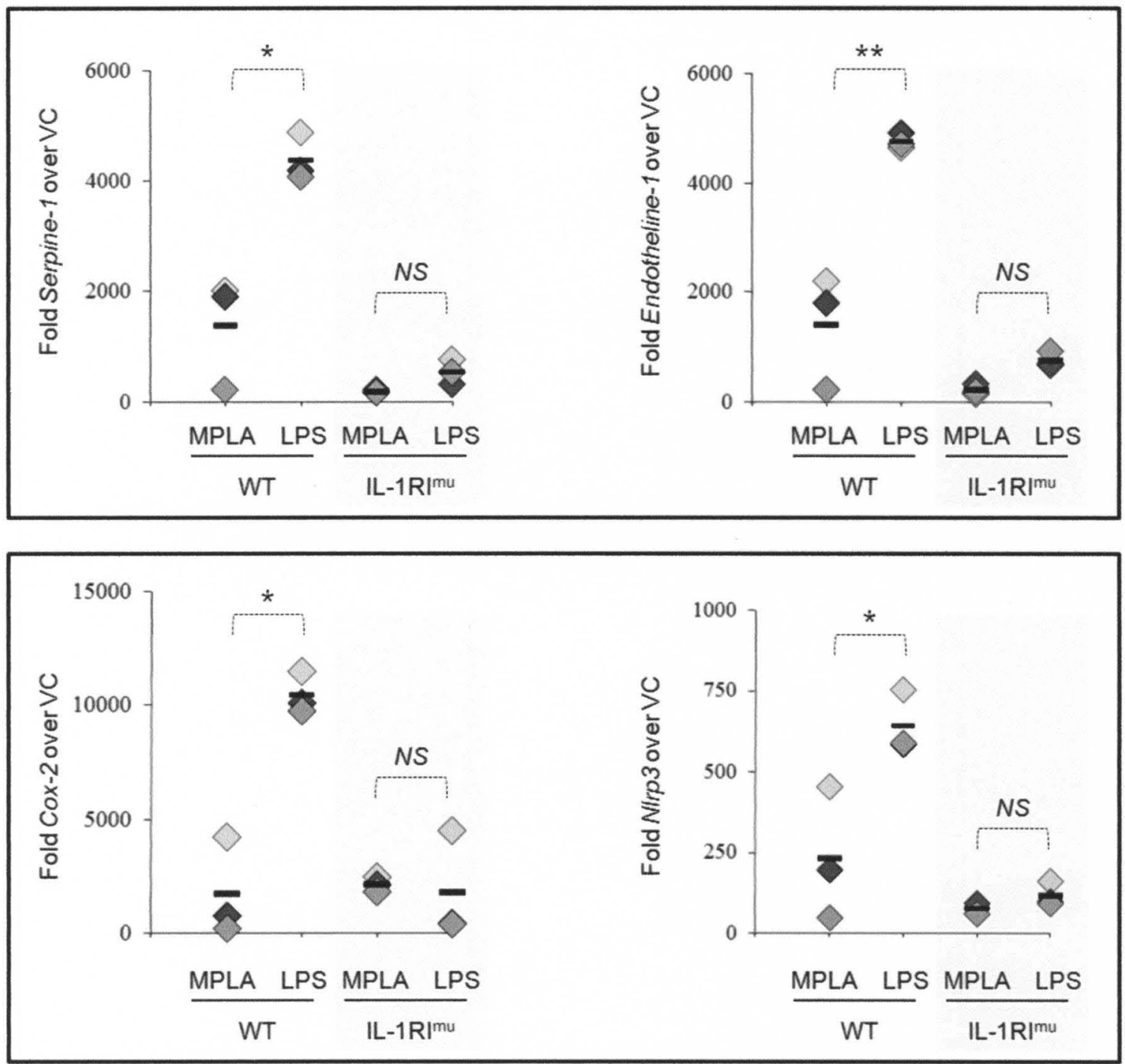

Figure 20. Splenic Endothelin-1, Serpine-1, Cox-2 and NIrp3 transcript levels. $100 \mu \mathrm{g}$ of MPLA or LPS was administered by I.V. injection to WT or IL-1RI ${ }^{\mathrm{mu}}$ mice. At 6h, spleens were taken and Endothelin-1, Serpine-1, Cox-2 and NIrp3 transcript levels analyzed by quantitative PCR. 


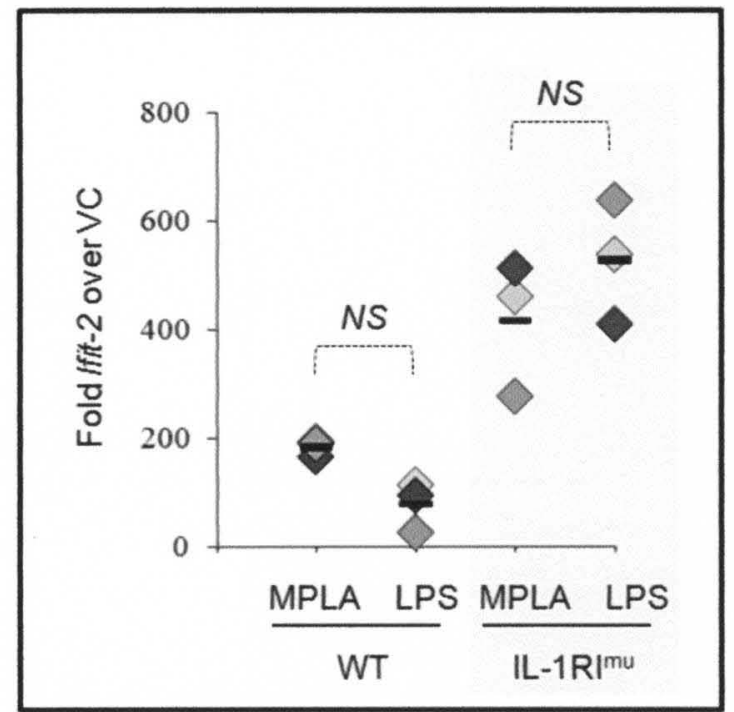

Figure 21. Splenic Ifit-2 transcript levels. $100 \mu \mathrm{g}$ of MPLA or LPS was administered by I.V. injection to WT or $\mid L-1 R I^{m u}$ mice. At $6 h$, spleens were taken and Ifit-2 transcript levels analyzed by quantitative PCR. 


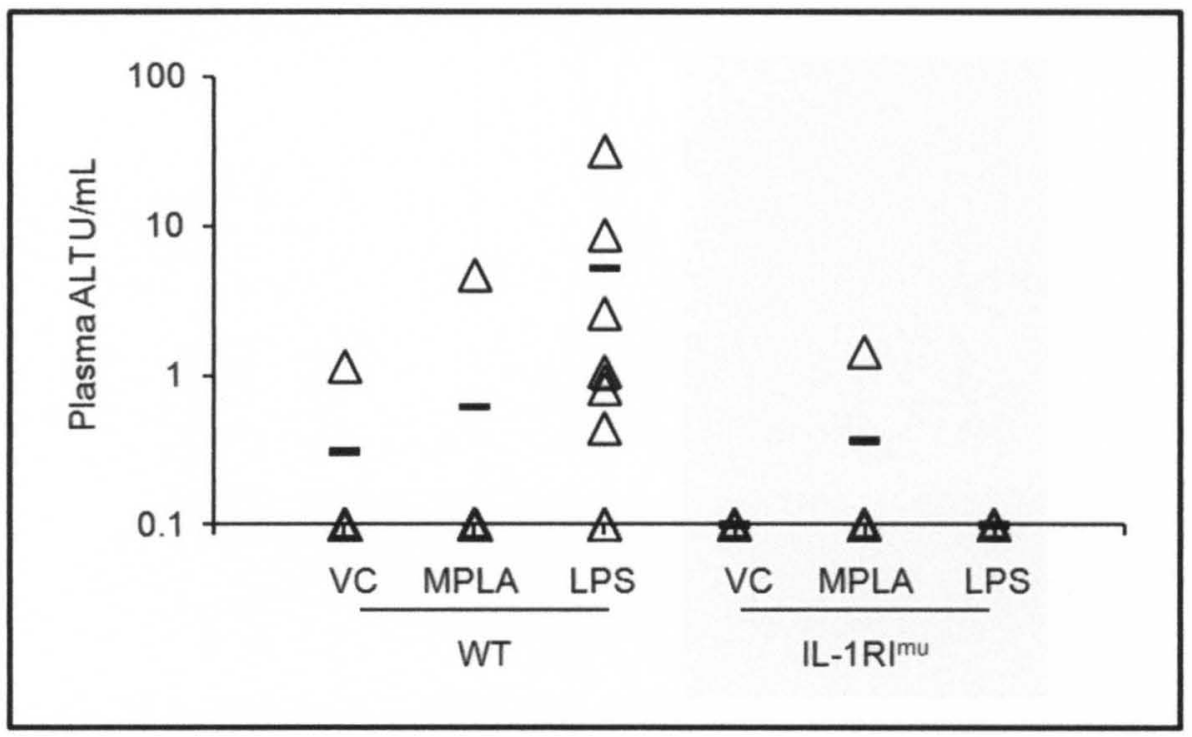

Figure 22. Liver toxicity in MPLA and LPS treated mice. WT and $\mid \mathrm{L}-1 \mathrm{RI} \mathrm{I}^{\mathrm{mu}}$ mice were given $100 \mu \mathrm{g}$ LPS or MPLA by intravenous injection. At $6 \mathrm{~h}$ plasma samples were taken and analyzed for alanine aminotransferase (ALT) levels by ELISA. 


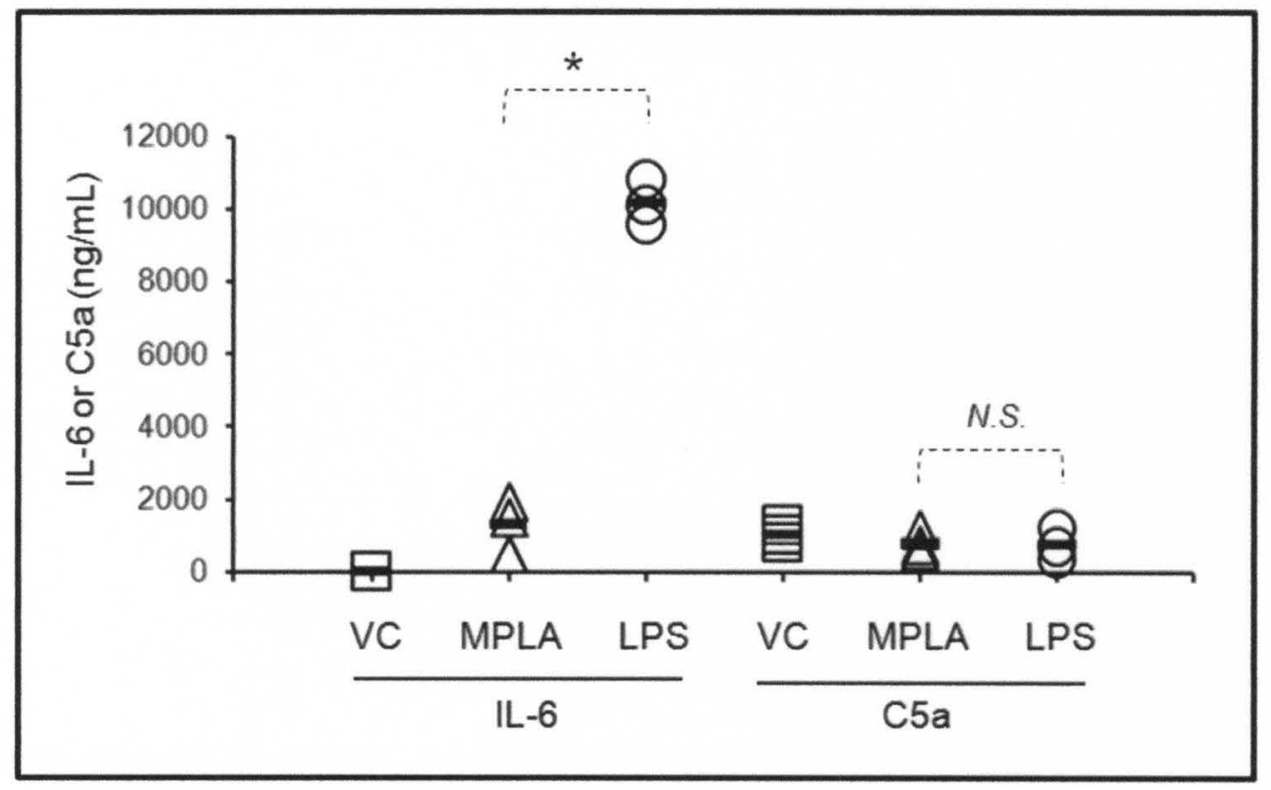

Figure 23. Plasma C5a levels. WT mice were given $100 \mu \mathrm{g}$ LPS or MPLA by intravenous injection. At $6 \mathrm{~h}$ plasma samples were taken and analyzed for IL-6 and C5a levels by ELISA. 


\section{CHAPTER V}

\section{COMPLEMENT AND TLR4 CORECEPTOR ACTIVATION BY LPS AND MPLA}

\section{INTRODUCTION}

Activation of TLR4 by LPS is not direct, but involves sequential handling of LPS by several shuttling molecules. Initially, the Lipid A head group of LPS is bound by LBP in serum which transfers LPS to soluble or membrane-bound CD14, primarily expressed on monocytes and macrophages [136]. CD14 transfers LPS to MD2, forming the MD2/LPS complex, which is then recognized by TLR4 [6]. CD14 contains an LRR region similar to TLR4 and a groove composed of $\beta$-sheets that contains two hydrophobic pockets with charged residues for LPS binding [137]. Although the $55 \mathrm{kDa}$ glycoprotein $\mathrm{CD} 14$ does not contain a transmembrane signaling domain, it has been extensively studied in terms of assisting TLR4 signaling [6]. At low concentrations of LPS, CD14 markedly increases the efficiency of transfer from LBP to MD2/TLR4. At very high concentrations however, CD14 appears dispensable for LPS-induced TLR4 signaling [138] [139]. There does seem to be critical dependence on CD14 for TRIFmediated signaling as CD14 mutant mice fail to produce Type-1 interferons in response to LPS [140].

While MD2, and TLR4 are the critical receptors involved in the 'LPS-sensing apparatus' [141] [142], several additional signaling molecules that serve as TLR4 co-receptors have been described. The chemokine receptor CXCR4 has been shown to directly bind LPS, and is capable of transducing LPS-dependent signaling, resulting in cell migration, IKB phosphorylation, p38 MAPK phosphorylation and IL-6 production in human monocytes. This made us question whether synthetic E. coli type MLA, which induces weak NF-kB activation [48], was able to fully engage CXCR4 signaling during TLR4 activation.

Other MD2-TLR4 co-receptors are potentially involved in bringing about MLA's TRIFbiased signaling attributes. Integrin alpha M (ITGAM), also known as CD11b, is a subunit of the 
heterodimeric Type 1 transmembrane protein known as complement receptor 3 (CR3) and macrophage antigen 1 (Mac-1). CD11b is expressed mainly on monocytes, granulocytes and NK cells, and its chief function has been characterized as assisting phagocytosis of complement coated substances and supporting cellular adhesion to activated endothelium [143]. CD11b has also been shown to contribute to LPS-mediated TLR4 signaling and can directly bind LPS [144, 145]. In macrophages, CD11b, in concert with CD18 (the additional subunit of CR3/Mac-1), activates the MAPK pathway and NF-KB transcriptional activity, leading to enhanced production of COX-2, IL-12 p35/p40 and IL-6 downstream of TLR4 activation $[10,146]$. Because MLA and Lipid A differ structurally, in terms of phosphoryl groups known to interact directly with TLR4 and its co-receptors, we tested the hypothesis that MLA's TRIF-biased was the result of differential interaction with these receptors. Figure 24 shows co-receptors involved in the LPS recognition that may play a role in MLA's TRIF-bias.

Interactions with the complement system offer another explanation for MLA's low toxicity. The complement system is a complex cascade of extracellular protein fragmentation initiated by pathogen interaction with antibodies (classical pathway), or through mannose-binding lectins or ficollins (lectin pathway) or spontaneous hydrolysis of C3 (alternative pathway). Direct recognition of LPS can also induce C3 hydrolysis, a mechanism included in the alternative complement pathway. All three complement pathways converge at C3 hydrolysis which results in subunits C3a and C3b. While C3a can act directly on cells expressing C3aR to induce inflammatory cytokine secretion and increased cell motility, C3b interacts with C5 convertase to cleave C5 in subunits $\mathrm{C} 5 \mathrm{a}$ and $\mathrm{C} 5 \mathrm{~b}$. $\mathrm{C5a}$ induces inflammation in a manner similar to $\mathrm{C} 3 \mathrm{a}$, while $\mathrm{C} 3 \mathrm{~b}$, along with several other complement proteins, forms the membrane attack complex, or MAC. In addition to this classic activation pathway, thrombin, neutrophil elastases and macrophage serine proteases are thought to be capable of C3-independent C5 cleavage [147-150]. (Figure 25)

C5a activates the G-protein coupled receptor C5aR (CD88) as well as the G-protein independent C5a-like receptor 2 (C5LR, also known as GPR-77) [151]. C5aR is highly expressed on neutrophils, but is also present on lung and liver epithelium, monocytes and various leukocytes [152-156]. In neutrophils, C5a activation of the C5aR leads to production of the neutrophil chemo-attractant leukotriene $\mathrm{B}_{4}\left(\mathrm{LTB}_{4}\right)$, the platelet aggregation factor thromboxane 4 
( $\left.\mathrm{TX}_{4}\right)$ and arachidonic acid, which leads to NADPH oxidase assembly and superoxide formation [157, 158]. Macrophages respond to C5a by enhancing phagocytosis, increasing chemotaxis, while endothelial cells produce inflammatory cytokines such as IL-6, TNF and IL-8 when activated with C5a and LPS $[154,159,160]$. In normal immune function, C5a plays an important role in attracting immune cells to the site of infection and enhancing their anti-microbial functions. However, when production of $\mathrm{C5a}$ is over stimulated, as in septic shock, C5a production has pathogenic consequences. Blocking antibodies against C5a have been shown to inhibit many of the inflammatory events associated with septic shock [161], and protects against LPS-induced multi-organ failure, caspase activation and consumptive coagulopathy in rats [162-166]. In fact, administration of C5a leads to symptoms similar to those of septic shock [164]. During sepsis, serum levels of C5a reach $10-100 \mathrm{nM}$, and levels of C5aR rapidly decrease as the receptor-ligand complex is internalized $[167,168]$. Very high concentrations of C5a have an inhibitory effect on neutrophil functions; resulting in decreased NADPH oxidase activity and decreased bacterial killing (see Figure 26 for a summary of cellular activation by complement during sepsis).

While C5aR is not technically a TLR4 co-receptor, its co-stimulation during TLR4 activation leads to enhanced production of TNF- $\alpha, I L-23, I L-1 \beta$ and IL-6 [169]. Co-stimulation of C5LR and TLR4 increases production of pro-inflammatory HMGB1 while inhibiting TNF- $\alpha$ production [169]. The synergism between C5aR and TLR4 is proposed to be mediated by "mitogen-activated protein kinase kinases 1/2" (MEK1/2), JNK1/2, "phosphatidyl inositol-3 kinase" (PI3K) and possibly Akt signaling $[170,171]$. Because of C5a's potency and important role in endotoxic shock, we wanted to determine if differential complement activation was responsible for the increased toxicity and inflammatory properties of LPS compared to MPLA. Additionally, we wanted to assess the ability of LPS and MPLA TLR4 activation to synergize with C5aR activation for increased cytokine production. 


\section{MATERIALS AND METHODS}

\section{Reagents}

Synthetic Lipid A (Peptides International) and synthetic Monophosphate Lipid A (Invivogen) corresponding to the E. coli structures of LPS were reconstituted in DMSO, aliquoted and at stored at $-80^{\circ} \mathrm{C}$. Paired lots of Lipid A and MLA were used for all experiments, such that each aliquot went through only one freeze/thaw.

\section{Cells}

Bone marrow-derived dendritic cells and macrophages were used for experimentation. Refer to MATERIALS AND METHODS section (page 27) for derivation protocol.

\section{Inhibition of TLR4 co-receptors}

In order to determine the contribution of each co-receptor in TLR4 signaling, macrophages and dendritic cells were treated with blocking antibodies and chemical inhibitors for $30 \mathrm{~min}$ before activation with synthetic TLR4 agonists. Cells to be activated with TLR4 agonists alone were pretreated with isotype control antibodies, or vehicle control in the case of AMD3100. Cellular toxicity as determined by Trypan Blue uptake was not increased over vehicle control at the doses of inhibitors used for experimentation.

\section{In vitro C5aR and TLR4 synergy}

Macrophages and dendritic cells were plated at $2 \times 10^{5}$ per well of 96-well polystyrene plates and immediately activated with $50 \mathrm{nM}$ recombinant murine $\mathrm{C5a}$ and S. minnesota MPLA or Lipid A. Culture supernatant was collected at $5 \mathrm{~h}$ and stored at $-80^{\circ} \mathrm{C}$ until ELISA. 


\section{RESULTS}

Bone marrow-derived dendritic cells express CD11b, CD14 and CXCR4.

Expression levels of various TLR4 co-receptors can vary according to cell type and culture protocol after primary cell derivation, so we first determined expression levels of CD11b and CD14 on newly generated bone marrow-derived dendritic cells by flow cytometric analysis. Almost all CD11c positive dendritic cells stained positive for CD11b (Figure 27), as expected, and approximately $50 \%$ of CD11c cells stained positive for CD14 (Figure 28). We then analyzed CXCR4 expression on the bone marrow-derived dendritic cells by flow cytometry. The dendritic cells from our culture system stained brightly for CXCR4 as compared to isotype staining (Figure 29).

CD11b blockade does not inhibit TLR4-dependent IL-6 production in bone marrow-derived dendritic cells

CD11b, a subunit of Mac-1 in concert with CD18, is a co-receptor that has been shown to contribute to TLR4-dependent cytokine production. However, blockade of CD11b did not affect MLA or Lipid A-induced IL-6 production from our dendritic cells (Figure 30).

\section{Inhibition of CD14 increases MLA-induced IL-6 production}

CD14 is a critical TLR4 co-receptor for maximal TLR4-dependent signal transduction and cytokine production [172]. We hypothesized that differential interaction with CD14 based on the structurally distinct diglucosamine head groups of MLA and Lipid A could account for their observed disparities in cytokine production. We found that CD14 blockade resulted in increased levels of IL-6 production from dendritic cells for both MLA and Lipid A treatment (Figure 30), supporting the hypothesis that CD14 participates in TLR4 signal transduction. The percent increase in IL-6 production was significantly greater for MLA as compared to the percent increase Lipid $A$, indicating that the two agonists may differentially interact with CD14. 
Inhibition of CXCR4 inhibits MLA and Lipid A induced IL-6 production

CXCR4 has been characterized as a TLR4 co-receptor capable of inducing MAPK and NF-KB activation [142]. Because MLA induces less activation of the JNK, ERK1/2 MAPK and NFKB pathways as compared to Lipid A and LPS [48], we wondered if weaker engagement of CXCR4 by MLA might account for its TRIF-biased signaling compared to LPS. We used the chemical inhibitor AMD3100, also known as Plerixafor or Mozobil (developed by AnorMED) to determine if MLA and Lipid A differentially utilize CXCR4 for potentiation of TLR4-induced IL-6 production. Dendritic cells treated with MLA or Lipid A and the CXCR4 inhibitor showed a significant reduction of IL-6 production compared to Lipid A treatment alone (Figure 30). These data confirm that CXCR4 activation does contribute to TLR4-dependent cytokine production, and it appears that MPLA and LPS are both able to utilize this co-receptor to similar extents.

\section{No synergy observed between TLR4 and C5aR in dendritic cells}

It has been shown that TLRs can synergize with complement receptors for the induction of pro-inflammatory cytokines [169]. We wanted to determine if activation of TLR4 by MPLA or Lipid A and C5a would synergize for TNF-a production, a cytokine previously determined to increase in a synergistic fashion upon dual C5aR and TLR4 activation [169]. Interestingly, we did not see synergy for TNF-a production in dendritic cells activated with MPLA or Lipid A and C5a, and so we decided to analyze C5aRTLR4 synergy in macrophages, a cell type previously described to display the effect [169]. We found that MLA and Lipid A induced similar dosedependent production of TNF-a from macrophages, and that addition of C5a significantly increased levels of TNF- $\alpha$ (Figure 31). Importantly, the synergy between C5a and MLA- or Lipid A-activation of TLR4 was comparable, indicating that both agonists were able to induce TLR4mediated synergy with C5aR signaling. We did observe much higher overall levels of cytokines produced in dendritic cells compared to macrophages (this was also true for IL-6, IL-1 $\beta$ and MCP1), and it is therefore possible that this cell type is capable of producing maximal amounts of TNFa through TLR4 alone, or that dendritic cells do not express functional C5aR. 


\section{DISCUSSION}

TLR4 uses many co-receptors for optimal signal transduction. Because we observe different activation of TLR4 adapter signaling when comparing MLA and Lipid A, we hypothesized that differential interaction with TLR4 co-receptors could explain the TRIF-bias of MLA.

CD14 blockade during TLR4 activation resulted in a significant increase in IL-6 production for MLA, but not Lipid A-treated cells. This result suggests a differential CD14interaction between the two agonists. However, we cannot yet determine whether the results indicate a stronger or weaker interaction of MLA with CD14 compared to Lipid A because either could generate the observed pattern. If MLA fails to strongly interact with CD14, overall TLR4activation and subsequent signal transduction may be weaker as well. However, because CD14 engagement is associated with MyD88-independent signal transduction [140], MLA may strongly bind CD14, resulting in rapid internalization of the TLR4 receptor such that blockade of this pathway may increase MyD88-dependent signaling such as that involved in IL-6 production. More studies will be required to determine whether the strength of MLA-CD14 binding is similar to that of Lipid A.

Because Lipid A-CXCR4 binding contributes to activation of NF-KB and JNK-MAPK, we hypothesized that weak interaction between MLA and CXCR4 could possibly account for the appearance of TRIF-bias; however IL-6 production in response to Lipid A or MLA were both decreased when CXCR4 was blocked. This indicates that CXCR4 signaling does contribute to TLR4-mediated cytokine production, but likely does not explain the TRIF-biased signaling pattern of MLA.

Activation of TLR4 by both Lipid A and MLA synergized with C5aR signaling for cytokine production in macrophages, but no synergy was observed in dendritic cells. We have yet to determine the relative expression of C5aR on these two cell types. Additionally, human alveolar macrophages and polymorphonuclear cells (PMNs) are known to release bioactive C5a in response to TLR4 stimulation or activation with PMA [150]. As we have not assessed the amounts, if any, of $\mathrm{C} 5 \mathrm{a}$ released by these cells we cannot rule out differential production of endogenous $\mathrm{C} 5 \mathrm{a}$ as an explanation for failure of dendritic cells to display synergy. However, because MLA appears competent at synergizing with C5aR in macrophages for cytokine 
production, we are less inclined to elucidate the reasons why dendritic cells fail to respond to exogenous $\mathrm{C} 5 \mathrm{a}$. We have observed differences in 'degree' of TRIF-biased signaling in these two cells types, and these findings may indicate a difference in inflammatory potential between macrophages and dendritic cells. 


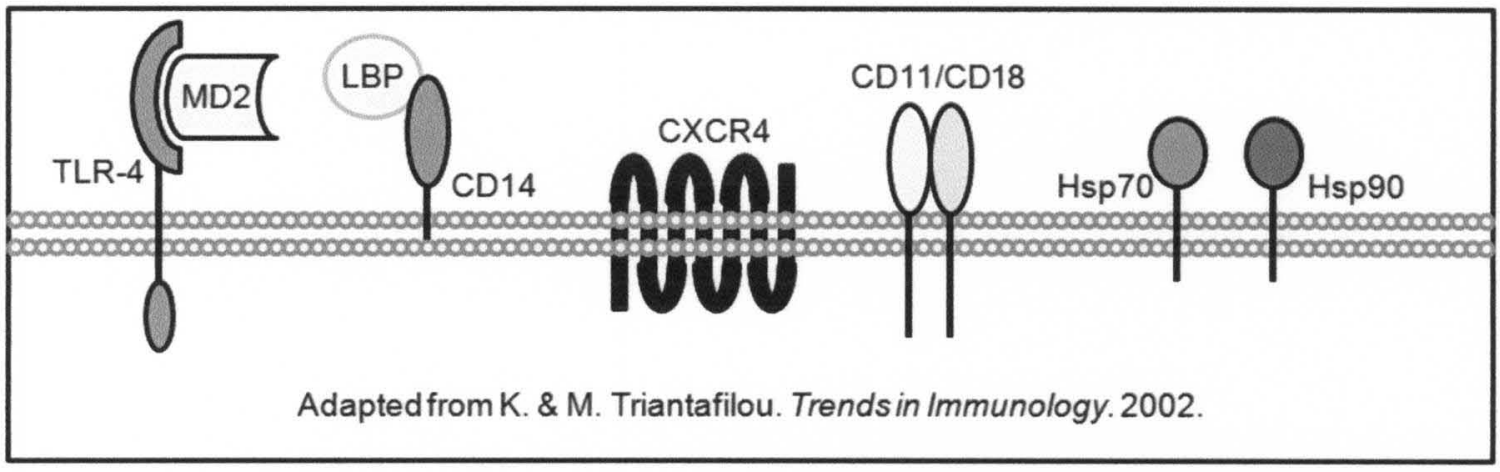

Figure 24. The LPS activation cluster. Lipopolysaccharide-binding protein (LBP) binds and transfers LPS to membrane bound CD14. Signaling molecules such as CXCR4, CD11/CD18, Hsp70, and Hsp90are recruited, LPS is released from CD14 and binds MD2/TLR4 and various co-receptors that make up the LPS activation cluster for signal transduction. 


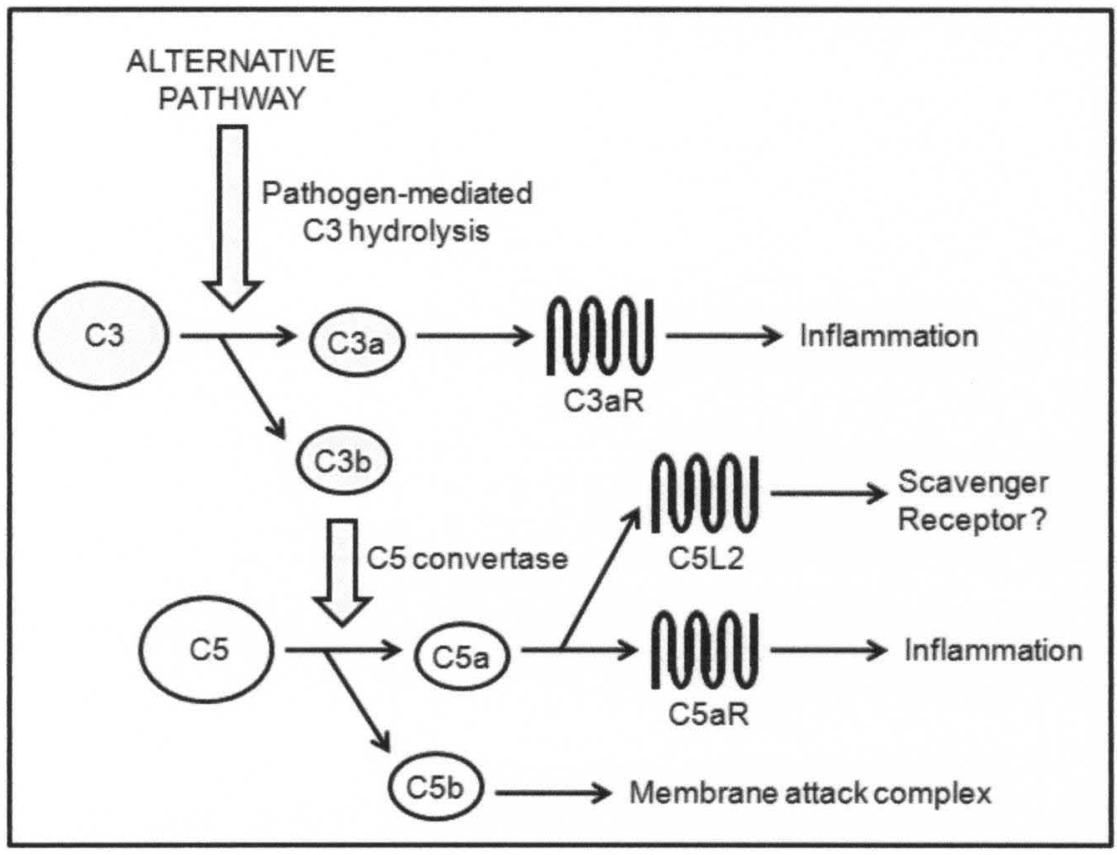

Figure 25. The alternative pathway of the complement cascade. C3 is spontaneously hydrolyzed into $\mathrm{C} 3 \mathrm{a}$ and $\mathrm{C} 3 \mathrm{~b}$ subunits via interaction with pathogen (or LPS). C3a then activates $\mathrm{C} 3 \mathrm{aR}$ inducing production of inflammatory mediators. C3b-containing C5 convertase acts to cleave C5 into C5a and C5b. C5a is detected by $\mathrm{C} 5 \mathrm{aR}$, inducing inflammatory cytokine production, or by $\mathrm{C} 5 \mathrm{~L} 2$ which appears to act as a weak or non-signaling scavenging type receptor. C5b joins with other proteins to form the membrane attack complex, or MAC. 


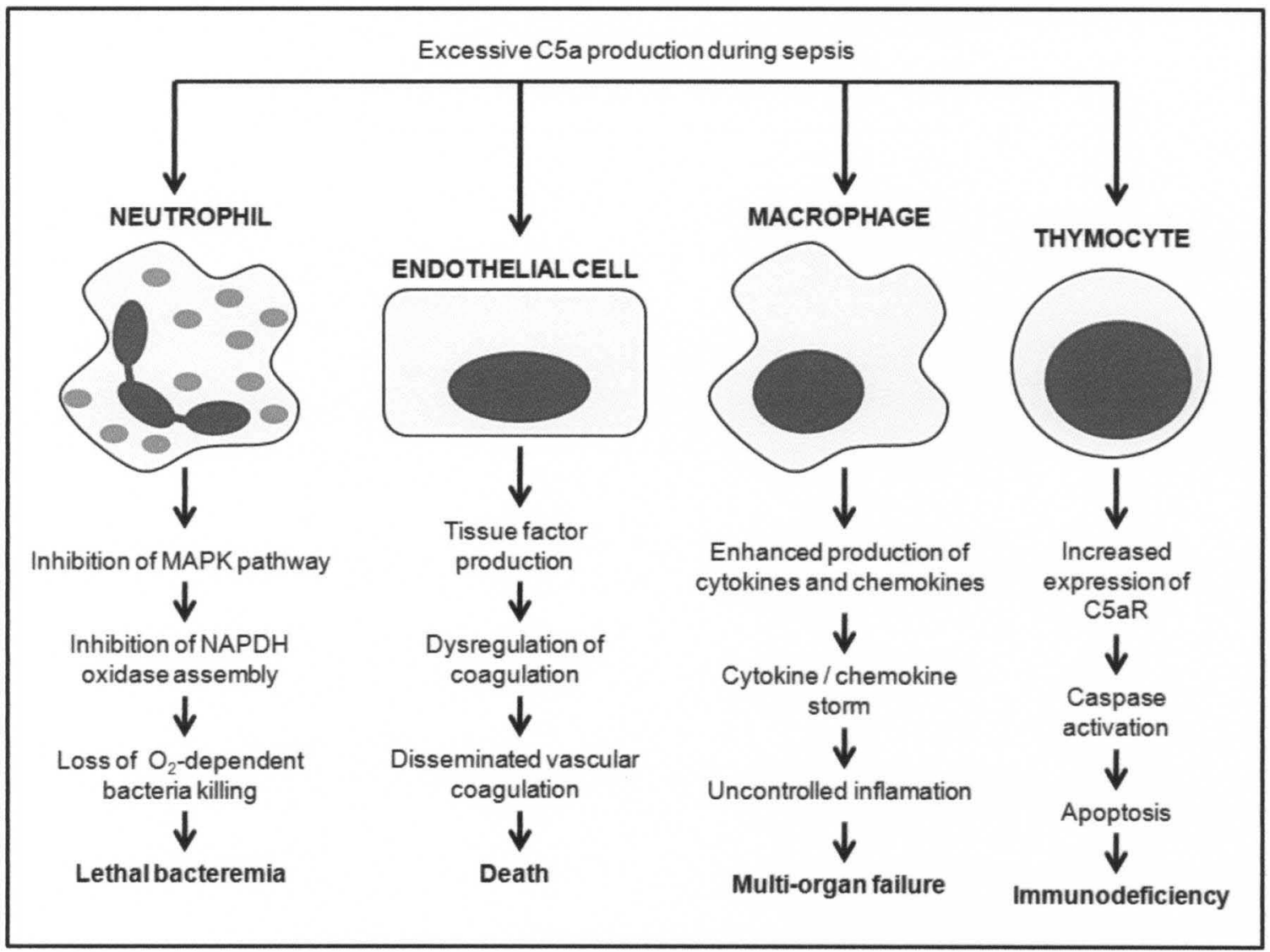

Figure 26. C5a contributes to pathogenesis of sepsis. Sepsis, as well as endotoxic shock, leads to the overproduction of $\mathrm{C} 5 \mathrm{a}$, which has pathogenic pro-inflammatory effects on various cell types. Excessive C5a has an inhibitory effect on neutrophil function, resulting in unchecked bacterial multiplication. Endothelial cells respond to $\mathrm{C} 5 \mathrm{a}$ by producing tissue factors that induce vascular coagulation resulting in death. Macrophages produce inflammatory cytokines and chemokines in response to $\mathrm{C} 5 \mathrm{a}$, which may lead to multi-organ failure, while $\mathrm{C} 5 \mathrm{aR}$ activation in thymocytes results in apoptosis and deletion of critical immune precursors. (Adapted from P.A. Ward; The dark side of C5a in sepsis; Nature Reviews Immunology; 2004) 


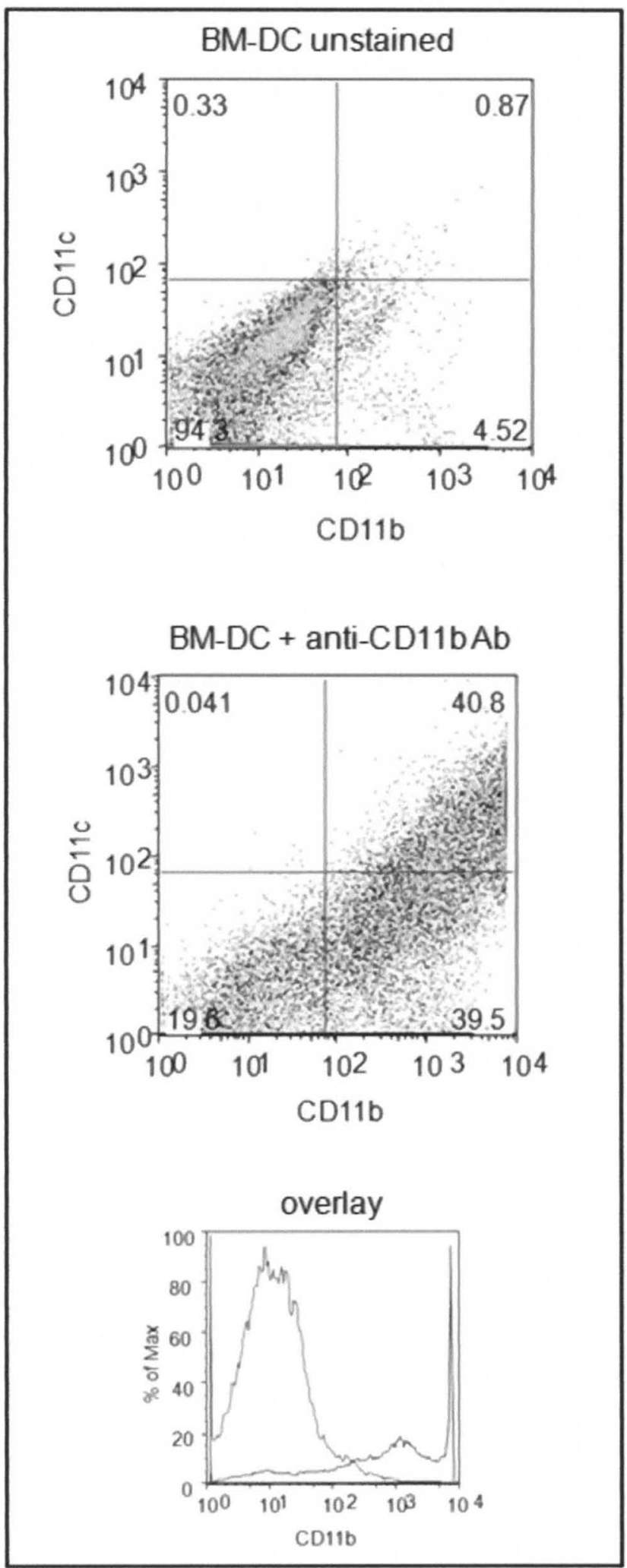

Figure 27. CD11b expression on bone marrow-derived dendritic cells. $1 \times 10^{6}$ BM-DCs were stained with fluorochrome labeled anti CD11c, CD11b or isotype control antibodies. CD11c positive cells coexpressing $C D 11 b$ was then determined by flow cytometric analysis. 


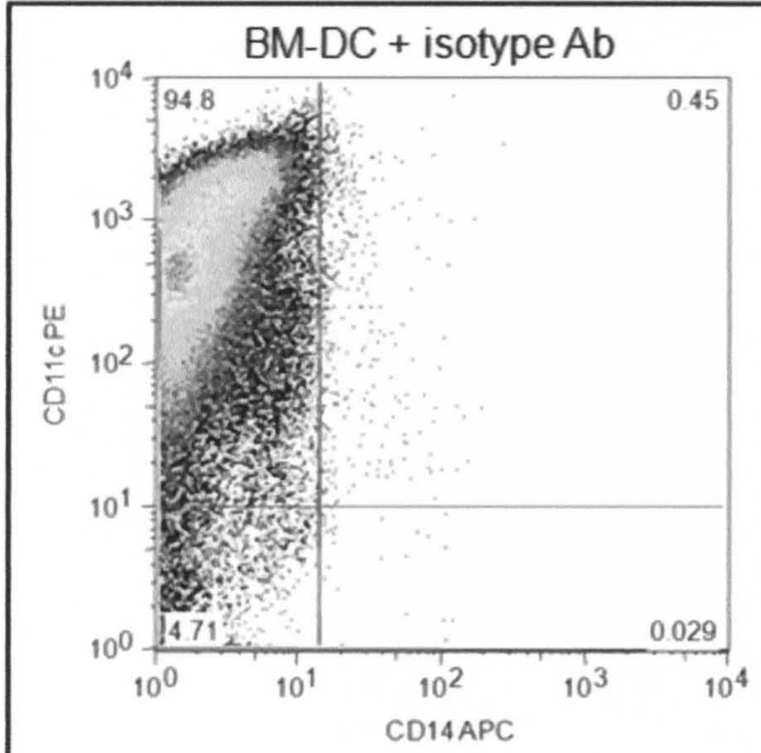

Figure 28. CD14 expression on bone marrow-derived dendritic cells. $1 \times 10^{6}$ BM-DCs were stained with fluorochrome labeled anti CD11c, CD14 or isotype control antibody. CD11c positive cells coexpressing CD14 was then determined by flow cytometric analysis.
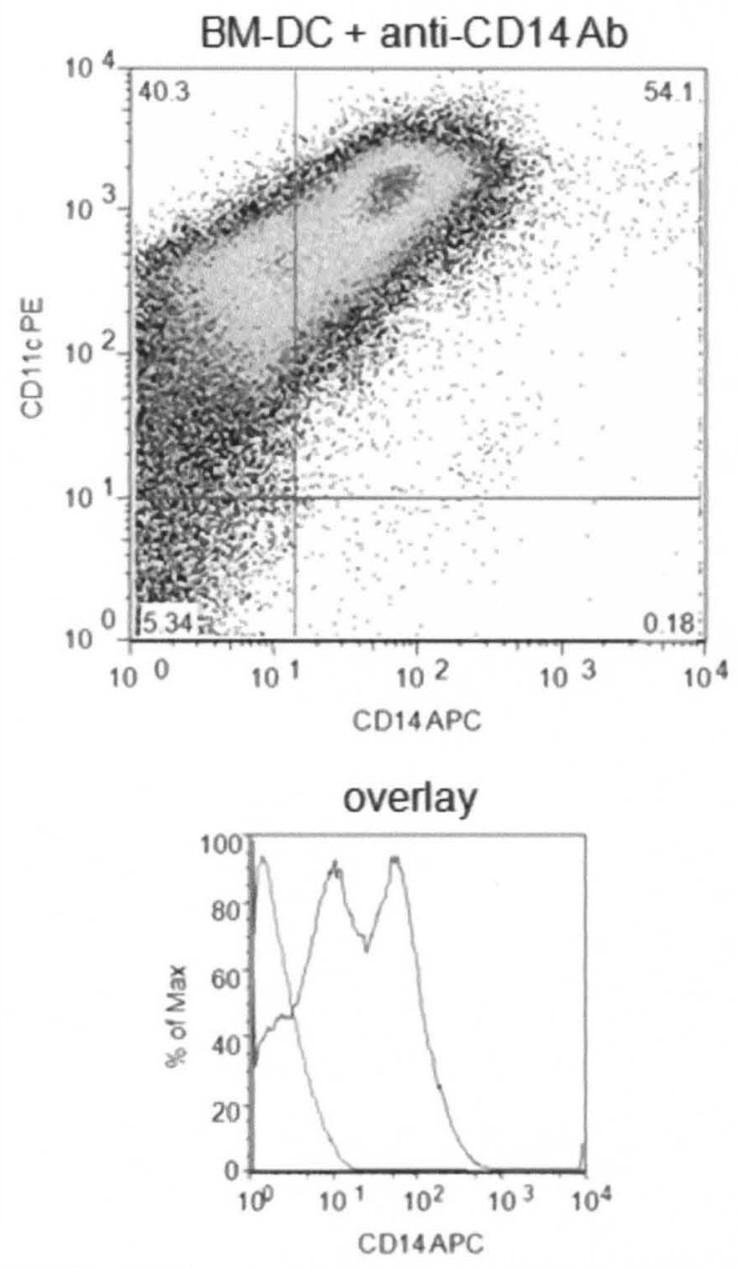


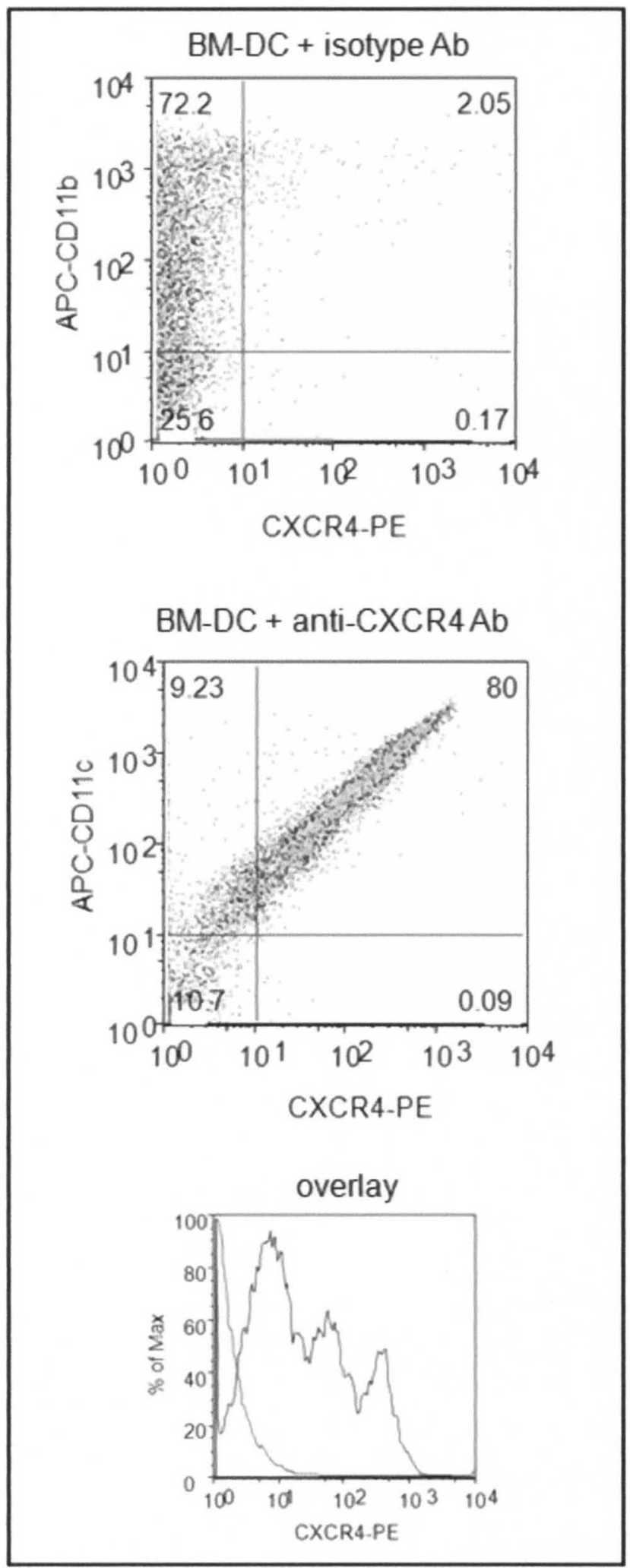

Figure 29. CXCR4 expression on bone marrow-derived dendritic cells. $1 \times 10^{6}$ BM-DCs were stained with fluorochrome labeled anti CD11c, CXCR4 or isotype control antibodies. CXCR4 expression was then determined by flow cytometric analysis. 


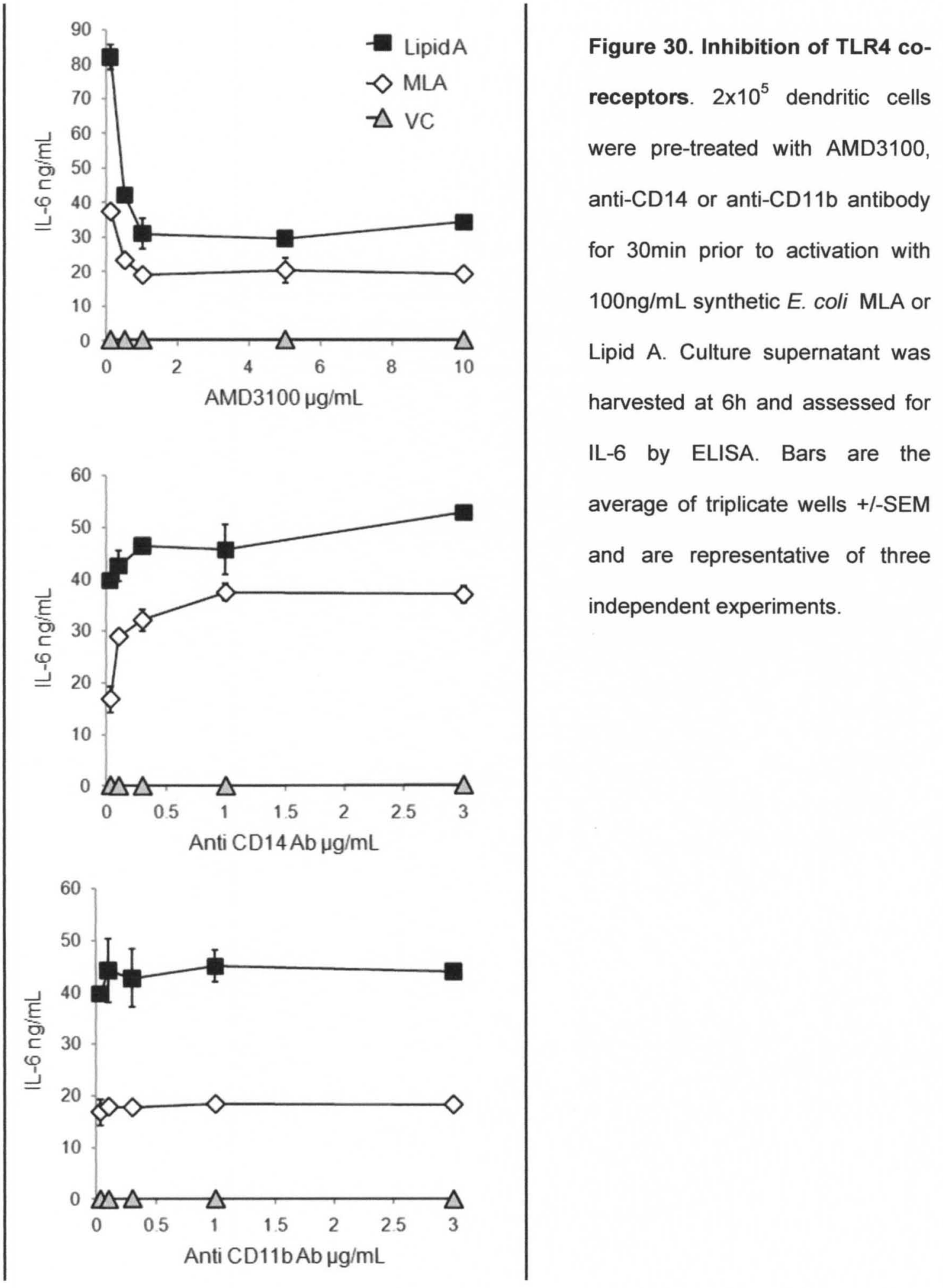



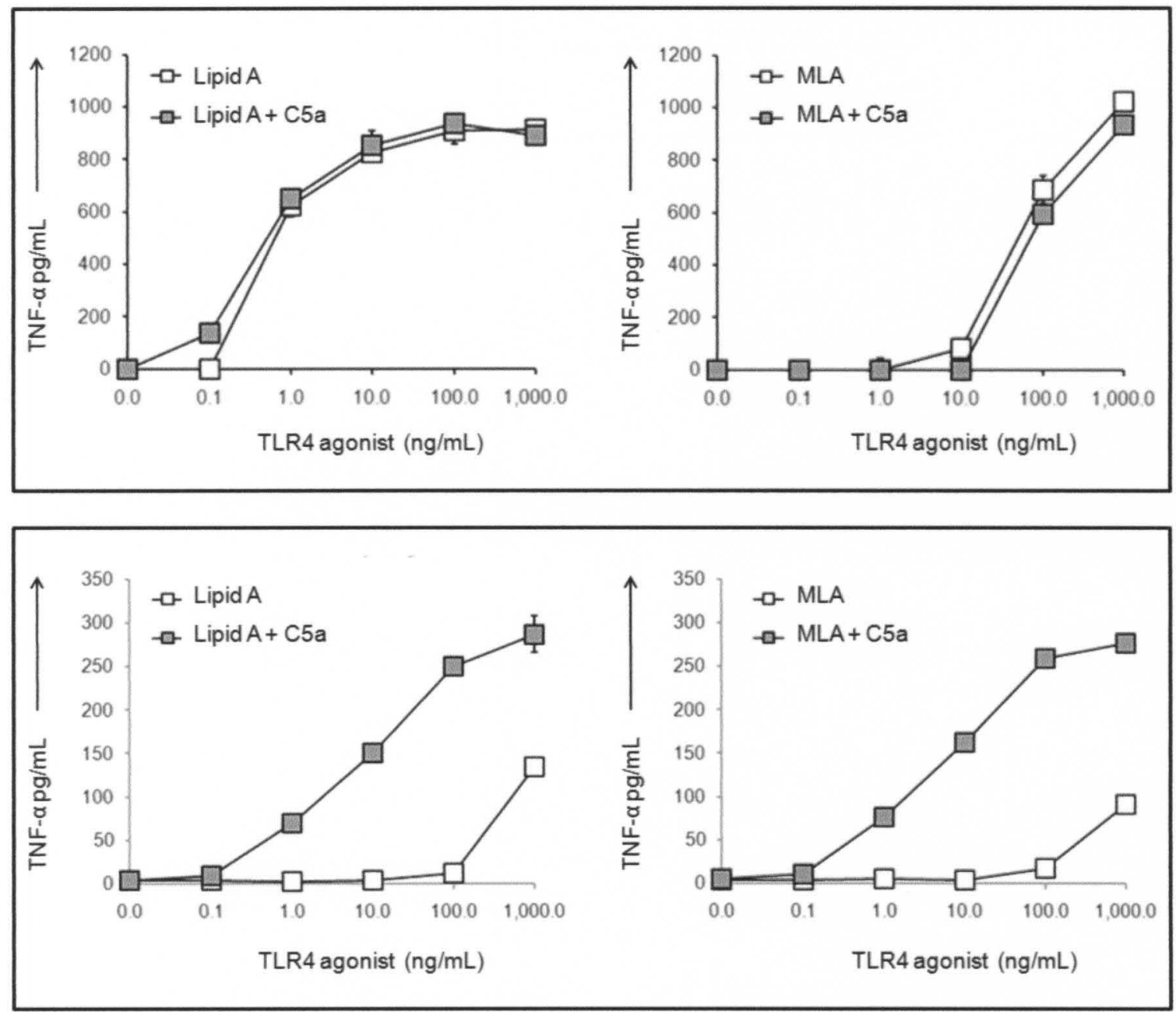

Figure 31. Tests of TLR4 synergy with C5aR in dendritic cells and macrophages. $2 \times 10^{5}$ bone marrow-derived dendritic cells and macrophages were activated simultaneously with $50 \mathrm{nM}$ recombinant murine $\mathrm{C} 5 \mathrm{a}$ and various concentrations of biological S. minnesota MPLA and Lipid A. Culture supernatants were harvested at $6 \mathrm{~h}$ and assessed for TNF- $\alpha$ by ELISA. 


\section{CHAPTER VI: DISCUSSION}

\section{The NLRP3 inflammasome as a therapeutic target for MPLA}

It has been well established that MPLA can be administered prior to LPS treatment for the induction of 'endotoxic tolerance', which is characterized by reduced inflammatory cytokine production, decreased febrile response and heart rate [60]. MPLA pretreatment of organs to be transplanted also prevents cell death subsequent to tissue reperfusion (7), an event partially mediated by IL-1B production (12). In this dissertation we have shown that MLA fails to induce IL$1 \beta$ maturation because its TRIF-biased TLR4 signaling leads to weak MyD88-dependent NLRP3 induction (see Chapter IV). This signaling resulted in protection against secondary stimuli for NLRP3 inflammasome activation because not all necessary components (NLRP3 protein) were induced. MLA is also capable of inhibiting Lipid A-induced inflammasome activation when given as a pretreatment to cells subsequently challenged with Lipid A. While this mechanism surely involved classic endotoxin tolerance mechanisms, we propose that MLA also induces a form of 'inflammasome tolerance'. Cells pretreated with MLA fail to respond to a second attempt at inflammasome priming through TLR4 activation, and will also not respond to inflammasome activating stimuli such as ATP (and possibly any other agent of inflammasome activation). Because of this MPLA could be used as a therapeutic agent in conditions where NLRP3activating DAMPs (such as amyloid $\beta$, cholesterol crystals, uric acid crystais) are known to play a role in the pathogenesis of IL-1 $\beta$-mediated inflammatory disease (such as Alzheimer's, atherosclerosis and gout, respectively) [59].

\section{Loss of NLRP3 inflammasome activation and the adjuvanticity of MPLA}

MPLA is an effective vaccine adjuvant, and is currently approved for human use in GlaxoSmithKline's Hepatitis B vaccine Fendrix and its human papillomavirus vaccine Cervarix under the name MPL adjuvant $B$ [37]. The role of NLRP3 inflammasome activation and IL-1B 
production in mediating adjuvanticity has been debated. While some say the two events are necessary for robust adjuvant effects of aluminum hydroxide (alum) [93], other groups have shown inflammasome activation and IL-1 $\beta$ production are dispensable for such effects $[93,95$, 173]. These two findings do not necessarily rule each other out, as one study demonstrated that alum-induced antibody production is independent of NLRP3 inflammasome [173], and the other showed NLRP3-dependence of Th1 T cell generation [174]. Therefore, adjuvant effects can be separated into IL-1/NLRP3-dependent and -independent categories. It is also probable that the fitness of a particular adjuvant should be determined by taking its function into consideration. For example, MPL $\otimes$ adjuvant may provide protective immunity for a particular viral infection, while its use in therapeutic anti-tumor vaccines may require supplementation with an agonist that more effectively promotes Th1 responses It is easy to image next generation adjuvants being as tailored to their particular target as to the pathogen's antigens themselves.

The importance of TLR4 co-receptor activation in MPLA's TRIF-biased signaling

Initiation of TLR4 signaling is a complex dance involving serum proteins and soluble factors, co-receptors and intracellular adapter proteins. While MPLAMLA and LPS/Lipid A from any one bacterial species vary only slightly in their overall structures, the nature of Lipid A binding to any of the aforementioned factors is such that very small structural changes can have large consequences on signal transduction. For example, removal of two acyl chains from hexaacylated LPS transforms a potent agonist into an antagonist [175], and removal of all but one phosphate from the Lipid $A$ head group results in TRIF-biased TLR4 signaling $[17,48]$. We therefore theorized that differential interactions with TLR4 co-receptors could explain MLA and Lipid A's unique signaling. Inhibition of CD11b did not affect TLR4-dependent cytokine induction; while CXCR4 inhibition resulted in a similar percent decrease in IL-6 production for MLA and Lipid A (see Chapter V). CD14 blockade greatty increased MLA-induced IL-6, while only slightly increasing Lipid A-induced IL-6 (Figure 30). It is interesting that CD14 inhibition alters MPLAinduced cytokine production so significantly, because CD14 can directly interact with the Lipid A head group and has been shown to be involved specifically in enabling the TRIF-signaling pathway $[137,140]$. These results are very exciting, as they could potentially explain MLA's TRIF- 
bias, and studies are currently underway to determine how MLA/MPLA may be interacting with CD14 differently than Lipid ALPS.

\section{Summary: TRIF-biased TLR4 signaling as the ultimate cause of MPLA's reduced toxicity}

MPLA displays $0.1-1 \%$ as much toxicity as its parent molecule LPS [19-24], but the mechanism responsible for this phenomenon is undetermined. When it was determined that MPLA fails to promote production of the pro-inflammatory cytokine IL-1B, this event was credited as the primary cause of MPLA's reduced toxicity compared to LPS [17]. However, we have shown that TRIF-biased TLR4 signaling is ultimately responsible for loss of IL-1 $\beta$ maturation because NLRP3, a protein required for inflammasome function and caspase-1 activation, is MyD88-dependent and not induced by MLA (see Chapter IV; C.A. Eaves et al. Science Signaling, accepted for publication). We have also shown that MPLA's TRIF-dependent loss of IL-1 $\beta$ production contributes to reduced MyD88-dependent induction of pro-inflammatory factors (see Chapter V). While IL-1RI signaling does not fully explain the differences between LPS and MPLA in their promotion of inflammation in vivo, we believe that TRIF-biased signaling ultimately explains this disparity. LPS induces high levels of MyD88-dependent inflammatory products (IL$1 \beta$, IFN- $\gamma$, etc.) that promote a cascade of inflammation and subsequent toxicity. MPLA displays reduced toxicity because of its failure to promote this inflammatory pathway due to its TRIFbiased TLR4 signaling. The findings in this dissertation can serve as a foundation for the development of targeted therapies for NLRP3/IL-1 $\beta$-mediated disease, and describe TRIF-biased TLR4 activation as a model for induction of potent immunogenicity with low associated toxi 


\section{REFERENCES}

1. Chen, G.Y. and G. Nunez, Sterile inflammation: sensing and reacting to damage. Nat Rev Immunol, 2010. 10(12): p. 826-37.

2. Eldred, J.A., et al., Stress-induced ATP release from and growth modulation of human lens and retinal pigment epithelial cells. Biochem Soc Trans, 2003. 31(Pt 6): p. 1213-5.

3. Duncan, J.A., et al., Cryopyrin/NALP3 binds ATP/dATP, is an ATPase, and requires ATP binding to mediate inflammatory signaling. Proc Natl Acad Sci U S A, 2007. 104(19): p. $8041-6$.

4. Piccinini, A.M. and K.S. Midwood, DAMPening inflammation by modulating TLR signalling. Mediators Inflamm, 2010. 2010.

5. Takada, H. and S. Kotani, Structural requirements of lipid A for endotoxicity and other biological activities. Crit Rev Microbiol, 1989. 16(6): p. 477-523.

6. Wright, S.D., et al., CD14, a receptor for complexes of lipopolysaccharide (LPS) and LPS binding protein. Science, 1990. 249(4975): p. 1431-3.

7. lovine, N., et al., The carboxyl-terminal domain of closely related endotoxin-binding proteins determines the target of protein-lipopolysaccharide complexes. J Biol Chem, 2002. 277(10): p. $7970-8$.

8. Shimazu, R., et al., MD-2, a molecule that confers lipopolysaccharide responsiveness on Toll-like receptor 4. J Exp Med, 1999. 189(11): p. 1777-82.

9. Park, B.S., et al., The structural basis of lipopolysaccharide recognition by the TLR4-MD2 complex. Nature, 2009. 458(7242): p. 1191-5.

10. Kagan, J.C. and R. Medzhitov, Phosphoinositide-mediated adaptor recruitment controls Toll-like receptor signaling. Cell, 2006. 125(5): p. 943-55.

11. Li, S., et al., IRAK-4: a novel member of the IRAK family with the properties of an IRAKkinase. Proc Natl Acad Sci U S A, 2002. 99(8): p. 5567-72. 
12. Cao, Z., et al., TRAF6 is a signal transducer for inteneukin-1. Nature, 1996. 383(6599): p. $443-6$.

13. Wesche, H., et al., MyD88: an adapter that recruits IRAK to the IL-1 receptor complex. Immunity, 1997. 7(6): p. 837-47.

14. Yamin, T.T. and D.K. Miller, The interleukin-1 receptor-associated kinase is degraded by proteasomes following its phosphorylation. J Biol Chem, 1997. 272(34): p. 21540-7.

15. Jiang, Z., et al., Interleukin-1 (IL-1) receptor-associated kinase-dependent IL-1-induced signaling complexes phosphorylate TAK1 and TAB2 at the plasma membrane and activate TAK1 in the cytosol. Mol Cell Biol, 2002. 22(20): p. 7158-67.

16. Sato, S., et al., Essential function for the kinase TAK1 in innate and adaptive immune responses. Nat Immunol, 2005. 6(11): p. 1087-95.

17. Mata-Haro, V., et al., The vaccine adjuvant monophosphoryl lipid $A$ as a TRIF-biased agonist of TLR4. Science, 2007. 316(5831): p. 1628-32.

18. Beutler, B., et al., Genetic analysis of innate immunity: identification and function of the TIR adapter proteins. Adv Exp Med Biol, 2005. 560: p. 29-39.

19. Qureshi, N., K. Takayama, and E. Ribi, Purification and structural determination of nontoxic lipid A obtained from the lipopolysaccharide of Salmonella typhimurium. J Biol Chem, 1982. 257(19): p. 11808-15.

20. Evans, J.T., et al., Enhancement of antigen-specific immunity via the TLR4 ligands MPL adjuvant and Ribi.529. Expert Rev Vaccines, 2003. 2(2): p. 219-29.

21. Bentala, H., et al., Removal of phosphate from lipid A as a strategy to detoxify lipopolysaccharide. Shock, 2002. 18(6): p. 561-6.

22. Takayama, K., et al., Separation and characterization of toxic and nontoxic forms of lipid A. Rev Infect Dis, 1984. 6(4): p. 439-43.

23. Vosika, G.J., C. Barr, and D. Gilbertson, Phase-l study of intravenous modified lipid A. Cancer Immunol Immunother, 1984. 18(2): p. 107-12.

24. Johnson, A.G., et al., Characterization of a nontoxic monophosphoryl lipid A. Rev Infect Dis, 1987. 9 Suppl 5: p. S512-6. 
25. Chase, J.J., et al., Effect of monophosphoryl lipid $A$ on host resistance to bacterial infection. Infect Immun, 1986. 53(3): p. 711-2.

26. Carozzi, S., et al., Effect of monophosphoryl lipid A (MPLA) on peritoneal leukocyte function. Adv Perit Dial, 1989. 5: p. 143-50.

27. Tomai, M.A., et al., The adjuvant properties of a nontoxic monophosphoryl lipid $A$ in hyporesponsive and aging mice. J Biol Response Mod, 1987. 6(2): p. 99-107.

28. Baker, P.J., et al., Ability of monophosphoryl lipid A to augment the antibody response of young mice. Infect Immun, 1988. 56(12): p. 3064-6.

29. Tomai, M.A. and A.G. Johnson, $T$ cell and interferon-gamma involvement in the adjuvant action of a detoxified endotoxin. J Biol Response Mod, 1989. 8(6): p. 625-43.

30. Thompson, B.S., et al., The low-toxicity versions of LPS, MPL adjuvant and RC529, are efficient adjuvants for CD4+ T cells. J Leukoc Biol, 2005. 78(6): p. 1273-80.

31. Hamdy, S., et al., Enhanced antigen-specific primary $\mathrm{CD4}+$ and $\mathrm{CD} 8+$ responses by codelivery of ovalbumin and toll-like receptor ligand monophosphoryl lipid $A$ in poly(D,Llactic-co-glycolic acid) nanoparticles. J Biomed Mater Res A, 2007. 81(3): p. 652-62.

32. Zhong, Z., et al., A novel liposomal vaccine improves humoral immunity and prevents tumor pulmonary metastasis in mice. Int J Pharm, 2010. 399(1-2): p. 156-62.

33. Ravindran, R., et al., Companison of BCG, MPL and cationic liposome adjuvant systems in leishmanial antigen vaccine formulations against murine visceral leishmaniasis. BMC Microbiol, 2010. 10: p. 181.

34. Di Paolo, D., et al., One-year vaccination against hepatitis $B$ vinus with a MPL-vaccine in liver transplant patients for HBV-related cirmosis. Transpl Int, 2010. 23(11): p. 1105-12.

35. Kolibab, K., et al., Highly persistent and effective prime/boost regimens against tuberculosis that use a multivalent modified vaccine virus Ankara-based tuberculosis vaccine with intenleukin-15 as a molecular adjuvant. Clin Vaccine Immunol, 2010. 17(5): p. $793-801$.

36. Rosewich, M., et al., Tolerance induction after specific immunotherapy with pollen allergoids adjuvanted by monophosphoryl lipid $A$ in children. Clin Exp Immunol, 2010. 160(3): p. 403-10. 
37. Beran, J., [The importance of the second generation adjuvanted systems in "new" vaccines]. Klin Mikrobiol Infekc Lek, 2008. 14(1): p. 5-12.

38. Kumada, H., et al., Structural study on the free lipid $A$ isolated from lipopolysaccharide of Porphyromonas gingivalis. J Bacteriol, 1995. 177(8): p. 2098-106.

39. Coats, S.R., et al., The lipid A phosphate position determines differential host Toll-like receptor 4 responses to phylogenetically related symbiotic and pathogenic bacteria. Infect Immun, 2011. 79(1): p. 203-10.

40. Weintraub, A., et al., Structural characterization of the lipid A component of Bacteroides fragilis strain NCTC 9343 lipopolysaccharide. Eur J Biochem, 1989. 183(2): p. 425-31.

41. Ogawa, T., et al., Immunobiological activities of chemically defined lipid $A$ from Helicobacter pylori LPS in comparison with Porphyromonas gingivalis lipid $A$ and Escherichia coli-type synthetic lipid A (compound 506). Vaccine, 1997. 15(15): p. 1598605.

42. Moran, A.P., Lipopolysaccharide in bacterial chronic infection: insights from Helicobacter pylor lipopolysaccharide and lipid A. Int J Med Microbiol, 2007. 297(5): p. 307-19.

43. Al-Qutub, M.N., et al., Hemin-dependent modulation of the lipid A structure of Porphyromonas gingivalis lipopolysaccharide. Infect Immun, 2006. 74(8): p. 4474-85.

44. Coats, S.R., et al., Human Toll-like receptor 4 responses to $P$. gingivalis are regulated by lipid A 1- and 4'-phosphatase activities. Cell Microbiol, 2009. 11(11): p. 1587-99.

45. Hynes, S.O., et al, Comparative chemical and biological characterization of the lipopolysaccharides of gastric and enterohepatic helicobacters. Helicobacter, 2004. 9(4): p. $313-23$.

46. Loppnow, $H$., et al., $I L-1$ induction-capacity of defined lipopolysaccharide partial structures. J Immunol, 1989. 142(9): p. 3229-38.

47. Okemoto, K., et al., A potent adjuvant monophosphoryl lipid A triggers vanious immune responses, but not secretion of IL-1beta or activation of caspase-1. J Immunol, 2006. 176(2): p. 1203-8.

48. Cekic, C., et al., Selective activation of the p38 MAPK pathway by synthetic monophosphoryl lipid A. J Biol Chem, 2009. 284(46): p. 31982-91. 
49. Bauernfeind, F.G., et al., Cutting edge: NF-kappaB activating pattem recognition and cytokine receptors license NLRP3 inflammasome activation by regulating NLRP3 expression. J Immunol, 2009. 183(2): p. 787-91.

50. Franchi, L., T. Eigenbrod, and G. Nunez, Cutting edge: TNF-alpha mediates sensitization to ATP and silica via the NLRP3 inflammasome in the absence of microbial stimulation. J Immunol, 2009. 183(2): p. 792-6.

51. Franchi, L., et al., The inflammasome: a caspase-1-activation platform that regulates immune responses and disease pathogenesis. Nat Immunol, 2009. 10(3): p. 241-7.

52. Fernandes-Ainemri, T., et al., The pyroptosome: a supramolecular assembly of ASC dimers mediating inflammatory cell death via caspase-1 activation. Cell Death Differ, 2007. 14(9): p. 1590-604.

53. Bryan, N.B., et al., Activation of inflammasomes requires intracellular redistribution of the apoptotic speck-like protein containing a caspase recruitment domain. J Immunol, 2009. 182(5): p. 3173-82.

54. Thornberry, N.A., et al., A novel heterodimeric cysteine protease is required for interleukin-1 beta processing in monocytes. Nature, 1992. 356(6372): p. 768-74.

55. Becker, C.E., E.M. Creagh, and L.A. O'Neill, Rab39a binds caspase-1 and is required for caspase-1-dependent interleukin-1beta secretion. J Biol Chem, 2009. 284(50): p. 345317.

56. Fantuzzi, G., et al., Response to local inflammation of IL-1 beta-converting enzymedeficient mice. J Immunol, 1997. 158(4): p. 1818-24.

57. Re, F., et al., The type "/ "receptor" as a decoy target for interleukin 1 in polymorphonuclear leukocytes: characterization of induction by dexamethasone and ligand binding properties of the released decoy receptor. J Exp Med, 1994. 179(2): p. 739-43.

58. Arend, W.P., et al., Interleukin-1 receptor antagonist: role in biology. Annu Rev Immunol, 1998. 16: p. 27-55.

59. Rock, K.L., et al., The sterile inflammatory response. Annu Rev Immunol, 2010. 28: p. $321-42$. 
60. Astiz, M.E., et al., Pretreatment of normal humans with monophosphoryl lipid A induces tolerance to endotoxin: a prospective, double-blind, randomized, controlled trial. Crit Care Med, 1995. 23(1): p. 9-17.

61. Gustafson, G.L., M.J. Rhodes, and T. Hegel, Monophosphoryl lipid A as a prophylactic for sepsis and septic shock. Prog Clin Biol Res, 1995. 392: p. 567-79.

62. Wy, C.A., et al., Prophylactic treatment of endotoxic shock with monophosphoryl lipid A in newbom rats. Biol Neonate, 2000. 77(3): p. 191-5.

63. Palsson-McDermott, E.M. and L.A. O'Neill, Signal transduction by the lipopolysaccharide receptor, Toll-like receptor-4. Immunology, 2004. 113(2): p. 153-62.

64. Persing, D.H., et al., Taking toll: lipid A mimetics as adjuvants and immunomodulators. Trends Microbiol, 2002. 10(10 Suppl): p. S32-7.

65. Ribi, E., Beneficial modification of the endotoxin molecule. J Biol Response Mod, 1984. 3(1): p. 1-9.

66. Didierlaurent, A.M., et al., AS04, an aluminum salt- and TLR4 agonist-based adjuvant system, induces a transient localized innate immune response leading to enhanced adaptive immunity. J Immunol, 2009. 183(10): p. 6186-97.

67. Davis, B.K. and J.P. Ting, NLRP3 has a sweet tooth. Nat Immunol, 2010. 11(2): p. 105-6.

68. Mitroulis, I., P. Skendros, and K. Ritis, Targeting IL-1beta in disease; the expanding role of NLRP3 inflammasome. Eur J Intern Med, 2010. 21(3): p. 157-63.

69. Suzuki, S. and L.H. Toledo-Pereyra, Interleukin 1 and tumor necrosis factor production as the initial stimulants of liver ischemia and reperfusion injury. J Surg Res, 1994. 57(2): p. 253-8.

70. Tang, $Y_{.}$, et al., Fluorofenidone protects mice from lethal endotoxemia through the inhibition of TNF-alpha and IL-1beta release. Int Immunopharmacol, 2010. 10(5): p. 5803.

71. Torres, R., et al., Hyperalgesia, synovitis and multiple biomarkers of inflammation are suppressed by interteukin 1 inhibition in a novel animal model of gouty arthritis. Ann Rheum Dis, 2009. 68(10): p. 1602-8. 
72. Voronov, E., et al., IL-1 beta-deficient mice are resistant to induction of experimental SLE. Eur Cytokine Netw, 2006. 17(2): p. 109-16.

73. Yamasaki, Y., et al., Interleukin-1 as a pathogenetic mediator of ischemic brain damage in rats. Stroke, 1995. 26(4): p. 676-80; discussion 681.

74. Maldonado, C., et al., Preconditioning of latissimus dorsi muscle flaps with monophosphoryl lipid a. Plast Reconstr Surg, 2003. 111(1): p. 267-74.

75. Sharony, R., et al., Pharmacological preconditioning with monophosphoryl lipid A improves post ischemic diastolic function and modifies TNF-alpha synthesis. Eur J Cardiothorac Surg, 2005. 27(3): p. 501-7.

76. Xiuhua, L., et al., Signaling pathway of cardioprotection induced by monophosphoryl lipid A in rabbit myocardium. Pathophysiology, 2002. 8(3): p. 193-196.

77. Yamashita, N., et al., Monophosphoryl lipid A provides biphasic cardioprotection against ischaemia-reperfusion injury in rat hearts. Br J Pharmacol, 1999. 128(2): p. 412-8.

78. Yoshida, T., et al., Preconditioning of swine heart with monophosphoryl lipid A improves myocardial preservation. Ann Thorac Surg, 2000. 70(3): p. 895-900.

79. Zhu, H.Q., et al., The protective effects of monophosphoryl lipid A on the ischemic myocardium and endothelium in rats. Cardiovasc Drugs Ther, 2003. 17(4): p. 311-8.

80. Shikama, Y., et al., Muramyldipeptide augments the actions of lipopolysaccharide in mice by stimulating macrophages to produce pro- $L-1 B$ and by down-regulation of suppressor of cytokine signaling 1 (SOCS1). Innate Immun, 2009.

81. Hsu, L.C., et al., A NOD2-NALP1 complex mediates caspase-1-dependent IL-1beta secretion in response to Bacillus anthracis infection and muramyl dipeptide. Proc Natl Acad Sci U S A, 2008. 105(22): p. 7803-8.

82. Ferwerda, G., et al., Engagement of NOD2 has a dual effect on prolL-1beta mRNA transcription and secretion of bioactive IL-1beta. Eur J Immunol, 2008. 38(1): p. 184-91.

83. Vacheron, F., M. Guenounou, and C. Nauciel, Induction of interleukin 1 secretion by adjuvant-active peptidoglycans. Infect Immun, 1983. 42(3): p. 1049-54. 
84. Yamamoto, M., et al., ASC is essential for LPS-induced activation of procaspase-1 independently of TLR-associated signal adaptor molecules. Genes Cells, 2004. 9(11): p. $1055-67$.

85. Harder, J., et al., Activation of the NIrp3 inflammasome by Streptococcus pyogenes requires streptolysin O and NF-kappa B activation but proceeds independently of TLR signaling and $P 2 X 7$ receptor. J Immunol, 2009. 183(9): p. 5823-9.

86. Munoz-Planillo, R., et al., A critical role for hemolysins and bacterial lipoproteins in Staphylococcus aureus-induced activation of the NIrp3 inflammasome. J Immunol, 2009. 183(6): p. 3942-8.

87. Toma, C., et al., Pathogenic Vibrio activate NLRP3 inflammasome via cytotoxins and TLR/nucleotide-binding oligomerization domain-mediated NF-kappa B signaling. J Immunol, 2010. 184(9): p. 5287-97.

88. Taxman, D.J., et al., Cutting edge: ASC mediates the induction of multiple cytokines by Porphyromonas gingivalis via caspase-1-dependent and -independent pathways. J Immunol, 2006. 177(7): p. $4252-6$.

89. Kawai, T., et al., Unresponsiveness of MyD88-deficient mice to endotoxin. Immunity, 1999. 11(1): p. 115-22.

90. Pelegrin, P., C. Barroso-Gutierrez, and A. Surprenant, $P 2 X 7$ receptor differentially couples to distinct release pathways for IL-1beta in mouse macrophage. J Immunol, 2008. $180(11)$ : p. $7147-57$.

91. Huang, M.T., et al., Critical role of apoptotic speck protein containing a caspase recruitment domain (ASC) and NLRP3 in causing necrosis and ASC speck formation induced by Porphyromonas gingivalis in human cells. J Immunol, 2009. 182(4): p. 2395404.

92. Rajan, J.V., et al., Activation of the NLRP3 inflammasome by intracellular poly I:C. FEBS Lett, 2010. 584(22): p. 4627-32.

93. $\mathrm{Li}, \mathrm{H}$., et al., Cutting edge: inflammasome activation by alum and alum's adjuvant effect are mediated by NLRP3. J Immunol, 2008. 181(1): p. 17-21. 
94. Kool, M., et al., Cutting edge: alum adjuvant stimulates inflammatory dendritic cells through activation of the NALP3 inflammasome. J Immunol, 2008. 181(6): p. 3755-9.

95. Franchi, L. and G. Nunez, The NIrp3 inflammasome is critical for aluminium hydroxidemediated IL-1beta secretion but dispensable for adjuvant activity. Eur J Immunol, 2008. 38(8): p. 2085-9.

96. Spreafico, R., P. Ricciardi-Castagnoli, and A. Mortellaro, The controversial relationship between NLRP3, alum, danger signals and the next-generation adjuvants. Eur $\mathrm{J}$ Immunol, 2010. 40(3): p. 638-42.

97. Guarda, G., et al., $T$ cells dampen innate immune responses through inhibition of NLRP1 and NLRP3 inflammasomes. Nature, 2009. 460(7252): p. 269-73.

98. Saitoh, T., et al., Loss of the autophagy protein Atg16L1 enhances endotoxin-induced IL1 beta production. Nature, 2008. 456(7219): p. 264-8.

99. Naik, E. and V.M. Dixit, Modulation of Inflammasome Activity for the Treatment of Autoinflammatory Disorders. J Clin Immunol, 2010.

100. Cook, G.P., et al., The NLRP3 inflammasome, a target for therapy in diverse disease states. Eur J Immunol, 2010. 40(3): p. 631-4.

101. Wanderer, A.A., Rationale for IL-1beta targeted therapy for ischemia-reperfusion induced pulmonary and other complications in sickle cell disease. J Pediatr Hematol Oncol, 2009. 31(8): p. 537-8.

102. Terkeltaub, R., et al., The interleukin 1 inhibitor rilonacept in treatment of chronic gouty arthritis: results of a placebo-controlled, monosequence crossover, non-randomised, single-blind pilot study. Ann Rheum Dis, 2009. 68(10): p. 1613-7.

103. Dinarello, C.A., Interleukin-1beta and the autoinflammatory diseases. N Engl J Med, 2009. 360(23): p. $2467-70$.

104. Hamilton-Davies, C. and A.R. Webb, Monophosphoryl lipid A and endotoxin tolerance. Crit Care Med, 1995. 23(10): p. 1789-90.

105. Luderitz, O., A.M. Staub, and O. Westphal, Immunochemistry of $O$ and $R$ antigens of Salmonella and related Enterobacteriaceae. Bacteriol Rev, 1966. 30(1): p. 192-255. 
106. Biswas, S.K. and E. Lopez-Collazo, Endotoxin tolerance: new mechanisms, molecules and clinical significance. Trends Immunol, 2009. 30(10): p. 475-87.

107. Lacey, D.L. and J.M. Erdmann, IL-1 and IL-4 modulate IL-1 receptor expression in a murine $T$ cell line. J Immunol, 1990. 145(12): p. 4145-53.

108. Agostini, L., et al., NALP3 forms an IL-1beta-processing inflammasome with increased activity in Muckle-Wells autoinflammatory disorder. Immunity, 2004. 20(3): p. 319-25.

109. Dode, C., et al., New mutations of CIAS1 that are responsible for Muckle-Wells syndrome and familial cold urticaria: a novel mutation underlies both syndromes. Am J Hum Genet, 2002. 70(6): p. 1498-506.

110. Feldmann, J., et al., Chronic infantile neurological cutaneous and articular syndrome is caused by mutations in CIAS1, a gene highly expressed in polymorphonuclear cells and chondrocytes. Am J Hum Genet, 2002. 71(1): p. 198-203.

111. Boschan, C., et al., Neonatal-onset multisystem inflammatory disease (NOMID) due to a novel S331R mutation of the CIAS1 gene and response to interleukin-1 receptor antagonist treatment. Am J Med Genet A, 2006. 140(8): p. 883-6.

112. Opal, S.M. and C.E. Huber, Bench-to-bedside review: Toll-like receptors and their role in septic shock. Crit Care, 2002. 6(2): p. 125-36.

113. Caille, V., et al., [Physiopathology of severe sepsis]. Presse Med, 2004. 33(4): p. 256-61; discussion 269.

114. Michie, H.R., Metabolism of sepsis and multiple organ failure. World J Surg, 1996. 20(4): p. $460-4$.

115. Kumar, A., et al., Tumor necrosis factor alpha and interleukin 1beta are responsible for in vitro myocardial cell depression induced by human septic shock serum. J Exp Med, 1996. 183(3): p. 949-58.

116. Scatizzi, J.C., et al., The CDK domain of p21 is a suppressor of IL-1beta-mediated inflammation in activated macrophages. Eur J Immunol, 2009. 39(3): p. 820-5.

117. Furst, D.E., et al., Updated consensus statement on biological agents, specifically tumour necrosis factor \{alpha\} (TNF\{alpha\}) blocking agents and interleukin-1 receptor 
antagonist (IL-1ra), for the treatment of meumatic diseases, 2005. Ann Rheum Dis, 2005. 64 Suppl 4: p. iv2-14.

118. Hoebe, K., et al., Upregulation of costimulatory molecules induced by lipopolysaccharide and double-stranded RNA occurs by Trif-dependent and Trif-independent pathways. Nat Immunol, 2003. 4(12): p. 1223-9.

119. Blanque, R., et al., Dual mechanisms of action of interferon-gamma in potentiating responses to LPS in mice: IL1, TNFalpha and IL6 production in serum and hypothermia. Gen Pharmacol, 1999. 32(4): p. 453-61.

120. Zimmerman, H.J., Drug-induced liver disease. Drugs, 1978. 16(1): p. 25-45.

121. Seubert, A., et al., The adjuvants aluminum hydroxide and MF59 induce monocyte and granulocyte chemoattractants and enhance monocyte differentiation towand dendritic cells. J Immunol, 2008. 180(8): p. 5402-12.

122. Kawa, K., et al., IFN-gamma is a master regulator of endotoxin shock syndrome in mice primed with heat-killed Propionibacterium acnes. Int Immunol, 2010. 22(3): p. 157-66.

123. Lacour, S., et al., Cytokines as potential biomarkers of liver toxicity. Cancer Biomark, 2005. 1(1): p. 29-39.

124. Reyes-Gordillo, K., et al., Curcumin protects against acute liver damage in the rat by inhibiting NF-kappaB, proinflammatory cytokines production and oxidative stress. Biochim Biophys Acta, 2007. 1770(6): p. 989-96.

125. Lee, W.M., Acetaminophen toxicity: changing perceptions on a social/medical issue. Hepatology, 2007. 46(4): p. 966-70.

126. Kaplowitz, N., Acetaminophen hepatoxicity: what do we know, what don't we know, and what do we do next? Hepatology, 2004. 40(1): p. 23-6.

127. Cover, C., et al., Pathophysiological role of the acute inflammatory response during acetaminophen hepatotoxicity. Toxicol Appl Pharmacol, 2006. 216(1): p. 98-107.

128. Chen, C.J., et al., Identification of a key pathway required for the sterile inflammatory response triggered by dying cells. Nat Med, 2007. 13(7): p. 851-6.

129. Imaeda, A.B., et al., Acetaminophen-induced hepatotoxicity in mice is dependent on TIr9 and the Nalp3 inflammasome. J Clin Invest, 2009. 119(2): p. 305-14. 
130. Dierich, M.P., et al., Analysis of bypass activation of C3 by endotoxic LPS and loss of this potency. Immunology, 1973. 24(4): p. 721-33.

131. Hoffmann, E.M. and J.J. Houle, Failure of Brucella abortus lipopolysaccharide (LPS) to activate the altemative pathway of complement. Vet Immunol Immunopathol, 1983. 5(1): p. 65-76.

132. Fust, G., L. Bertok, and S. Juhasz-Nagy, Interactions of radio-detoxified Escherichia coli endotoxin preparations with the complement system. Infect Immun, 1977. 16(1): p. 26-31.

133. Joiner, K.A., et al., C3 binds preferentially to long-chain lipopolysaccharide during alternative pathway activation by Salmonella montevideo. J Immunol, 1986. 136(2): p. $710-5$.

134. Grossman, N. and L. Leive, Complement activation via the alternative pathway by purified Salmonella lipopolysaccharide is affected by its structure but not its O-antigen length. J Immunol, 1984. 132(1): p. 376-85.

135. Clas, F. and M. Loos, Requirement for an additional serum factor essential for the antibody-independent activation of the classical complement sequence by Gram-negative bacteria. Infect Immun, 1982. 37(3): p. 935-9.

136. Schumann, R.R., et al., Structure and function of lipopolysaccharide binding protein. Science, 1990. 249(4975): p. 1429-31.

137. Kim, J.I., et al., Crystal structure of CD14 and its implications for lipopolysaccharide signaling. J Biol Chem, 2005. 280(12): p. 11347-51.

138. Perera, P.Y., et al., CD14-dependent and CD14-independent signaling pathways in murine macrophages from normal and CD14 knockout mice stimulated with lipopolysaccharide or taxol. J Immunol, 1997. 158(9): p. 4422-9.

139. da Silva Correia, J., et al., Lipopolysaccharide is in close proximity to each of the proteins in its membrane receptor complex. transfer from CD14 to TLR4 and MD-2. J Biol Chem, 2001. 276(24): p. 21129-35.

140. Jiang, Z., et al., CD14 is required for MyD88-independent LPS signaling. Nat Immunol, 2005. 6(6): p. 565-70. 
141. Triantafilou, M. and K. Triantafilou, Lipopolysaccharide recognition: CD14, TLRs and the LPS-activation cluster. Trends Immunol, 2002. 23(6): p. 301-4.

142. Triantafilou, M., et al., Chemokine receptor 4 (CXCR4) is part of the lipopolysaccharide "sensing apparatus". Eur J Immunol, 2008. 38(1): p. 192-203.

143. Hynes, R.O., Integrins: bidirectional, allosteric signaling machines. Cell, 2002. 110(6): p. 673-87.

144. Ingalls, R.R. and D.T. Golenbock, CD11C/CD18, a transmembrane signaling receptor for lipopolysaccharide. J Exp Med, 1995. 181(4): p. 1473-9.

145. Ingalls, R.R., M.A. Arnaout, and D.T. Golenbock, Outside-in signaling by lipopolysaccharide through a tailless integrin. J Immunol, 1997. 159(1): p. 433-8.

146. Perera, P.Y., et al., CD11b/CD18 acts in concert with CD14 and Toll-like receptor (TLR) 4 to elicit full lipopolysaccharide and taxol-inducible gene expression. J Immunol, 2001. 166(1): p. 574-81.

147. Huber-Lang, M., et al., Generation of C5a in the absence of C3: a new complement activation pathway. Nat Med, 2006. 12(6): p. 682-7.

148. Wetsel, R.A. and W.P. Kolb, Expression of C5a-like biological activities by the fifth component of human complement (C5) upon limited digestion with noncomplement enzymes without release of polypeptide fragments. J Exp Med, 1983. 157(6): p. 2029-48.

149. Ward, P.A. and J.H. Hill, C5 chemotactic fragments produced by an enzyme in lysosomal granules of neutrophils. J Immunol, 1970. 104(3): p. 535-43.

150. Huber-Lang, M., et al., Generation of C5a by phagocytic cells. Am J Pathol, 2002. 161(5): p. $1849-59$.

151. Monk, P.N., et al., Function, structure and therapeutic potential of complement C5a receptors. Br J Pharmacol, 2007. 152(4): p. 429-48.

152. Chenoweth, D.E. and T.E. Hugli, Demonstration of specific C5a receptor on intact human polymorphonuclear leukocytes. Proc Natl Acad Sci U S A, 1978. 75(8): p. 3943-7.

153. van Epps, D.E. and D.E. Chenoweth, Analysis of the binding of fluorescent C5a and C3a to human peripheral blood leukocytes. J Immunol, 1984. 132(6): p. 2862-7. 
154. Riedemann, N.C., et al., Expression and function of the C5a receptor in rat alveolar epithelial cells. J Immunol, 2002. 168(4): p. 1919-25.

155. Schellenberg, R.R. and A. Foster, In vitro responses of human asthmatic airway and pulmonary vascular smooth muscle. Int Arch Allergy Appl Immunol, 1984. 75(3): p. 23741.

156. Haviland, D.L., et al., Cellular expression of the C5a anaphylatoxin receptor (C5aR): demonstration of C5aR on nonmyeloid cells of the liver and lung. J Immunol, 1995. 154(4): p. 1861-9.

157. Zaitsu, M., et al., New induction of leukotriene $A(4)$ hydrolase by interleukin-4 and interleukin-13 in human polymorphonuclear leukocytes. Blood, 2000. 96(2): p. 601-9.

158. Pompeia, C., T. Lima, and R. Curi, Arachidonic acid cytotoxicity: can arachidonic acid be a physiological mediator of cell death? Cell Biochem Funct, 2003. 21(2): p. 97-104.

159. Hopken, U., et al., Inhibition of interleukin-6 synthesis in an animal model of septic shock by anti-C5a monoclonal antibodies. Eur J Immunol, 1996. 26(5): p. 1103-9.

160. Strieter, R.M., et al., Cytokine-induced neutrophil-derived interteukin-8. Am J Pathol, 1992. 141(2): p. $397-407$.

161. Hangen, D.H., et al., Complement levels in septic primates treated with anti-C5a antibodies. J Surg Res, 1989. 46(3): p. 195-9.

162. Laudes, I.J., et al., Anti-c5a ameliorates coagulation/fibrinolytic protein changes in a rat model of sepsis. Am J Pathol, 2002. 160(5): p. 1867-75.

163. Guo, R.F., et al., Protective effects of anti-C5a in sepsis-induced thymocyte apoptosis. J Clin Invest, 2000. 106(10): p. 1271-80.

164. Smedegard, G., L.X. Cui, and T.E. Hugli, Endotoxin-induced shock in the rat. A role for C5a. Am J Pathol, 1989. 135(3): p. 489-97.

165. Czermak, B.J., et al., Protective effects of C5a blockade in sepsis. Nat Med, 1999. 5(7): p. $788-92$.

166. Huber-Lang, M., et al., Role of C5a in multiorgan failure during sepsis. J Immunol, 2001. 166(2): p. 1193-9. 
167. Solomkin, J.S., et al., Neutrophil dysfunction in sepsis. II. Evidence for the role of complement activation products in cellular deactivation. Surgery, 1981. 90(2): p. 319-27.

168. Guo, R.F., et al., Neutrophil C5a receptor and the outcome in a rat model of sepsis. FASEB J, 2003. 17(13): p. 1889-91.

169. Hajishengallis, G. and J.D. Lambris, Crosstalk pathways between Toll-like receptors and the complement system. Trends Immunol, 2010. 31(4): p. 154-63.

170. Rittirsch, D., et al., Functional roles for C5a receptors in sepsis. Nat Med, 2008. 14(5): p. $551-7$.

171. Chen, N.J., et al., C5L2 is critical for the biological activities of the anaphylatoxins C5a and C3a. Nature, 2007. 446(7132): p. 203-7.

172. Gioannini, T.L., et al., Isolation of an endotoxin-MD-2 complex that produces Toll-like receptor 4-dependent cell activation at picomolar concentrations. Proc Natl Acad Sci U S A, 2004. 101(12): p. 4186-91.

173. Eisenbarth, S.C., et al., Crucial role for the Nalp3 inflammasome in the immunostimulatory properties of aluminium adjuvants. Nature, 2008. 453(7198): p. 11226.

174. Ghiringhelli, F., et al., Activation of the NLRP3 inflammasome in dendritic cells induces IL-1beta-dependent adaptive immunity against tumors. Nat Med, 2009. 15(10): p. 1170-8.

175. Ohto, U., et al., Crystal structures of human MD-2 and its complex with antiendotoxic lipid IVa. Science, 2007. 316(5831): p. 1632-4. 
Current Address

145 Lucie Ave

DeLand, FL 32720

502-544-1946

chelseaves@gmail.com
Lab Address

Institute for Cellular Therapeutics 570 S. Preston St. Suite 411 Louisville, KY 40202

\section{EDUCATION}

University of Louisville School of Medicine

Department of Microbiology and Immunology

Ph.D. in Microbiology and Immunology

GPA: 3.69

American Heart Association Fellow; 2009-2011

University of Louisville School of Medicine

Department of Microbiology and Immunology

M.S. in Microbiology and Immunology

GPA: 3.69

Integrated Programs in Biomedical Sciences Fellow; 2007-2009
Louisville, $\mathrm{KY}$

February 2011
Louisville, $K Y$

December 2008
Old Dominion University

B.S. in Biology and Biochemistry
Norfolk, VA

May 2007

GPA: 3.65

Naval Amphibious Base Scholarship; 2005-2006 
RESEARCH POSITIONS

Graduate Research Associate

$05.2007-02.2011$

Barnstable Brown Laboratory

Institute for Cellular Therapeutics; Louisville, $K Y$

Supervisor: Thomas C. Mitchell, Ph.D.

- Performed independent research on the activation mechanisms of the NLRP3 inflammasome downstream of TLR4 activation and the low toxicity mechanisms of the vaccine adjuvant monophosphoryl Lipid A

Research Assistant

10.2005-05.2007

Old Dominion University; Norfolk VA

Supervisor: Robert Ratzlaff, Ph.D.

- Assisted graduate students in characterizing the pathogenic Panulirus argus virus 1 (PaV1) which infects Caribbean spiny lobsters

\section{ADDITIONAL EXPERIENCE}

\section{Curriculum Committeo Representative}

2008-2009

University of Louisville School of Medicine

Department of Microbiology and Immunology

Louisville, $K Y$

President; Microbiology and Immunology Student Organization

2009-2010

University of Louisville School of Medicine

Department of Microbiology and Immunology

Louisville, $K Y$

Graduate Student Mentor

2008-2011

Institute for Cellular Therapeutics

Barnstable Brown Laboratory

Louisville, $\mathrm{KY}$ 
PUBLICATIONS

C.A. Embry, L. Franchi, G. Nunez and T.C. Mitchell. IL-1beta loss contributes to TRIF- bias and reduced toxicity of monophosphoryl Lipid A in vivo. In prep.

C.A. Embry, L. Franchi, G. Nunez and T.C. Mitchell. TRIF-biased TLR4 signaling by Monophosphate Lipid A results in impaired NLRP3 inflammasome activation and IL-1beta production. Science Signaling. Accepted for publication.

C.A. Eaves, L. Franchi, G. Nunez and T.C. Mitchell. Monophosphoryl Lipid A's TRIF-biased stimulation of TLR4 impairs NLRP3 inflammasome assembly and activation. The Joumal of Leukocyte Biology. 2010. Abstract. 150.

C. Cekic, C.R. Casella, C.A. Eaves, A. Matsuzawa, H. Ichijo and T.C Mitchell. Selective activation of the p38 MAPK pathway by the TRIF-biased agonist Monophosphoryl Lipid A. Joumal of Biological Chemistry. 2009.

C. Cekic, C.R. Casella, C.A. Eaves and T.C. Mitchell. Promoter complexity model for TRIFbiased stimulation of TLR4 by synthetic Monophosphoryl Lipid A. The Joumal of Immunology. 2009. Abstract 44.28 . 